\author{
UNIVERSIDADE DE SÃO PAULO \\ FACULDADE DE ECONOMIA, ADMINISTRAÇÃO E CONTABILIDADE \\ DEPARTAMENTO DE ADMINISTRAÇÃO \\ PROGRAMA DE PÓS-GRADUAÇÃO EM ADMINISTRAÇÃO
}

\title{
EFEITOS DE PAÍS DE ORIGEM NA ESCOLHA DO CONSUMIDOR DE VINHO: UMA APLICAÇÃO DE CHOICE-BASED CONJOINT ANALYSIS
}

Caroline Graebin Orientadora: Dra. Adriana Backx Noronha Viana

SÃO PAULO

2018 


\section{Prof. Vahan Agopyan \\ Reitor da Universidade de São Paulo}

\section{Fábio Frezatti}

Diretor da Faculdade de Economia, Administração e Contabilidade

Prof. Dr. Moacir de Miranda Oliveira Junior

Chefe de Departamento de Administração

Prof. Dr. Moacir de Miranda Oliveira Júnior

Coordenador do Programa de Pós-Graduação em Administração 
CAROLINE GRAEBIN

\section{EFEITOS DE PAÍS DE ORIGEM NA ESCOLHA DO CONSUMIDOR DE VINHO: UMA APLICAÇÃO DA CHOICE-BASED CONJOINT ANALYSIS}

Dissertação apresentada ao Programa de Pós Administração da Faculdade de Economia, Administração e Contabilidade da Universidade de São Paulo, como requisito parcial para a obtenção do título de Mestre em Ciências.

Orientadora: Dra. Adriana Backx Noronha Viana

Versão corrigida

(versão original disponível na biblioteca da Faculdade de Economia, Administração e Contabilidade)

SÃO PAULO 
Autorizo a reprodução e divulgação total ou parcial deste trabalho, por qualquer meio convencional ou eletrônico, para fins de estudo e pesquisa, desde que citada a fonte.

FICHA CATALOGRÁFICA

Elaborada por Rafael Mielli Rodrigues - CRB-8/7286 Seção de Processamento Técnico do SBD/FEA/USP

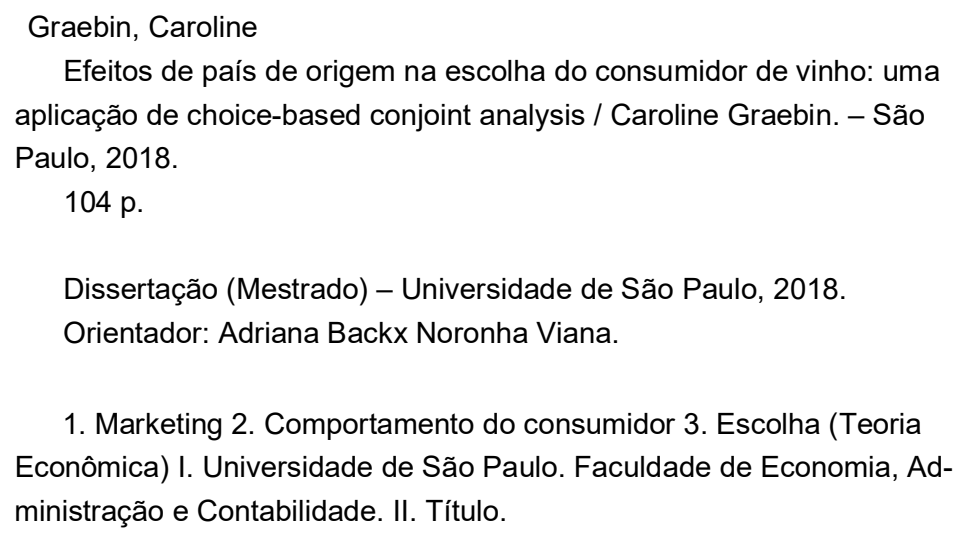


Nome: Graebin, Caroline

Título: Efeitos de país de origem na escolha do consumidor de vinho: uma aplicação de choice-based conjoint analysis

Dissertação apresentada ao Departamento de Administração da Faculdade de Economia, Administração e Contabilidade da Universidade de São Paulo, como um dos requisitos para obtenção do título de Mestre em Administração.

Aprovado em:

Banca Examinadora

Profa. Dra.

Instituição

Julgamento

Profa. Dra.

Instituição

Julgamento

Prof. Dr.

Instituição

Julgamento 

Ao Everton, pelo apoio incondicional. 



\section{AGRADECIMENTOS}

Agradeço à FEA/USP por me proporcionar um ensino gratuito e de alta qualidade.

Agradeço à minha orientadora professora $\operatorname{Dr}^{\mathrm{a}}$ Adriana Backx Noronha Viana por ter aceitado me orientar e por toda confiança depositada no meu trabalho.

Agradeço à professora $\operatorname{Dr}^{\mathrm{a}}$ Luísa Margarida Cagica Carvalho pelas valorosas contribuições na ocasião da minha qualificação.

Agradeço ao professor Dr José Afonso Mazzon pelas contribuições à minha pesquisa, por se colocar sempre disponível para ajudar seus alunos e por colaborar com minha evolução acadêmica mesmo antes de eu ingressar no mestrado.

Agradeço aos queridos colegas e amigos João do Carmo, Wilderson Furtado e Gabriela Gual por todo apoio e companheirismo, tornando mais leve todo o processo do mestrado.

Agradeço à Caroline Berezuschy, colega e amiga onde encontrei apoio, empatia e sonoridade.

Agradeço à Patrícia Rosa por sempre ter me apoiado no meu projeto de carreira acadêmica.

Agradeço ao amigo de sempre Cássio Arthur Wollmann, presente nos principais momentos da minha vida.

Agradeço aos meus pais, por todos os esforços que fizeram para que eu pudesse ter a oportunidade de estudar, oportunidade que a eles foi privada.

Agradeço ao meu marido Everton Rafael Delai por alimentar meus sonhos, me incentivar e estar sempre ao meu lado. Agradeço por toda compreensão e companheirismo! 

O que sabemos é uma gota; o que ignoramos é um oceano.

Isaac Newton

In vino veritas. Plínio 



\section{RESUMO}

Graebin, C. (2018). Efeitos de país de origem na escolha do consumidor de vinho: uma aplicação da choice-based conjoint analysis (Dissertação de Mestrado). Faculdade de Economia, Administração e Contabilidade, Universidade de São Paulo, São Paulo.

O processo de escolha de um produto é bastante complexo, pois depende de variáveis como características intrínsecas e extrínsecas do produto, situação de compra, percepções, memórias e estilo de vida dos consumidores. O produto vinho pode ser caracterizado pela alta complexidade de fatores envolvidos em seu processo de escolha. Nesse contexto, país de origem é um dos atributos que possui uma série de particularidades nas preferências dos consumidores. Assim, o objetivo desse trabalho é identificar como o país de origem do produto interfere na escolha do consumidor de vinho. O efeito país de origem no processo de escolha foi analisado sob três enfoques distintos: diferenças entre produtos tipificados e não tipificados, diferenças conforme proximidade do consumidor ao centro produtor, e diferenças oriundas do envolvimento do consumidor com o produto. Aderente à teoria de escolhas, o método utilizado no trabalho foi a implementação de experimentos de escolha utilizando a técnica da choice-based conjoint analysis. A amostra comtemplada foi formada por consumidores frequentes de vinho, residentes em dois estados do Brasil. Os resultados encontrados revelam que vinho é um produto em que o país de origem assume grande relevância como qualificador para o processo de escolha, ao contrário do que acontece com saca-rolhas, que é um produto associado ao consumo de vinho, mas sem associação clara com marca ou país de origem. Ao comparar um estado próximo ao centro produtor de vinhos (Rio Grande do Sul) com um estado afastado do centro produtor, mas ainda assim com grande consumo de vinho (São Paulo), percebe-se uma clara diferenciação entre as preferências conforme o país de origem do produto. Vinhos brasileiros apresentaram a maior utilidade para consumidores do Rio Grande do Sul, mas a menor utilidade para consumidores de São Paulo. No que se refere ao envolvimento, consumidores mais envolvidos com vinho apresentaram maior utilidade associada ao país de origem quando comparados com consumidores com menor envolvimento. A partir da análise das escolhas dos consumidores de vinho no Brasil, contemplando características como o grau de envolvimento e proximidade ao centro produtor, este trabalho oferece uma contribuição em relação à identificação de diferentes efeitos de país de origem no contexto de consumidores brasileiros.

Palavras-chave: Escolha. País de origem. Vinho. Choice-based conjoint analysis. 


\begin{abstract}
Graebin, C. (2018). Effects of country of origin on wine consumer's choice: an application of choice-based conjoint analysis (Dissertação de Mestrado). Faculdade de Economia, Administração e Contabilidade, Universidade de São Paulo, São Paulo.
\end{abstract}

The process of choosing a product is quite complex because it depends on variables such as intrinsic and extrinsic characteristics of the product, purchase situation, perceptions, memories, and consumer lifestyle. The wine product can be characterized by the high complexity of factors involved in its process of choice. In this context, the country of origin is one of the attributes that has a series of particularities in the preferences of consumers. Thus, the objective of this work is to identify how the country of origin of the product interferes in the choice of the wine consumer. The country-of-origin effect in the choice process was analyzed under three different approaches: differences between typified and non-typified products, differences according to the proximity of the consumer to the producer center, and differences arising from the consumer's involvement with the product. Adhering to choice theory, the method used in the work was the implementation of experiments of choice using the technique of choice-based conjoint analysis. The contemplated sample consisted of frequent wine consumers living in two Brazilian states. The results show that wine is a product in which the country of origin assumes great relevance as a qualifier for the process of choice, unlike what happens with corkscrews, which is a product associated with wine consumption, but without a clear association with brands or country of origin. When comparing a state close to the wine producing center of Brazil (Rio Grande do Sul) with a state away from the producer center, but still with great consumption of wine (São Paulo), a clear differentiation between the preferences according to the country of origin of the product can be noticed. Brazilian wines presented the greatest utility for consumers in Rio Grande do Sul, but the lowest utility for consumers in São Paulo. With regard to the involvement, consumers more involved with wine had more utility associated with the country of origin when compared to consumers with less involvement. Based on the analysis of the choices of wine consumers in Brazil, considering the characteristics of the degree of involvement and proximity to the producer center, this work offers a contribution in relation to the identification of different country of origin effects in the context of Brazilian consumers.

Keywords: Choice. Country of Origin. Wine. Choice-based conjoint analysis. 


\section{SUMÁRIO}

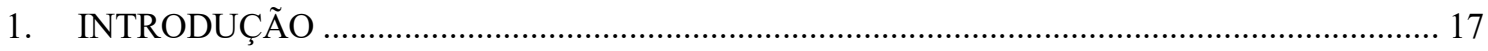

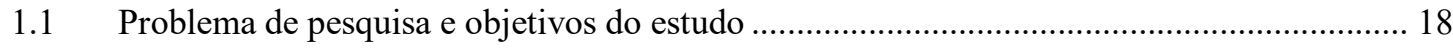

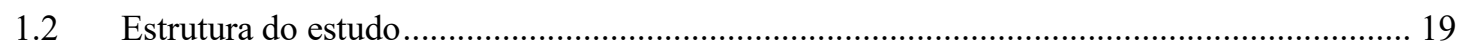

2. PANORAMA DO MERCADO BRASILEIRO DE VINHOS …............................................. 21

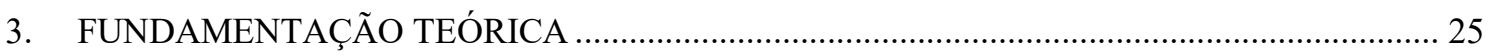

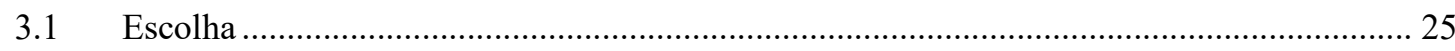

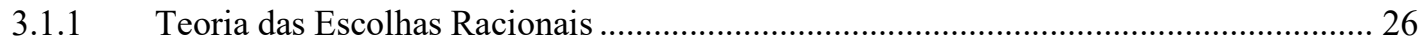

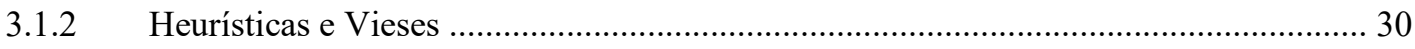

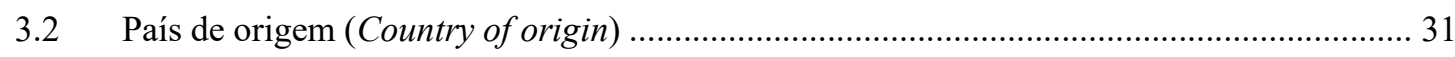

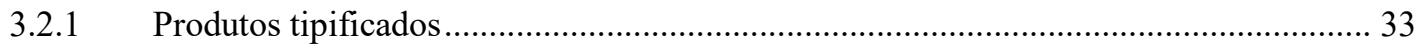

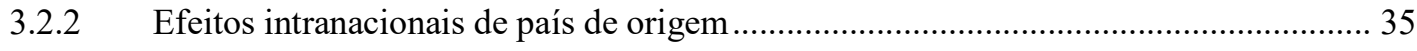

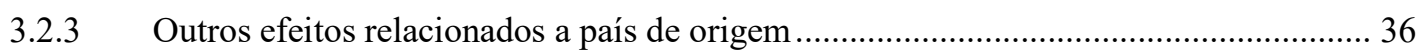

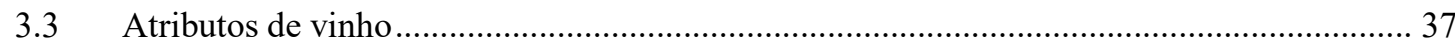

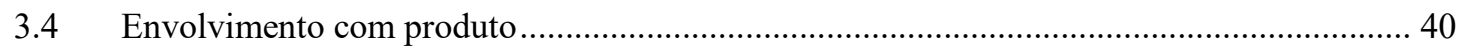

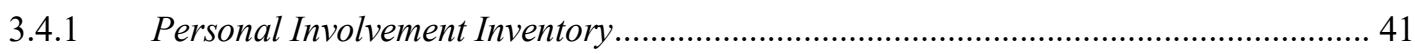

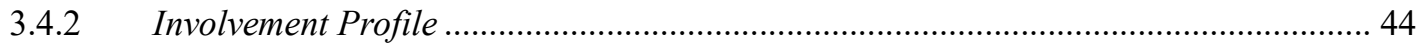

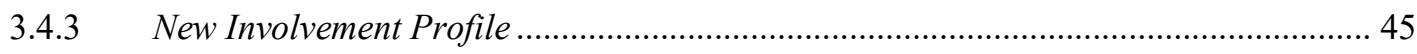

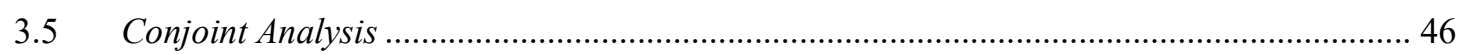

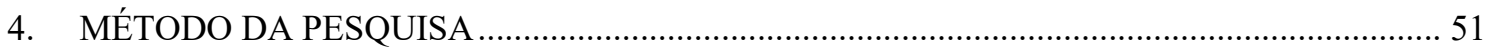

4.1 Sujeito da pesquisa e delineamento do estudo ................................................................. 52

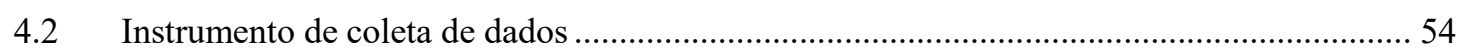

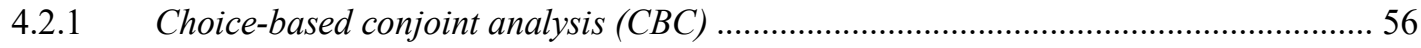

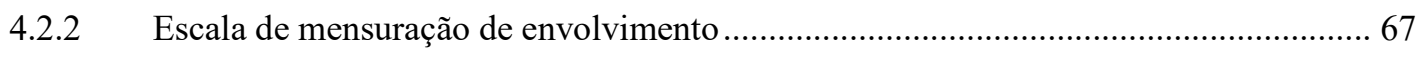

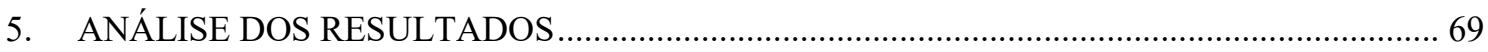

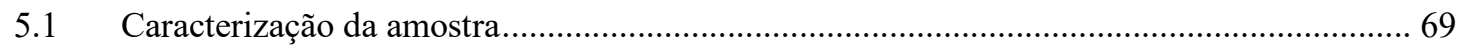

5.2 Efeito país de origem para produtos tipificados ………....................................................... 73

5.3 Efeito país de origem entre região produtora e não produtora de vinho no Brasil................ 76

5.4 Efeito país de origem conforme envolvimento com vinho ................................................ 81

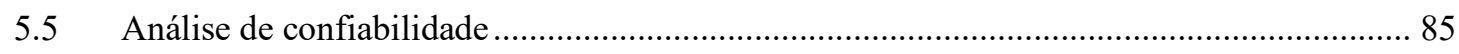

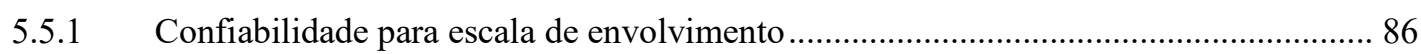

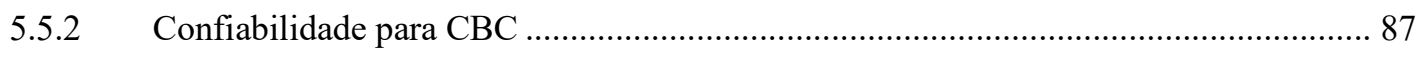

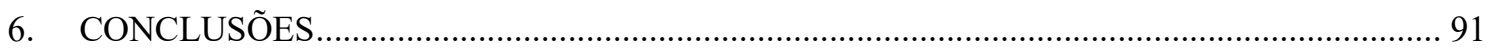

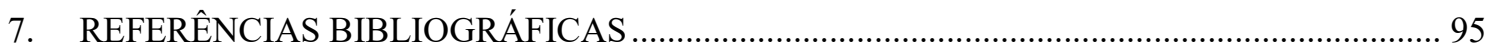

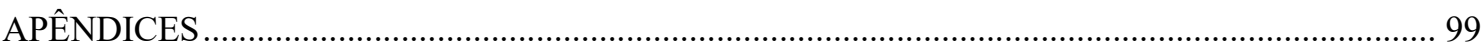

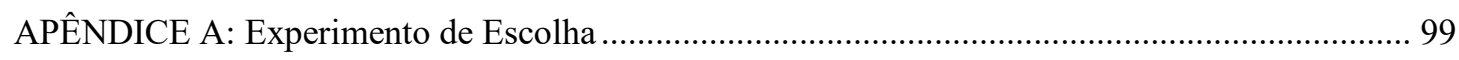

APÊNDICE B: Importância relativa e utilidade conforme envolvimento para o produto saca-rolhas 


\section{LISTA DE GRÁFICOS}

Gráfico 1: Produção mundial de vinho - ano 2016 ........................................................... 21

Gráfico 2: Consumo de vinho total e per capita - ano 2016 ............................................ 22

Gráfico 3: Curva de Indiferença ..................................................................................... 28

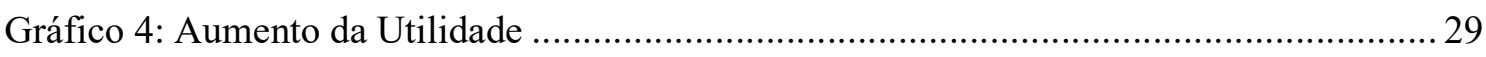

Gráfico 5: Distribuição dos respondentes conforme idade .............................................. 71

Gráfico 6: Distribuição da amostra conforme classe social ................................................ 71

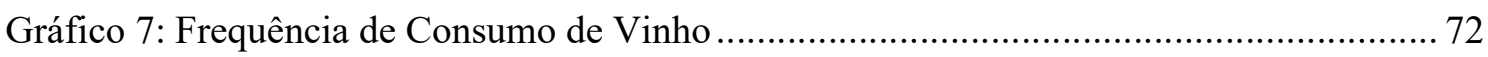

Gráfico 8: Distribuição da frequência dos níveis de envolvimento..................................... 82 


\section{LISTA DE FIGURAS}

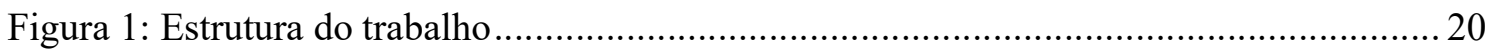

Figura 2: Importações brasileiras por país de origem (em milhões de litros) ........................ 23

Figura 3: Comercialização de vinhos por empresas do RS (em milhões de litros) ................. 24

Figura 4: Paradigma do processo de escolha............................................................... 26

Figura 5: Fatores que influenciam o envolvimento do consumidor .................................... 41

Figura 6: Personal Involvement Inventory - escala 20 pares (Zaichkowsky, 1985)............. 42

Figura 7: Personal Involvement Inventory Revisada - escala 10 pares (Zaichkowsky, 1994) 44

Figura 8: New Involvement Profile (Jain \& Srinivasan, 1990).......................................... 46

Figura 9: Visão geral dos aspectos metodológicos da pesquisa .......................................... 52

Figura 10: Etapas para a condução de uma Choice-Based Conjoint Analysis ........................ 57

Figura 11: Exemplo de apresentação de utilidade .............................................................. 65

Figura 12: Distribuição da amostra conforme sexo dos respondentes................................ 70

Figura 13: Importância relativa e utilidade para vinho ................................................. 74

Figura 14: Importância relativa e utilidade para saca-rolhas ........................................ 75

Figura 15: Importância relativa e utilidade para vinho para respondentes com domicílio no RS

Figura 16: Importância relativa e utilidade para vinho para respondentes com domicílio em SP 78

Figura 17: Importância relativa e utilidade para saca-rolhas conforme domicílio dos

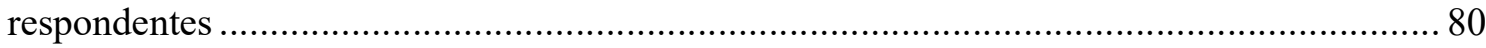

Figura 18: Importância relativa e utilidade para vinho conforme envolvimento com produto -

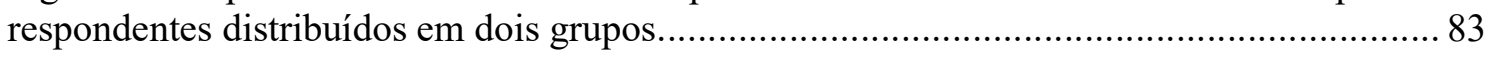

Figura 19: Classificação da escala de envolvimento em três grupos.................................. 84

Figura 20: Importância relativa e utilidade para vinho conforme envolvimento com produto respondentes distribuídos em três grupos .................................................................. 84

Figura 21: Alfa de Cronbach para a escala de envolvimento............................................. 87 


\section{LISTA DE QUADROS}

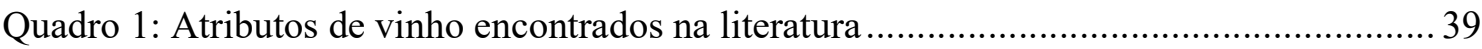

Quadro 2: Visão geral dos aspectos metodológicos da pesquisa ........................................ 54

Quadro 3: Atributos e níveis para o produto vinho .......................................................... 58

Quadro 4: Atributos e níveis para o produto saca-rolhas................................................. 59

Quadro 5: Combinações de pares proibidos para saca-rolhas ............................................. 59

Quadro 6: Exemplo de cálculo de importância de atributo................................................66

Quadro 7: Importância relativa e utilidade do experimento de vinho para grupos

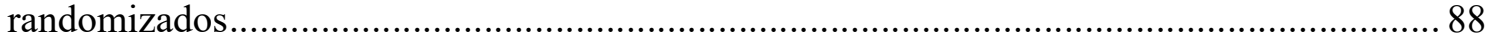

Quadro 8: Importância relativa e utilidade do experimento de saca-rolhas para grupos

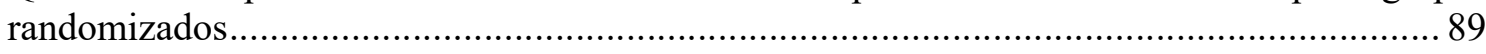




\section{INTRODUÇÃO}

O processo de abertura comercial brasileira ocorrido no início dos anos 90 possibilitou ao consumidor local o acesso a produtos importados que antes eram limitados pela política restritiva de importações (Azevedo \& Portugal, 1998). A partir de então abriu-se espaço para o desenvolvimento de estudos sobre o comportamento do consumidor brasileiro em relação ao país de origem de produto, ainda que internacionalmente o tema tenha sido estudado desde os anos 60 (Dinnie, 2004; Verlegh \& Steenkamp, 1999).

Antes do processo de abertura comercial do início dos anos 90 a oferta de vinhos, assim como outros produtos importados, era restrita no Brasil. Nesse mesmo período, a produção brasileira em escala comercial de vinhos finos era incipiente.

O Brasil não é reconhecido como um produtor importante de vinhos no cenário mundial. As primeiras videiras foram trazidas ao Brasil logo após o início da colonização portuguesa. Durante aproximadamente três séculos foram feitas tentativas com pouco sucesso na produção de vinho. Aos poucos a plantação de Vitis vinifera foi se concentrando no estado do Rio Grande do Sul, mas a produção de vinho só deu um salto com a chegada dos imigrantes italianos no estado, o que se deu por volta de 1875. A partir de 1980, no Vale dos Vinhedos, foram feitas transformações nos vinhedos e a partir de 1990 as vinícolas passaram a produzir vinhos com maior qualidade. $\mathrm{O}$ ano de 2002 trouxe uma expressiva conquista para a região: o selo de Indicação de Procedência aos vinhos do Vale dos Vinhedos. Desde 2012, entretanto, o Vale dos Vinhedos possui o reconhecimento de Denominação de Origem.

Atualmente a Serra Gaúcha é a principal região produtora de vinhos finos no Brasil, concentrando cerca de $90 \%$ do total da produção nacional. Outras regiões vêm apresentando crescimento na qualidade e volume de produção. Nesse grupo destacam-se a Região da Campanha e Serra do Sudeste (RS) e o Vale do São Francisco (BA e PE).

Dados da União Brasileira de Vitivinicultura (UVIBRA) demonstram que entre os anos de 2008 e 2014 cerca de 80\% do consumo de espumantes no Brasil era proveniente de produção nacional e $20 \%$ do consumo de espumantes era de produtos importados. Entretanto, quando analisamos o consumo brasileiro de vinhos finos nota-se o oposto: $80 \%$ do consumo de vinhos finos é de origem importada e apenas $20 \%$ é de vinhos finos ${ }^{1}$ nacionais.

\footnotetext{
${ }^{1}$ Vinhos finos são elaborados a partir de variedade de Vitis vinifera e apresentam maior qualidade do que vinhos de mesa, que são elaborados a partir de outras espécies de videiras (geralmente americanas). Por estar associada a maior qualidade, vinhos finos usualmente são mais caros do que vinhos de mesa.
} 
O vinho é um produto cuja caracterização é complexa, pois não possui uma natureza padronizada. O conteúdo de cada garrafa é único pois depende de uma série de variáveis como safra, fermentação, tipo de uva, terroir ${ }^{2}$, entre outros. Devido à ampla possibilidade de atributos relacionados ao vinho, a escolha desse produto é uma tarefa bastante complexa para o consumidor. Em função dessas características, o vinho é um produto interessante para testar se os processos de tomada de decisão diferem entre os países (Lockshin \& Cohen, 2011).

As pesquisas sobre país de origem de produto têm avaliado os seus efeitos, do ponto de vista cognitivo, como um estímulo informacional que o consumidor relaciona à qualidade do produto. Assim, país de origem tem sido avaliado com um atributo extrínseco ao produto, tal como preço ou marca (Verlegh \& Steenkamp, 1999).

\subsection{Problema de pesquisa e objetivos do estudo}

$\mathrm{Na}$ literatura selecionada para esta pesquisa foram encontrados trabalhos que tratam de diferenças entre produtos tipificados e não tipificados na escolha do consumidor (Ahmed \& D'Astous, 2001; Sharma, 2011; Tseng \& Balabanis, 2011); foram encontrados também trabalhos que relacionam país de origem com envolvimento com produto (Huang, 2012; Rodríguez-Santos, González-Fernández, \& Cervantes-Blanco, 2013); e, foram identificados trabalhos que analisam efeitos de país de origem em diferentes regiões dentro de um mesmo país (Heslop, Papadopoulos, \& Bourk, 1998). No entanto, a pesquisa bibliográfica realizada neste trabalho não identificou trabalhos nos seguintes temas:

a. Escolhas de consumidores entre produtos tipificados e não tipificados no contexto brasileiro.

b. Relações entre país de origem e envolvimento de produto no contexto brasileiro.

c. Comparação de escolhas de consumidores entre diferentes regiões de um país não reconhecido internacionalmente como produtor de vinho.

A partir das lacunas teóricas expostas, este trabalho propõe responder o seguinte problema de pesquisa:

\section{Qual o efeito do país de origem sobre a escolha do consumidor de vinho?}

Para o melhor delineamento do problema proposto são necessárias algumas definições. Por escolha pretende-se medir o resultado da tomada de decisão de compra. Consumidor de

\footnotetext{
${ }^{2} \mathrm{O}$ conceito de terroir está relacionado ao ambiente natural de determinada região que em conjunto com a ação humana gera uma bebida com caráter singular.
} 
vinho será considerado aquele que consome o produto ao menos uma vez a cada quinzena, independentemente de ser o responsável pela compra do produto. País de origem refere-se ao país onde o produto foi criado e produzido, relacionado ao "made in..." integrante dos rótulos. Por fim, vinho contempla qualquer tipo de vinho, sem distinção de vinho de mesa ou vinhos finos.

A fim de responder à pergunta de pesquisa proposta, o objetivo geral deste trabalho é identificar como o país de origem do produto interfere na escolha do consumidor de vinho. Partindo desse objetivo geral, foram desenvolvidos objetivos específicos, a saber:

a. Identificar qual o efeito país de origem na escolha do consumidor para produtos tipificados.

b. Identificar a diferença do efeito país de origem entre regiões produtoras e não produtoras de vinho dentro de um país não reconhecido internacionalmente como produtor.

c. Identificar a diferença do efeito país de origem entre consumidores conforme seu envolvimento com vinho.

\subsection{Estrutura do estudo}

Além desta introdução, este trabalho possui outras quatro seções. O capítulo 2 apresenta a fundamentação teórica que orienta essa pesquisa. O capítulo 3 apresenta o método adotado para conduzir a pesquisa, detalhando passo a passo todas os procedimentos realizados. A análise dos resultados é discutida no capítulo 4. Nessa seção, os resultados foram divididos em subseções para atender aos objetivos específicos propostos no trabalho. Por fim, no capítulo 5 são apresentadas as conclusões, limitações do estudo e perspectivas futuras dessa pesquisa. A estrutura geral do trabalho é apresentada na Figura 1. 
Figura 1: Estrutura do trabalho

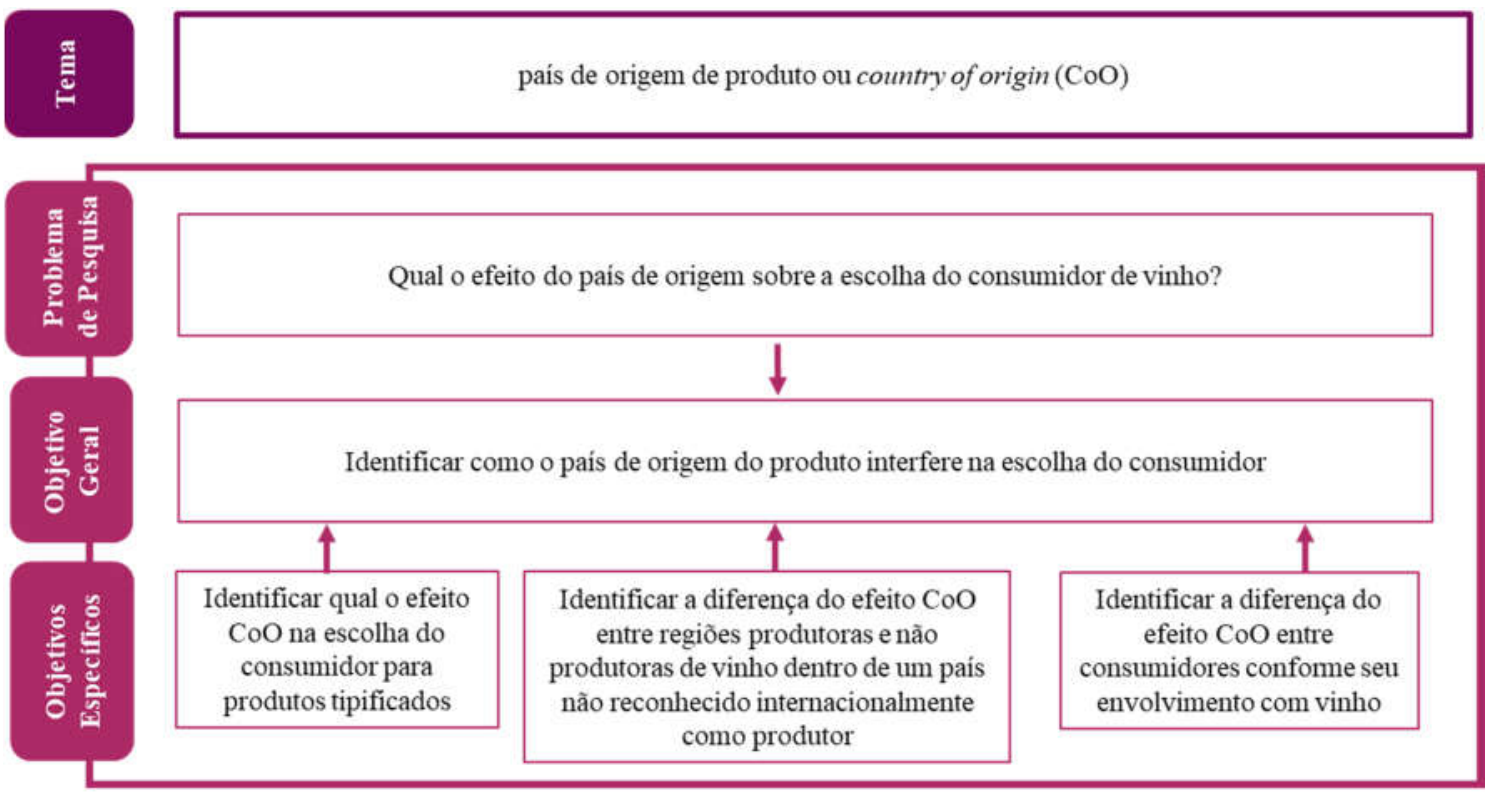

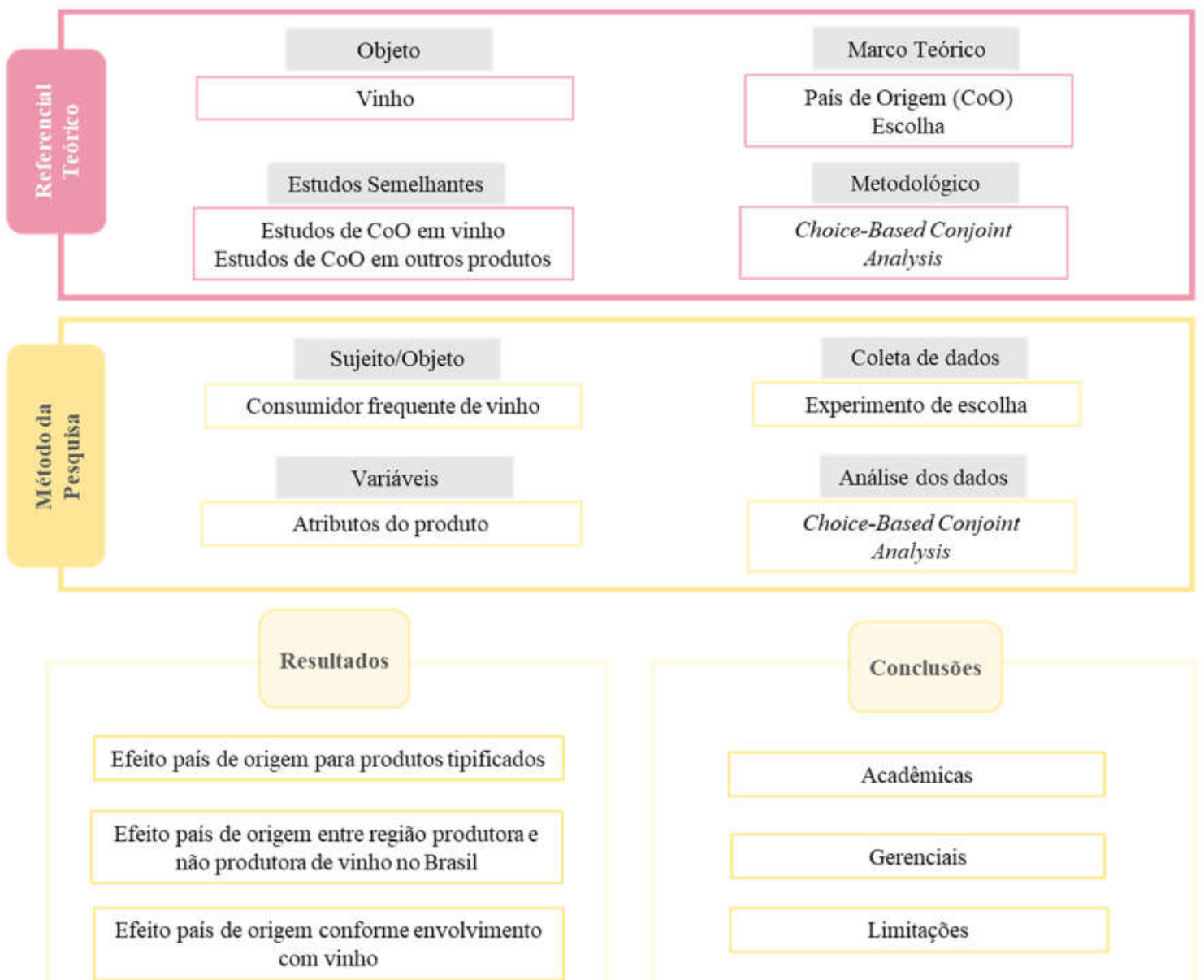

Fonte: elaborado pela autora 


\section{PANORAMA DO MERCADO BRASILEIRO DE VINHOS}

A produção de vinho no Brasil é relativamente recente se comparada aos principais países produtores, especialmente os europeus. Enquanto nesses países a produção vinícola é uma cultura milenar, no Brasil, embora as primeiras videiras tenham sido trazidas após a colonização, a produção de fato só teve início concreto no século XIX a partir da chegada dos imigrantes italianos. Em função dessas características, o Brasil não é reconhecido mundialmente como um país importante na produção de vinhos no cenário internacional.

O Gráfico 1 apresenta dados sobre a produção mundial de vinhos em 2016, medida em milhões de hectolitros. Segundo relatório da OIV (2018), os países com maior produção de vinhos são Itália, França e Espanha, todos com produção superior a 40 milhões de hectolitros. Considerando o mesmo período, o Brasil ocupou a $20^{\mathrm{a}}$ posição mundial em produção de vinho, com 1,3 milhão de hectolitros.

Gráfico 1: Produção mundial de vinho - ano 2016

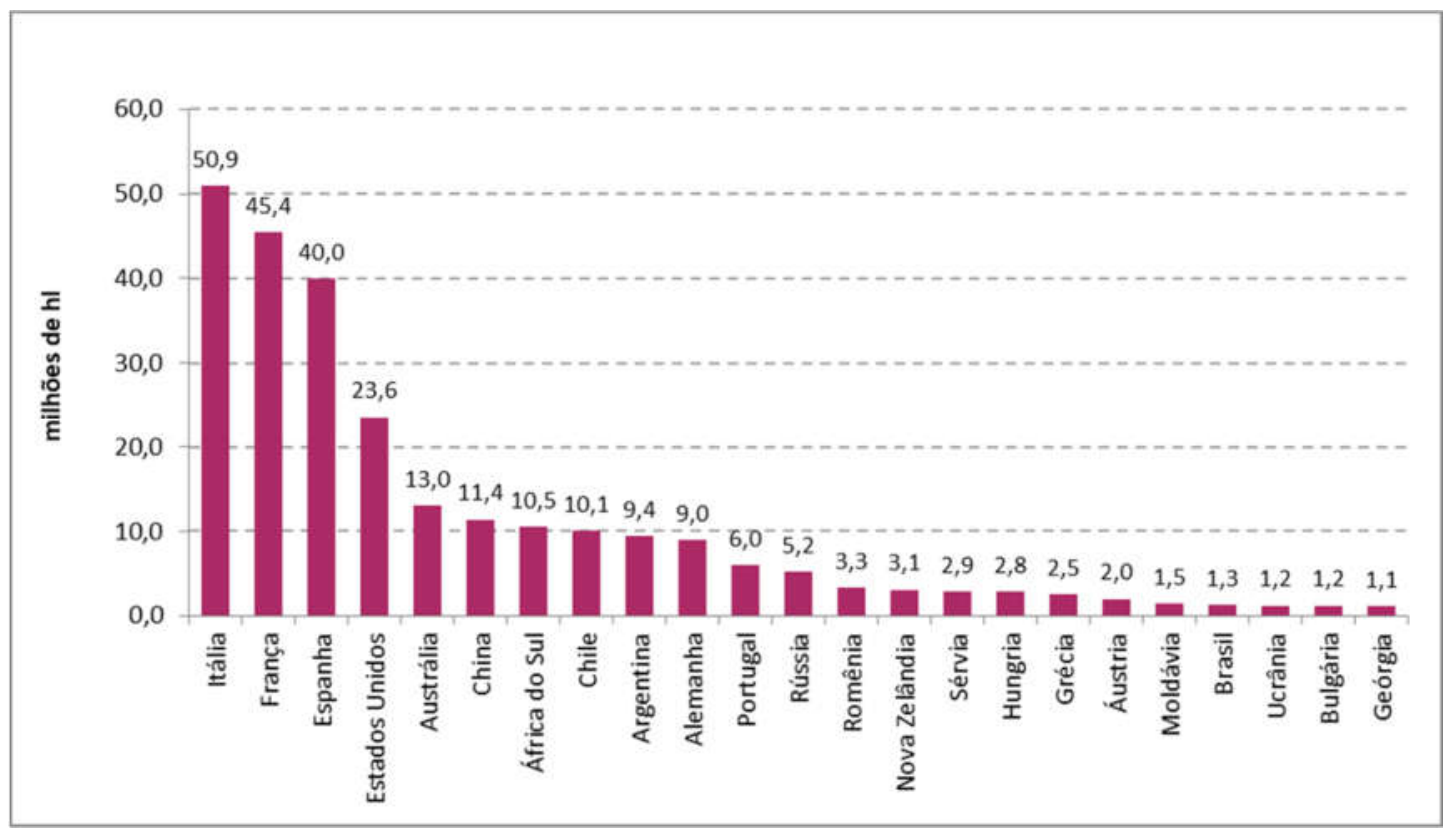

Fonte: State of The Vitiviniculture World Market - OIV

O Gráfico 2 apresenta o consumo de vinho total e per capita para 2016. No que se refere a consumo total de vinhos, os Estados Unidos possuem o maior consumo mundial de vinhos, com 31,7 milhões de hectolitros em 2016. No entanto, ao considerar o consumo per 
capita, o país cai para a $16^{\mathrm{a}}$ posição mundial. No mesmo período, o consumo per capita brasileiro foi 1,9 litros por pessoa, bastante inferior quando comparado a países como Portugal, França e Itália. O menor consumo de vinhos no Brasil, em comparação com outros países, sugere que o comportamento de consumo de vinhos no Brasil seja distinto em relação aos países europeus.

Gráfico 2: Consumo de vinho total e per capita - ano 2016

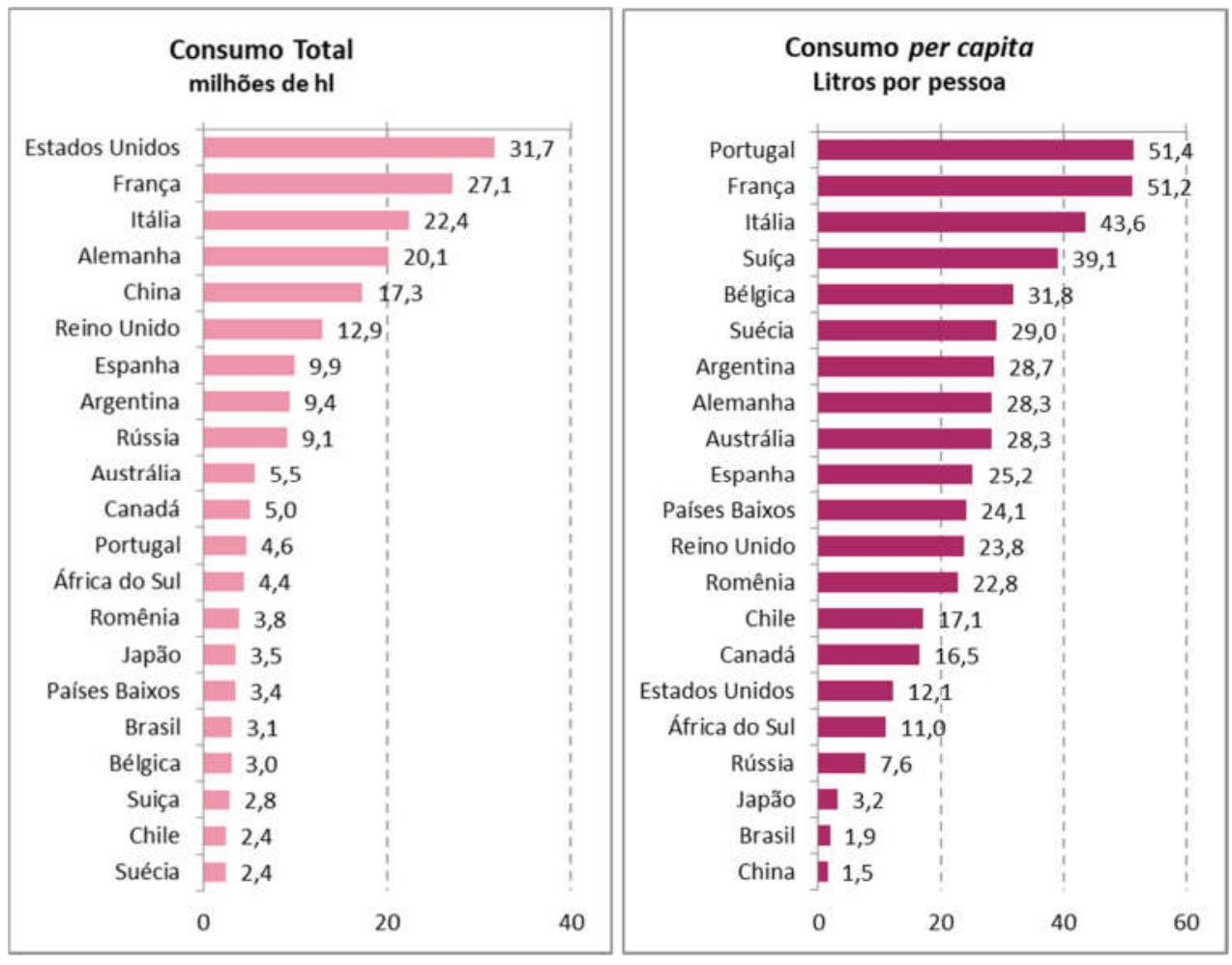

Fonte: State of The Vitiviniculture World Market - OIV

O consumo de vinhos importados vem aumentando no Brasil ao longo da última década. Dados do Cadastro Vinícola (IBRAVIN, 2007) mostram que as importações de vinho (em milhões de litros) aumentaram de 50,9 milhões de litros em 2006 para 125,9 milhões de litros em 2017. Dentre os países que vendem vinho para o Brasil, o Chile figura em primeiro lugar com mais da metade do volume de vinhos importados pelo Brasil. A Argentina, que historicamente ocupava a segunda posição na participação de vinhos importados, perdeu espaço para Portugal, que vem aumentando suas vendas para o Brasil no período recente. Outros dois países com importante participação em vendas por volume de litros no Brasil são França e Itália. As importações brasileiras por país de origem estão dispostas na Figura 2. 
Figura 2: Importações brasileiras por país de origem (em milhões de litros)

\begin{tabular}{|cccccccc|}
\hline Ano & CHILE & ARGENTINA & ITALA & FRANÇA & PORTUGAL & Outros & Total \\
\hline 2006 & 15,2 & 13,7 & 9,4 & 3,7 & 6 & 3 & 50,9 \\
\hline 2007 & 18,9 & 16,2 & 10,4 & 3,8 & 6,8 & 4,7 & 60,9 \\
\hline 2008 & 18,7 & 15,4 & 10,8 & 3,5 & 6,3 & 3,2 & 57,9 \\
\hline 2009 & 22,5 & 14,8 & 9,1 & 3,5 & 5,9 & 3,3 & 59,1 \\
\hline 2010 & 26,5 & 18,1 & 13 & 4,3 & 8,1 & 5,4 & 75,3 \\
\hline 2011 & 26,7 & 17,7 & 13,2 & 5,1 & 8,6 & 6,3 & 77,6 \\
\hline 2012 & 30,3 & 15,6 & 11,6 & 5 & 9,8 & 7,2 & 79,5 \\
\hline 2013 & 28,4 & 13,4 & 9,2 & 4,7 & 9,3 & 7,2 & 72,2 \\
\hline 2014 & 35,6 & 14,2 & 9,7 & 4,8 & 9,8 & 7,1 & 81,2 \\
\hline 2015 & 36,92 & 12,96 & 9,28 & 4,96 & 10,01 & 7,67 & 81,8 \\
\hline 2016 & 43,5 & 14,5 & 9 & 5 & 10,9 & 9,2 & 92,1 \\
\hline 2017 & 51,6 & 16,1 & 13,9 & 12,8 & 16,6 & 14,9 & 125,9 \\
\hline
\end{tabular}

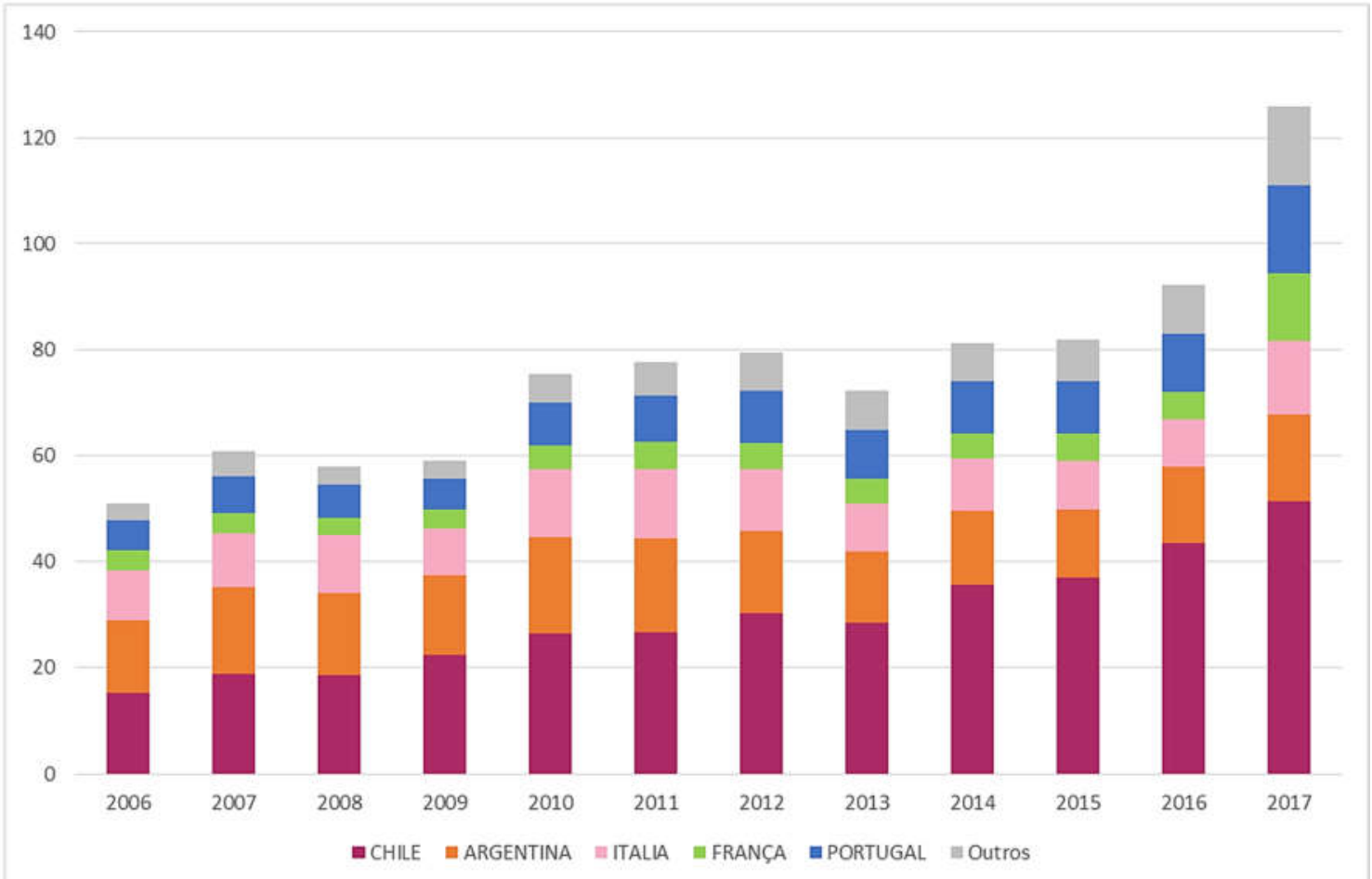

Fonte: Cadastro Vinícola (IBRAVIN, 2007)

A Figura 3 apresenta dados sobre a comercialização de vinhos por empresas do Rio Grande do Sul, mensurados em milhões de litros. Os dados apresentados referem-se apenas a vinhos finos, ou seja, produzidos a partir de vitis vinífera, não contemplando assim vinhos de mesa. Ao considerar dados de comercialização de 2015 , vinhos tintos representaram $42 \%$ das vendas, seguidos por espumantes com $34 \%$, moscateis com $12 \%$, vinhos brancos com $11 \%$ e, por fim, vinhos rosês com $1 \%$ na participação na comercialização. 
Esses dados apontam a grande representatividade na produção de vinhos tintos (que geralmente são os mais consumidos) e de vinhos espumantes, que apresentam grande expressividade principalmente na região da Serra Gaúcha. É importante salientar que a redução geral na produção de vinhos em 2017 é devida à quebra de safra de uvas ocorrida em 2016.

Figura 3: Comercialização de vinhos por empresas do RS (em milhões de litros)

\begin{tabular}{|ccccccc|}
\hline Ano & Brancos & Rosados & Tintos & \multicolumn{4}{c|}{ Espumantes Moscateis } & Total \\
\hline 2006 & 8 & 0,3 & 13,5 & 6,3 & 1,3 & 29,4 \\
\hline 2007 & 6,6 & 0,4 & 13 & 7 & 1,6 & 28,6 \\
\hline 2008 & 5,3 & 0,3 & 11,4 & 7,6 & 1,9 & 26,5 \\
\hline 2009 & 4,8 & 0,2 & 13 & 8,7 & 2,5 & 29,2 \\
\hline 2010 & 4,5 & 0,2 & 13,6 & 9,6 & 2,9 & 30,8 \\
\hline 2011 & 4,7 & 0,2 & 14,7 & 10,2 & 3 & 32,8 \\
\hline 2012 & 4,4 & 0,1 & 14,2 & 11,2 & 3,5 & 33,4 \\
\hline 2013 & 4,6 & 0,2 & 15,3 & 12,1 & 3,7 & 35,9 \\
\hline 2014 & 4,4 & 0,2 & 14,7 & 12,5 & 4,3 & 36,1 \\
\hline 2015 & 4,3 & 0,2 & 15,3 & 13,8 & 5 & 38,6 \\
\hline 2016 & 4,1 & 0,2 & 15 & 12,4 & 4,5 & 36,2 \\
\hline 2017 & 3,6 & 0,2 & 11,8 & 11,9 & 5,5 & 33 \\
\hline
\end{tabular}

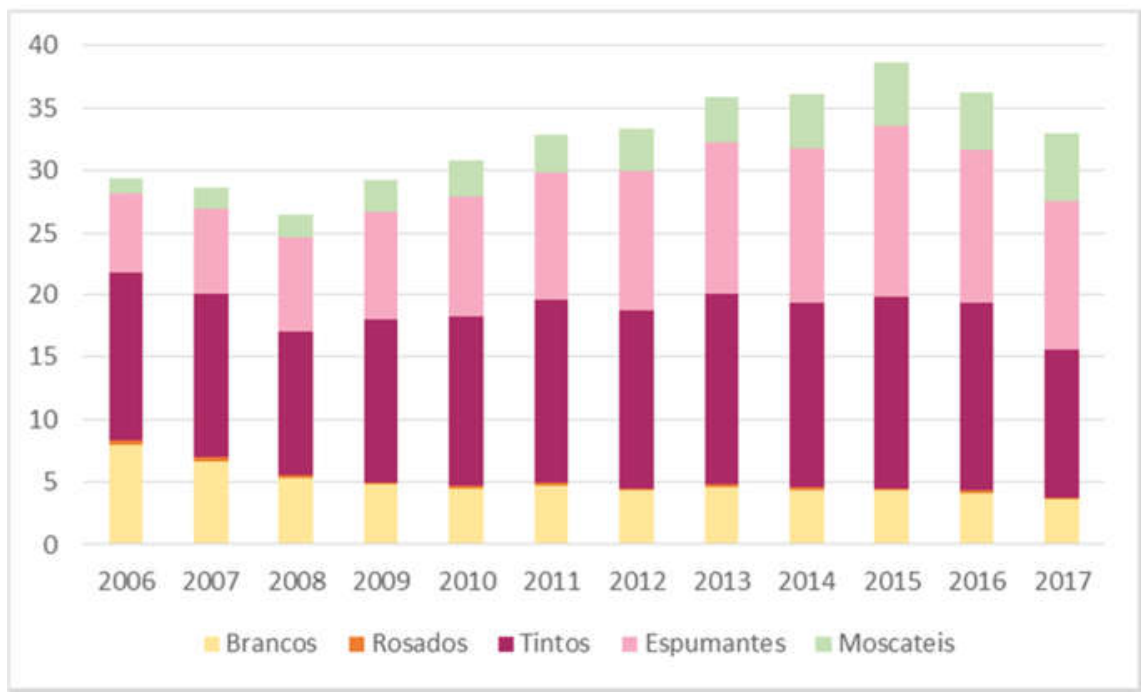

Fonte: Cadastro Vinícola (IBRAVIN, 2007) 


\section{FUNDAMENTAÇÃO TEÓRICA}

O referencial teórico desse trabalho é formado pelas teorias de escolha do consumidor, país de origem, atributos de vinho, envolvimento com produto e conjoint analysis, que preferencialmente serão aplicados no contexto do consumo de vinho, conforme discussão nas seções a seguir.

\subsection{Escolha}

O processo de escolha do consumidor é complexo e sua análise deve compreender também as etapas que antecedem sua ocorrência, considerando um ambiente de mercado. Em um conjunto de situações de escolha, o marketing deve avaliar as percepções, preferências e escolhas dos consumidores.

Uma situação genérica de escolha está representada na Figura 4. Um agente de marketing toma suas decisões de acordo com informações coletadas no ambiente de negócios. Tais informações levam em conta a firma, o ambiente competitivo, e variáveis como produto e preços. As decisões de marketing geram informações sobre estímulos, que juntamente com características individuais dos consumidores dão origem a percepções dos consumidores acerca do produto ou serviço em questão. As percepções levam à formação de preferências por parte de consumidores, que conjuntamente com a situação culminam nas escolhas. A escolha efetuada pelo consumidor normalmente se traduz em venda, o que gera uma resposta ao mercado, que novamente ajusta suas decisões de marketing para o recomeço do ciclo (Rao, 2014). 
Figura 4: Paradigma do processo de escolha

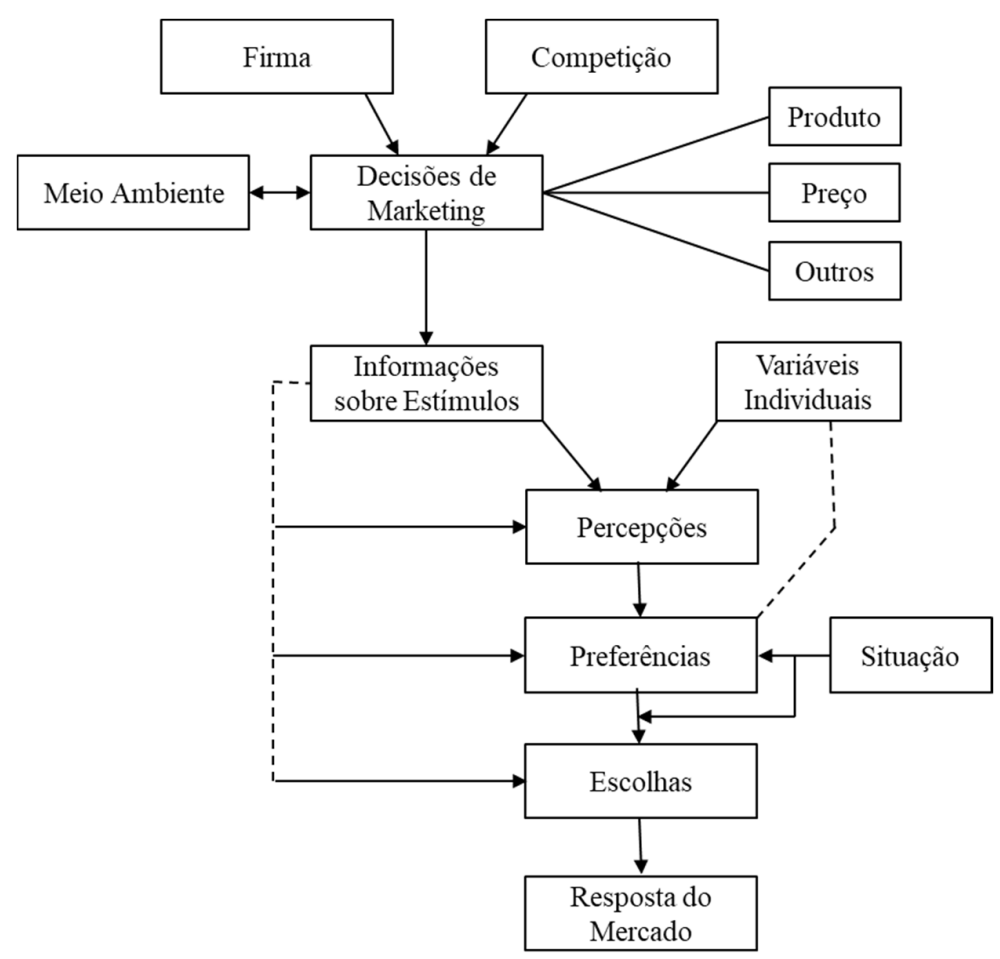

Fonte: adaptado de Rao (2014), p. 2

Nesta seção o referencial teórico foi dividido em duas seções, uma com a abordagem da teoria das escolhas racionais, e outra sobre heurísticas e vieses oriundos do processo de escolha.

\subsubsection{Teoria das Escolhas Racionais}

A teoria do consumidor é um ramo da teoria econômica cuja formulação busca descrever o comportamento do consumidor na tomada de decisão. Diversas vertentes e modelos foram desenvolvidos ao longo do tempo e esta seção se propõe a apresentar de maneira breve as principais abordagens observadas na literatura.

Jehle e Reny (2011) apresentam formulações acerca do comportamento do consumidor destacando a seguinte frase: "é importante ter em mente que a teoria do consumidor, por si só, é de fato uma rica e flexível teoria da escolha". O comportamento do consumidor também citado por Kreps (1990), que coloca o consumidor como elemento central do estudo da teoria microeconômica, definindo-o como um agente que faz escolhas a partir de um conjunto de opções viáveis. 
Uma das vertentes amplamente mencionadas na literatura é a teoria da escolha racional, formulação que se baseia nas preferências dos consumidores para nortear as suas escolhas, assumindo como um princípio básico a ideia de que os consumidores são racionais.

Para apresentar as noções básicas da teoria de escolha racional, faz-se necessário uma caracterização das preferências dos consumidores e o que representa a racionalidade. Nicholson e Snyder (2011) definem o conceito de preferência da seguinte maneira: "se um indivíduo considera que A é preferível a B então, num contexto geral, ele se sente melhor sob a situação A do que sob a situação B” (p. 89).

A partir das elaborações de Nicholson e Snyder (2011) e Mas-Colell, Whinston e Green (1995), são apresentados a seguir os postulados que caracterizam o comportamento racional, também conhecidos como axiomas da escolha racional:

1) Completude: Sejam A e B são duas situações quaisquer. O indivíduo é sempre capaz de especificar uma das 3 seguintes possibilidades:
a. "A é preferível a B",
b. "B é preferível a A", ou
c. "A e B são igualmente atrativos"

O axioma 1 formaliza a noção de que o consumidor é capaz de realizar comparações, isto é, de que ele possui as informações e conhecimento necessários para decidir sobre a conveniência de quaisquer duas alternativas. A suposição garante ainda que as preferências sejam assimétricas, ou seja, exclui a possibilidade de que o indivíduo possa considerar que A é preferível a B e que B é preferível a $\mathrm{A}$, e evita que os indivíduos sejam paralisados pela indecisão.

2) Transitividade: se o consumidor considera "A preferível a B" e "B preferível a C", então ele também considera que "A é preferível a C". Essa suposição é adotada de forma a garantir que as escolhas sejam internamente consistentes. Embora a assunção dessa propriedade num primeiro momento pareça natural, este axioma é fraco e controverso, pois experimentos empíricos revelaram que as preferências dos seres humanos reais nem sempre são transitivas.

3) Continuidade: se o consumidor considera que "A é preferível a B", então as situações muito similares a "A" também devem ser preferíveis a "B". Esta é uma suposição técnica, cujo objetivo é descartar certos tipos de preferências descontínuas, 
que viriam a apresentar problemas para o desenvolvimento matemático da teoria da escolha.

As suposições de completude, transitividade e continuidade sobre as preferências dos consumidores garantem que estes são capazes de classificar, dentre várias situações, da menos desejável à mais desejável. Isso permite a construção de uma escala ordinal de preferências, à qual se associa o conceito de utilidade: se uma pessoa preferir a situação A à situação B, convenciona-se que a utilidade atribuída à opção $\mathrm{A}$, denotada por U(A), é superior à utilidade atribuída a B, denotada por $\mathrm{U}(\mathrm{B})$.

Em sentido mais amplo, a utilidade de um indivíduo não é afetada apenas pelo consumo de mercadorias físicas, mas também por atitudes psicológicas, experiências pessoais e o ambiente cultural geral. Entretanto, para tornar a análise de escolhas gerenciável dentro de um cenário simplificado, uma prática comum é dedicar atenção exclusivamente a escolhas entre opções quantificáveis, como as quantidades relativas entre dois bens, por exemplo, mantendo constantes todas as outras variáveis que possam influenciar o comportamento. Essa suposição é conhecida na literatura como pressuposto ceteris paribus, e é geralmente invocada nas análises econômicas de escolhas maximizadoras de utilidade.

Com base nos pressupostos mencionados anteriormente, podemos ilustrar um conjunto de escolhas entre as quantidades de dois bens $(\mathrm{x}, \mathrm{y})$ e sua respectiva utilidade. Supondo $\mathrm{U}(\mathrm{x}, \mathrm{y})$ sendo a utilidade do consumidor ao escolher uma certa quantidade dos bens $\mathrm{x}$ e $\mathrm{y}$, temos o Gráfico 3:

Gráfico 3: Curva de Indiferença

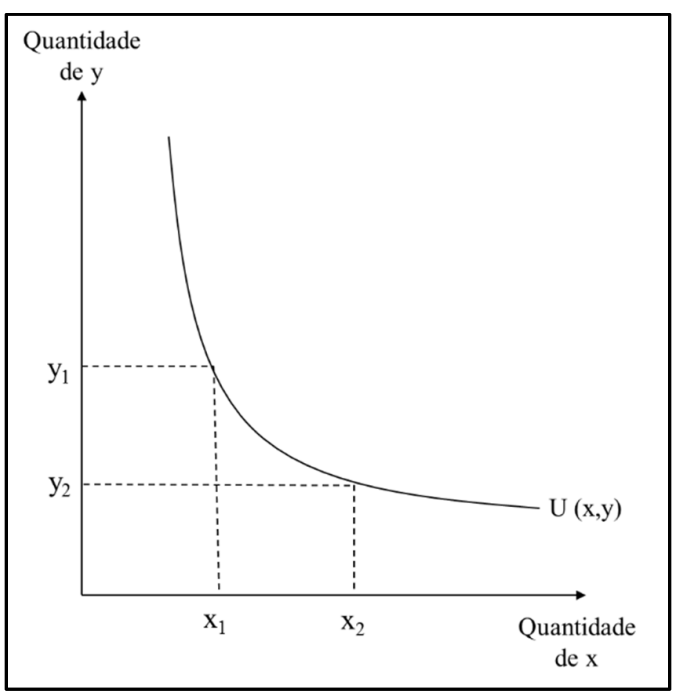

Fonte: elaborado pela autora 
A curva $\mathrm{U}(\mathrm{x}, \mathrm{y})$ representa a utilidade do consumidor, ou seja, o nível de satisfação ao escolher uma certa combinação entre as quantidades dos bens x e y. Qualquer combinação de escolha sobre essa curva reflete um mesmo nível de satisfação, isto é, a utilidade obtida ao escolher o par de quantidades $(\mathrm{x} 1, \mathrm{y} 1)$ é idêntica à utilidade obtida ao escolher o par (x2, y2). Essa curva é conhecida na teoria econômica como curva de indiferença.

Para cada ponto definido no plano $(\mathrm{x}, \mathrm{y})$ há uma curva de indiferença representando as combinações de x e y e o respectivo nível de satisfação ou utilidade que o indivíduo associa a estas combinações, conforme demonstrado no gráfico a seguir.

\section{Gráfico 4: Aumento da Utilidade}

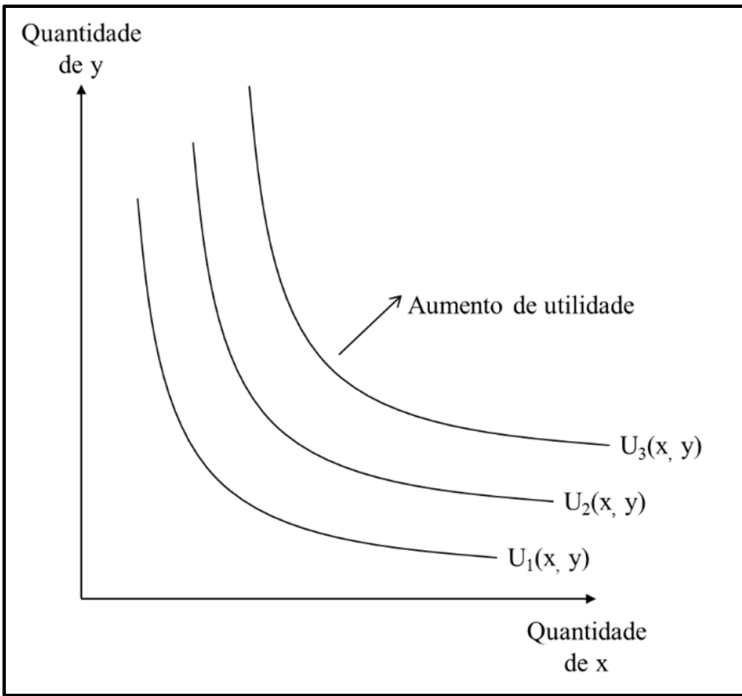

Fonte: elaborado pela autora

O grau de utilidade aumenta à medida que o conjunto de escolha se movimenta no sentido representado pela seta no gráfico. Qualquer combinação de x e y sobre a curva $\mathrm{U}_{2}$ apresenta utilidade superior às combinações de $\mathrm{x}$ e y sobre a curva $\mathrm{U}_{1}$. Da mesma forma, qualquer combinação de $\mathrm{x}$ e y sobre a curva $\mathrm{U}_{3}$ apresenta utilidade superior às combinações de $\mathrm{x}$ e y sobre a curva $\mathrm{U}_{2} \mathrm{e}$, consequentemente, superior às combinações de $\mathrm{x}$ e y sobre a curva $\mathrm{U}_{1}$. 


\subsubsection{Heurísticas e Vieses}

A economia comportamental surge como uma crítica à teoria das expectativas racionais. Kahneman e Tversky (1979) defendem que a decisão em um ambiente de risco apresenta vários efeitos que são incompatíveis com a teoria utilitarista. Pessoas atribuem pouca importância a resultados que são meramente prováveis em comparação a resultados que são obtidos com certeza. Essa tendência, chamada de efeito certeza, contribui à aversão ao risco em escolhas envolvendo ganhos certos e a propensão ao risco em escolhas envolvendo perdas certas.

A prospect theory é apresentada por Kahneman e Tversky (1979) como uma teoria alternativa à teoria utilitarista. Uma das principais críticas é a de que as pessoas possuem preferências inconsistentes quando a mesma escolha é apresentada em diferentes formas. Em outras palavras, os axiomas das preferências do consumidos podem não ser respeitados pois as escolhas dos consumidores nem sempre são racionais. Neste caso o pressuposto da transitividade é violado e duas curvas de indiferença podem se cruzar.

Para a formulação da prospect theory são observados dois fenômenos no processo de escolha dos consumidores. O reflection effect ocorre quando o risco de uma perda é preferível à certeza de uma perda. Outro efeito é o isolation effect: a fim de simplificar o processo de escolha, os agentes não examinam todas as características de uma alternativa, mas focam naquilo que as distingue. Isso pode gerar preferências inconsistentes.

A função valor, a qual representa o valor que os indivíduos atribuem para determinados níveis de ganhos ou perdas, normalmente é côncava para ganhos e convexa para perdas, e geralmente mais íngreme para perdas do que para ganhos. Isso quer dizer que os consumidores obtêm maior desutilidade em caso de pequenas perdas do que utilidade em pequenos ganhos.

Em Kahneman, Knetsch, \& Thaler (1991) há o reforço de que a economia se distingue das demais ciências sociais pela crença de que a maior parte do comportamento pode ser explicado assumindo que os agentes têm preferências estáveis e bem definidas e que fazem escolhas racionais. Entretanto, algumas situações não podem ser descritas pela racionalidade são o que os autores chamam de anomalias. Na situação de endowment effect as pessoas exigem mais por um bem do que aquilo que estariam dispostas a pagar por ele. Status quo bias ocorre quando há preferência pelo estado atual do que por uma situação de compra ou de venda. Esses dois conceitos são anomalias de assimetria de valor, chamadas de loss aversion 
- quando a desutilidade de se desfazer de um objeto é maior do que a utilidade associada a adquiri-lo.

Segundo Kahneman et al. (1991) as percepções de equidade e de justiça são fortemente dependentes da maneira como as questões são apresentadas, se como redução de ganhos ou como perdas. Uma implicação do efeito endowment é que as pessoas tratam custos de oportunidade diferentemente de custos "out-of-pocket". Ganhos não recebidos, portanto, afetam menos que perdas realizadas.

Thaler (1999) trata dos efeitos da contabilidade mental. Segundo esse conceito, as pessoas possuem percepções diferenciadas sobre descontos conforme a maneira a qual ele é apresentado. Embora em termos absolutos o desconto possa ser igual em duas opções de compra, o consumidor estará mais propenso a consumir o produto que tiver o maior desconto relativo. Outra implicação da contabilidade mental é que os consumidores possuem percepções diferenciadas sobre perdas e ganhos. Uma perda é melhor aceita quando apresentada de forma agrupada, como é o exemplo de uma fatura de cartão de crédito. Já um conjunto de ganhos gera maior satisfação quando é apresentado separadamente: presentes de Natal causam uma melhor impressão quando apresentados em embrulhos separados do que reunidos em um mesmo embrulho.

O processo de escolha do consumidor em função da quantidade de produtos disponíveis é examinado por Iyengar e Lepper (2000). Seria a satisfação com o produto escolhido diferente quando é necessário escolher entre um número maior de produtos? Segundo os experimentos apresentados pelos autores a resposta é afirmativa: a satisfação é maior quando o conjunto de escolha é limitado. Embora os consumidores prefiram um número maior de opções, essa variedade de escolha causa uma espécie de sofrimento e usa um excesso de recursos cognitivos. Esses resultados contradizem e teoria econômica neoclássica, que prega que quanto mais opções o livre mercado oferecer maior será a satisfação do consumidor.

\subsection{País de origem (Country of origin)}

O fluxo de comércio internacional tem crescido substancialmente nas últimas décadas. Se por um lado as empresas alcançam mercados outrora inacessíveis, por outro lado competem cada vez mais para conquistar clientes. Nesse contexto, um dos atributos mais relevantes para o consumidor ao escolher um produto é seu país de origem. 
O primeiro trabalho identificado na literatura em estudos de revisão sistemática do tema país de origem (Dinnie, 2004; Verlegh \& Steenkamp, 1999) foi o de Schooler (1965). Neste trabalho, o autor estudou quais características constituíam barreiras às transações comerciais dentro da Central American Commom Market, concluindo que atitudes em relação às pessoas de determinado país eram fator relevante nas concepções formadas em relação aos produtos desse país.

Estudos anteriores à década de 80 já identificavam que país de origem de um produto poderia influenciar sua qualidade percebida, conforme Bilkey e Nes (1982). Nesse estudo, os autores identificaram através de revisão da literatura diversos vieses dos consumidores a respeito de avaliações de produto em que a informação de país de origem estava disponível. Os autores encontraram evidências de que quando são comparados produtos de países com alto grau de desenvolvimento econômico, os consumidores tendem a avaliar melhor os produtos do próprio país do que produtos estrangeiros. Embora vários estudos relacionem positivamente qualidade percebida de produto com o grau de desenvolvimento de um país, essa relação é diferente para cada grupo de consumidores, ou seja, consumidores dos países A e B provavelmente avaliarão de forma distinta produtos do país C.

Outros indícios levantados por Bilkey e Nes (1982) referem-se a características demográficas e de personalidade. Pessoas mais velhas, com maior renda, mulheres e com maior nível educacional tendem a avaliar melhor produtos estrangeiros. Pessoas não brancas tendem a avaliar melhor produtos nigerianos, latino-americanos e indianos do que pessoas brancas. Por outro lado, pessoas brancas avaliaram melhor produtos dos Estados Unidos e da América do Norte do que pessoas não brancas. Foi observado, também, relações entre dogmatismo e país de origem. Quanto maior o conservadorismo, pior a atitude em relação a produtos estrangeiros.

Efeitos de país de origem com foco em aspectos cognitivos, afetivos e normativos foram estudados por Verlegh \& Steenkamp (1999). Aspectos cognitivos referem-se a julgamentos de qualidade inferidos a partir da sugestão de país de origem. Aspectos afetivos produzem a partir do país de origem um valor simbólico e emocional aos consumidores. Os aspectos normativos tratam de normas pessoais e sociais que os consumidores formam a partir do país de origem do produto ou serviço. Segundo os autores os efeitos cognitivos, afetivos e normativos não ocorrem separadamente, pelo contrário, interagem entre si.

Em um estudo de meta-análise desenvolvido por Verlegh e Steenkamp (1999) foram avaliados efeitos de país de origem sobre qualidade percebida, atitude e intenção de compra. 
Como principais resultados os autores concluíram que os efeitos de país de origem são maiores para o julgamento de qualidade do que para atitudes e intenção de compra. Ainda como resultado do estudo, foi identificado que os efeitos de país de origem são maiores quando são comparados produtos ou serviços de países desenvolvidos com países em desenvolvimento. Esse efeito, entretanto, é menor quando países com mesmo grau de desenvolvimento são comparados entre si. Esse resultado sugere que consumidores acreditam que produtos mais elaborados precisam ser feitos em países com mão-de-obra mais treinada e com maior nível educacional. Assim, produtos de países desenvolvidos em geral são melhor avaliados.

Enquanto a maior parte dos estudos de país de origem focam nas avaliações dos consumidores em relação à origem do produto, Gürhan-Canli e Maheswaran (2000) discutem o efeito das informações disponíveis de um produto sobre as percepções de país de origem. Dessa forma, foram realizados dois experimentos para investigar os fatores que influenciam as avaliações de país de origem e seus processos psicológicos subjacentes. Os resultados encontrados sugerem que consumidores sujeitos a uma condição de baixa motivação são mais propensos a atribuir maior importância ao país de origem no julgamento de um produto do que consumidores expostos a uma condição de alta motivação.

Os temas a seguir foram selecionados da literatura de país de origem como base teórica para responder o problema de pesquisa proposto.

\subsubsection{Produtos tipificados}

Em décadas de estudo sobre os efeitos de país de origem foram identificadas muitas particularidades a respeito das atitudes do consumidor em relação à origem de produto. Vários resultados encontrados em pesquisas mostraram que os efeitos de país de origem são diferentes conforme a categoria do produto, dificultando a generalização da teoria. A produção de alguns produtos é associada a determinados países, como perfumes à França, carros à Alemanha, eletrônicos ao Japão. Assim, a dimensão do efeito país de origem pode apresentar diferentes intensidades conforme a categoria de produto analisada (Tseng \& Balabanis, 2011).

A tipicidade de um produto pode ser definida como a probabilidade a qual o consumidor o classifica como pertencente à determinada categoria (Loken \& Ward, 1990). No 
estudo de tipicidade em país de origem duas dimensões podem ser destacadas: tipicidade étnica e tipicidade de país. Tipicidade étnica relaciona-se ao grupo de países que é reconhecido por produzir determinado produto, enquanto tipicidade de país refere-se ao conjunto de produtos que um determinado país é reconhecidamente associado (Tseng \& Balabanis, 2011). Através da realização de experimentos, Tseng e Balabanis (2011) concluíram que produtos típicos de um país atingiram atitudes mais favoráveis do que produtos não típicos do mesmo país ou de outros países.

A relação entre estímulos intrínsecos e extrínsecos e avaliações de produtos para produtos de origem típica e não típica é estudada por Spielmann (2015). A autora utiliza a classificação de tipicidade para um único produto - vinho - para estudar sua influência nas escolhas dos consumidores. Apesar de o vinho ser usualmente tratado como um produto típico, ele pode ser diferenciado conforme a tipicidade da região de origem do produto, isto é, vinhos do "velho mundo"3 e vinhos do "novo mundo".

Ao segmentar consumidores conforme seu grau de conhecimento em vinhos, Spielmann (2015) concluiu que consumidores com baixo conhecimento utilizaram predominantemente atributos extrínsecos para avaliar a origem de produtos tanto típicos quanto não típicos. Consumidores com médio conhecimento, entretanto, atribuíram maior importância a atributos intrínsecos para avaliar produtos típicos, e maior importância a atributos extrínsecos para avaliar produtos não típicos. Já os consumidores com alto grau de conhecimento avaliaram produtos típicos conforme atributos intrínsecos, e produtos não típicos conforme sua marca (atributo extrínseco). A autora ressalta que a classificação de produto típico e atípico por vezes possui caráter subjetivo, uma vez que depende do prévio conhecimento do consumidor sobre o produto e sua respectiva região de origem.

Produtos podem ser avaliados por fatores intrínsecos (ex: sabor, design, conforto, etc) ou por fatores extrínsecos (ex: preço, marca, garantia). Nesse sentido, o país de origem é um fator extrínseco ou um atributo intangível do produto (Ahmed \& D’Astous, 2001; Sharma, 2011).

\footnotetext{
${ }^{3}$ Vinhos do velho mundo se referem a regiões com séculos de história na produção de vinho, comumente se referindo a países europeus. Vinhos do novo mundo estão associados à produção mais recente de vinho, geralmente em áreas colonizadas, como Américas, Oceania e África do Sul.
} 


\subsubsection{Efeitos intranacionais de país de origem}

Embora a maior parte dos trabalhos sobre país de origem considere que a avaliação de seu efeito é homogênea para cada país, há evidências de efeitos intranacionais heterogêneos de país de origem (Aurifeille, Quester, Lockshin, \& Spawton, 2002; Cohen, D’Hauteville, \& Sirieix, 2009; Heslop et al., 1998).

Schouten e McAlexander (1995) definem a subcultura de consumo como um subgrupo particular da sociedade, agrupado conforme identificação com uma categoria produtos, marcas ou atividades de consumo. Esse subgrupo possui organização social identificável e um conjunto de crenças e valores em comum.

Objetos podem desempenhar um papel de instrumento facilitador para realizar coisas que de outra maneira as pessoas não seriam capazes, ou também podem proporcionar o sentimento de que alguém é diferente por possuir esse objeto, de modo que ter o objeto pode colaborar com o poder de fazer e ser (Belk, 1988).

Tais questões de diferenciação de pequenos grupos dentro de grupos maiores podem explicar efeitos de intranacionais de país de origem. Um estudo em nível subnacional para avaliar produtos foi realizado por Heslop et al. (1998) no Canadá, para consumidores de língua inglesa e de língua francesa. Os autores buscaram entender se as imagens atribuídas a produtos variavam não somente para produtos de diferentes regiões do país, mas também para produtos estrangeiros com os quais os consumidores apresentavam alguma similaridade cultural. Os resultados encontrados mostraram que quanto maior a proximidade da origem do produto com o consumidor, maior a influência da cultura nas avaliações dos produtos.

Conforme Cohen et al. (2009), o vinho é um produto cujo consumo está altamente relacionado à cultura local. Nesse trabalho, os autores se propuseram a identificar se diferenças culturais poderiam ser medidas através dos critérios de escolha usados em restaurantes por consumidores de vinho da França, Austrália e Reino Unido. Foram encontradas diferenças significativas entre os países, especialmente quando se compara França à Austrália e Reino Unido. Consumidores franceses são mais influenciados pela região de origem do produto, enquanto australianos e britânicos são mais afetados por características como tipo de uva. 


\subsubsection{Outros efeitos relacionados a país de origem}

Tipicidade e diferenças intranacionais considerando diferenças de efeito país de origem entre países emergentes e desenvolvidos foram considerados como fenômenos de maior relevância para responder o problema de pesquisa proposto nesse trabalho. No entanto, há outros efeitos de país de origem que merecem ser citados: marca de origem, etnocentrismo e animosidade.

Similar ao efeito de país de origem de produto, o efeito marca de origem também impacta as intenções de compra de consumidores e suas avaliações acerca da qualidade do produto. Em um estudo sobre preferências de medicamentos sem prescrição genéricos e associados a uma marca, por exemplo, Smaoui et al. (2016) observaram que a marca de origem era mais importante na avaliação dos consumidores do que o país de origem dos medicamentos.

Dentre os estudos sobre efeitos de país de origem há numerosos trabalhos realizados observando-se o contexto de países desenvolvidos (Bilkey \& Nes, 1982; Dinnie, 2004; Sharma, 2011). Efeitos de país de origem em países em desenvolvimento, no entanto, são distintos em relação aos produtos nacionais e estrangeiros quando comparados aos países desenvolvidos (Smaoui, Abdellah, \& Touzani, 2016). Ao comparar com produtos domésticos, consumidores de países em desenvolvimento avaliam produtos de países desenvolvidos como superiores em qualidade, e produtos de países emergentes como similares ou inferiores. Por outro lado, os consumidores de países desenvolvidos atribuem qualidade inferior aos produtos oriundos de países em desenvolvimento e qualidade similar ou superior aos produtos de outros países desenvolvidos (Sharma, 2011).

O processo de escolha de medicamentos genéricos e de marcas é estudado por Smaoui, Abdellah, e Touzani (2016). Os autores relatam que embora a marca seja o atributo mais importante para a escolha de medicamentos isentos de prescrição, outros atributos como preço e país de origem também são relevantes. Como sua maior contribuição, apontam o estudo do efeito país de origem versus marca em um país emergente - a Tunísia.

Através de uma conjoint analysis Fatma Smaoui et al. (2016) identificaram que consumidores tunisianos tinham preferência a medicamentos associados a uma marca, com preços mais elevados e oriundos da França, quando comparados com medicamentos genéricos, de preço mais baixo e da Tunísia. Embora o país de origem tenha sido apontado como menos importante do que a marca associada ao medicamento, o estudo concluiu que aos 
medicamentos oriundos de países industrializados são atribuídos maior qualidade, maior confiança e maior possibilidade de compra do que aos medicamentos de países emergentes.

\subsection{Atributos de vinho}

O processo de escolha de vinho tem sido tema de estudo de um grande número trabalhos nas últimas décadas. A abundância de estudos focados no produto pode ser justificada pela diversidade e complexidade de características que compõem uma garrafa de vinho, o que torna o processo de escolha uma tarefa complexa. Assim, essa seção levantou os principais atributos de vinho estudados em pesquisas anteriores.

No contexto de consumidores norte-americanos, Kelley et al. (2015) estudaram fatores extrínsecos que atraem consumidores e afetam sua decisão de compra de vinhos. Foram analisados atributos relacionados a informações presentes no rótulo e contra-rótulo do produto, como sugestão de harmonização com comida, informação de contato da vinícola e contato online, e informações específicas da vinícola. Os autores concluíram que essas informações impactam positivamente as escolhas dos consumidores com maior frequência de consumo, definidos como aqueles que comprassem vinho ao menos uma vez por semana.

Estudando uma amostra de consumidores espanhóis, Bernabéu, Díaz, Olivas, \& Olmeda (2012) analisaram quais atributos de vinho exercem maior influência nas escolhas dos consumidores. Utilizando a metodologia de best-worst scaling, foram avaliados os seguintes atributos: preço, ter provado previamente, região de origem, variedade da uva, safra, marca, teor alcoólico, design da garrafa e do rótulo, harmonização com comida, recomendação de amigos ou parentes, e produção orgânica. Os autores concluíram que os atributos mais importantes na escolha dos consumidores foram ter provado previamente, região de origem, preço e recomendações de amigos e parentes, sendo que essas preferências seguiram o mesmo padrão tanto para homens quanto para mulheres.

Com o intuito de verificar preferências de consumidores de acordo com a região de procedência de vinhos, Sanchez e Gil (1997) realizaram uma investigação com consumidores espanhóis utilizando a técnica da conjoint analysis. Foram utilizados três atributos para avaliar as escolhas dos consumidores: preço, região de origem e variedade de uva. Ao comparar escolhas de consumidores residentes em regiões rurais com consumidores residentes em regiões urbanas, os autores concluíram que os consumidores rurais 
apresentaram maior utilidade associada a vinhos de produção local, enquanto que esse fenômeno não foi verificado entre os consumidores urbanos. No entanto, para ambos os grupos o atributo com maior importância relativa foi a região de origem do vinho, demonstrando mais uma vez a importância desse atributo nos estudos sobre escolha em vinho.

A influência de atributos extrínsecos como preço e país de origem sobre a escolha do consumidor quando este julga atributos intrínsecos (acidez) através de experiências sensoriais foi estudada por Veale e Quester (2009). Os resultados encontrados confirmam a forte influência do país de origem na atribuição de qualidade do produto, uma vez que produtos com nível de acidez atribuídos a produtos de qualidade inferior foram melhor avaliados em função do país de origem associado. Curiosamente, ao serem perguntados sobre a importância dos atributos na fase inicial do experimento, os consumidores associaram maior importância à acidez do vinho do que ao país de origem.

Lockshin e Cohen (2011) estudaram o processo escolha de vinho para consumidores de 11 países distribuídos em cinco continentes, utilizando atributos de produto e de comunicação de varejo. Diferentemente de outros trabalhos que analisaram entre si consumidores oriundos de determinada região, os autores agruparam os consumidores conforme comportamentos semelhantes, para somente após esta análise verificar o percentual de consumidores de cada país que compôs cada cluster. Nesse contexto, 57,0\% da amostra de consumidores brasileiros mostraram preferências predominantemente relacionadas a questões cognitivas (variedade da uva, origem do vinho, marca e premiações), 27,6\% se mostraram mais alinhados com características de segurança (ter experimentado anteriormente ou recebido alguma recomendação) e, por fim, 15,4\% da amostra de consumidores brasileiros mostrou-se mais receptiva a características de varejo (promoções, informações extras disponíveis na adega e informações de rótulo e contra-rótulo).

Embora atratividade do rótulo seja um atributo de vinho importante para alguns consumidores, esse atributo é de difícil quantificação (Lockshin \& Cohen, 2011). Essa avaliação é bastante subjetiva e, portanto, passível de estudos mais direcionados. Isso acontece porque o próprio atributo rótulo é formado por outros atributos, como design, e a presença de informações como website da vinícola, enólogo (a) responsável, informações para contato, etc.

Alguns autores salientam que a relevância dos atributos na escolha dos consumidores é diferente conforme a situação de compra e de consumo. Nesse sentido, Cohen, D'Hauteville e Sirieix (2009), estudaram preferências de consumidores na escolha de vinho em ambiente de 
restaurante. Os atributos selecionados para este estudo foram: teor alcoólico, recomendação do garçom, harmonização com a comida escolhida, ter provado previamente e apreciado, sugestão do menu, sugestão por algum acompanhante na mesa, disponibilidade em taça, vontade de experimentar algo diferente, varietal, região de origem, cartão promocional na mesa, disponibilidade de garrafas de $375 \mathrm{ml}$, e ter lido a respeito, mas não ter provado.

Entre os atributos levantados, os autores concluíram que os menos relevantes para a totalidade da amostra eram teor alcoólico, sugestão do menu e disponibilidade de garrafas de $375 \mathrm{ml}$. Por outro lado, os atributos que se mostraram mais relevantes na escolha dos consumidores foram harmonização com a comida escolhida, ter provado previamente e apreciado, e ter lido a respeito, mas não ter provado (Cohen et al., 2009).

Os atributos de vinho encontrados na literatura que ampara este trabalho seguem esquematizados no Quadro 1.

Quadro 1: Atributos de vinho encontrados na literatura

\begin{tabular}{|c|c|}
\hline ATRIBUTOS & AUTORES \\
\hline Ter provado previamente & Lockshin e Cohen (2011); (Bernabéu et al., 2012) \\
\hline Ter recebido alguma recomendação & Lockshin e Cohen (2011); (Cohen et al., 2009); (Bernabéu et al., 2012) \\
\hline Variedade da uva & Lockshin e Cohen (2011); (Bernabéu et al., 2012); Sanchez e Gil (1997) \\
\hline Região ou país de origem do vinho & $\begin{array}{l}\text { Lockshin e Cohen (2011); Veale e Quester (2009); (Cohen et al., 2009); } \\
\text { Sanchez e Gil (1997) }\end{array}$ \\
\hline Marca & Lockshin e Cohen (2011); (Bernabéu et al., 2012) \\
\hline Premiações & Lockshin e Cohen (2011) \\
\hline Ter lido a respeito do vinho & Lockshin e Cohen (2011); (Cohen et al., 2009) \\
\hline Harmonização com comida & Lockshin e Cohen (2011) \\
\hline Informação de contra-rótulo & Lockshin e Cohen (2011); (Cohen et al., 2009) \\
\hline Informações na adega/varejo & Lockshin e Cohen (2011) \\
\hline Rótulo atrativo & Lockshin e Cohen (2011); (Bernabéu et al., 2012) \\
\hline Exibição promocional na loja & Lockshin e Cohen (2011) \\
\hline Teor alcoólico & Lockshin e Cohen (2011); (Cohen et al., 2009); (Bernabéu et al., 2012) \\
\hline Preço & Veale e Quester (2009); (Bernabéu et al., 2012); Sanchez e Gil (1997) \\
\hline Acidez & Veale e Quester (2009) \\
\hline Varietal & (Cohen et al., 2009) \\
\hline Envelhecimento & (Bernabéu et al., 2012) \\
\hline Harmonização com comida & Kelley et al. (2015); (Cohen et al., 2009) \\
\hline Contato da vinícola & Kelley et al. (2015) \\
\hline Página online da vinícola & Kelley et al. (2015) \\
\hline Informações da vinícola & Kelley et al. (2015) \\
\hline Disponível para compra em taça & (Cohen et al., 2009) \\
\hline Disponível em garrafa de $375 \mathrm{ml}$ & (Cohen et al., 2009) \\
\hline Cartão Promocional na mesa & (Cohen et al., 2009) \\
\hline Produção orgânica & (Bernabéu et al., 2012) \\
\hline
\end{tabular}

Fonte: elaborado pela autora 
Tomando como ponto de partida os atributos analisados na literatura para avaliar escolha de vinho e, considerando a natureza quantitativa desse trabalho, foram selecionados 4 atributos para serem avaliados por consumidores. A seleção de atributos contempla, também, as especificidades do mercado consumidor de vinho no Brasil. Esse trabalho abrange, assim, a avaliação de país de origem, preço, tipo de vinho e ter recebido alguma recomendação.

\subsection{Envolvimento com produto}

O constructo envolvimento é objeto de estudo na psicologia social desde o trabalho de Sherif e Cantril (1947). Somente nas décadas seguintes o constructo foi inserido nos estudos de comportamento do consumidor com os trabalhos de Krugman (1967), que estudou envolvimento em propaganda, e Bloch (1981), que levantou a necessidade quantificar o constructo através da construção de uma escala de envolvimento com produto.

Embora não se encontre consenso na literatura a respeito da definição do constructo envolvimento, Fonseca (1999) sintetiza que nos diversos trabalhos sobre envolvimento há uma significação comum, que diz respeito à “percepção de relevância pessoal, ou seja, o nível de envolvimento é determinado pelo grau de importância com que o consumidor percebe um objeto ou uma situação" (p. 21).

A definição apresentada considera que o envolvimento do consumidor é influenciado pelos fatores pessoal, físico e situacional, conforme Figura 5. Fatores pessoais são constituídos por interesses inerentes, valores e necessidades que motivam o indivíduo cerca de um objeto. Fatores físicos, por sua vez, são características do objeto que causam diferenciação e aumento de interesse. Por fim, fatores situacionais referem-se àquilo que temporariamente aumenta relevância ou interesse acerca de um objeto (Zaichkowsky, 1985; Fonseca, 1999). 
Figura 5: Fatores que influenciam o envolvimento do consumidor

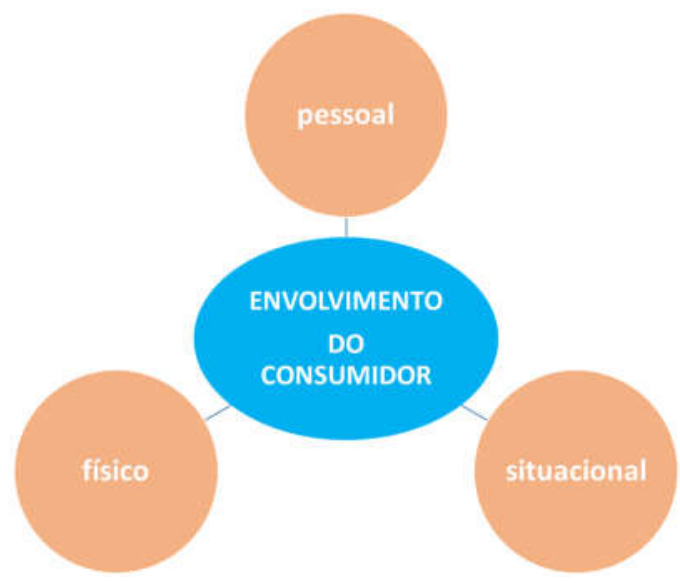

Fonte: elaborado pela autora

$\mathrm{Na}$ literatura é possível identificar várias propostas de escala de envolvimento com produto, o que denota a complexidade de definição e mensuração do constructo envolvimento. Dentre as escalas mais reproduzidas por pesquisadores estão a Personal Involvement Inventory, apresentada por Zaichkowsky (1985), a Involvement Profile, criada por Laurent e Kapferer (1985), e a New Involvement Profile, desenvolvida por Jain e Srinivasan (1990). Considerando a complexidade das escalas, ambas serão discutidas nas seções subsequentes.

\subsubsection{Personal Involvement Inventory}

A Personal Involvement Inventory (PII) é uma escala de envolvimento apresentada por Zaichkowsky (1985). A escala proposta definiu envolvimento como a percepção percebida de uma pessoa sobre o objeto com base em necessidades, valores e interesses inerentes. Visando a sistematização dos termos que seriam utilizados na escala a autora levantou na literatura 168 pares bipolares de palavras previamente gerados para representar o conceito de envolvimento. Foram levantados pares tais como importante/não importante, interessante/não interessante e emocionante/não emocionante.

Após uma série de etapas de refinamento desses pares, baseando-se em rodadas de julgamento de especialistas em comportamento do consumidor, foram relacionados 30 pares de palavras como resultado da análise de conteúdo. No momento seguinte, esses pares foram testados como escala para diferentes categorias de produtos, com o intuito de mensurar a 
consistência interna ou correlação entre os itens. Após esta etapa, seis pares foram excluídos por baixa correlação item-total, que é uma medida de confiabilidade para uma escala multiitem.

Os 24 pares restantes da etapa anterior foram submetidos à técnica teste-reteste de confiabilidade com uma nova amostra e um novo conjunto de categorias de produto. Após a comparação da comparação dos dados coletados entre duas amostras distintas, quatro pares foram dispensados da escala por apresentarem correlação média abaixo de 0,60 . Dessa forma, a escala de envolvimento PII foi criada a partir da mensuração de 20 pares de qualificadores, avaliados em uma escala de sete pontos, com resultado variando de 20 a 140, conforme Figura 6.

Figura 6: Personal Involvement Inventory - escala 20 pares (Zaichkowsky, 1985)

$$
\text { Para mim (insira o produto) é: }
$$

\begin{tabular}{|c|c|c|}
\hline importante & _|_|_|_|_|_|_ & não importante* \\
\hline não me preocupa & |_l_l_l. & me preocupa \\
\hline irrelevante & - & relevante \\
\hline significa muito para mim & -1-1 & significa nada para mim* \\
\hline sem utilidade & & útil \\
\hline valioso & -1 & sem valor* \\
\hline trivial & & fundamental \\
\hline benéfico & & não benéfico* \\
\hline importa para mim & |_l_l & não importa para mim* \\
\hline não interessado & - & interessado \\
\hline significativo & & insignificante* \\
\hline vital & - & supérfluo* \\
\hline chato & _ & interessante \\
\hline não emocionante & & emocionante \\
\hline atraente & & não atraente* \\
\hline comum & & fascinante \\
\hline essencial & & não essencial* \\
\hline não desejável & |_|_|_|_|_|_| & desejável \\
\hline procurado & |_|_|_|_|_|_| & não procurado* \\
\hline desnecessário & | & necessário \\
\hline
\end{tabular}

\footnotetext{
*indica que o item tem marcação reversa

os itens à esquerda são pontuados (1) baixo envolvimento até (7) alto envolvimento à direita. Os 20 itens totalizam uma pontuação entre o mínimo de 20 para o máximo de 140

Fonte: adaptado de Zaichkowsky (1985)
}

O envolvimento do consumidor com um produto pode variar conforme a situação de compra. Como exemplo, o envolvimento do consumidor com o produto vinho é diferente para 
a compra de uma garrafa para o consumo de dia-a-dia quando comparada à compra de uma garrafa para um jantar especial. Assim, algumas características específicas relacionando envolvimento de consumidor com a situação foram levantadas por Zaichkowsky (1985).

A primeira questão levantada diz respeito à busca por informações do produto. Consumidores com maior envolvimento são mais interessados em obter informações a respeito de um produto quando comparados a consumidores com baixo envolvimento. Isso leva à segunda característica levantada, que se refere à avaliação de alternativas concorrentes de um produto. Quando o consumidor busca informação de um produto, ele conscientemente realiza comparações entre produtos antes de efetuar uma escolha. A comparação de produtos alternativos leva à percepção da existência de diferenciação entre as marcas o que, por consequência, leva à formação de preferências por marcas específicas.

A PII foi analisada no trabalho de Mcquarrie e Munson (1987). Uma das críticas efetuadas pelos autores refere-se à escala PII ser composta por adjetivos comumente associados à envolvimento e, também, adjetivos que na literatura qualificam o constructo atitude. Dessa forma, apesar dos testes de confiabilidade de Zaichkowsky (1985) apresentarem alta consistência interna nos questionários, a escala estaria reproduzindo a teoria de dois diferentes constructos. Outra crítica feita pelos autores diz respeito ao caráter unidimensional da PII, que poderia gerar uma simplificação na mensuração do constructo envolvimento.

Uma sugestão de aprimoramento da PII foi apresentada por McQuarrie e Munson (1992). A escala proposta foi construída a partir de 10 itens, os quais resolveriam problemas de usabilidade, validade discriminante, validade de critério e validade de conteúdo.

Como resposta às críticas recebidas à PII, Zaichkowsky (1994) propôs uma atualização da escala, reduzindo a mesma à avaliação de 10 pares de adjetivos, sem incorrer em perdas importantes de confiabilidade. A Figura 7 mostra PII revisada: 
1994)

Figura 7: Personal Involvement Inventory Revisada - escala 10 pares (Zaichkowsky, Para mim (insira o produto) é:

\begin{tabular}{|c|c|c|}
\hline importante & |_|_|_|_|_|_|_| & não importante* \\
\hline chato & |_|_|_|_|_| & interessante \\
\hline relevante & | & irrelevante* \\
\hline emocionante & |_|_|_|_|_|_| & não emocionante* \\
\hline significa nada & & significa muito \\
\hline atraente & - & não atraente* \\
\hline fascinante & |_|_|_|_|_ & comum* \\
\hline sem valor & |_|_|_|_|_|_|| & valioso \\
\hline envolvente & |_|_|_|_|_|_|_| & não envolvente* \\
\hline desnecessário & |_|_|_|_|_|_|_| & necessário \\
\hline
\end{tabular}

Fonte: adaptado de Zaichkowsky (1994)

\subsubsection{Involvement Profile}

A abordagem de Laurent e Kapferer (1985) sobre envolvimento do consumidor destaca a existência de mais de um tipo de envolvimento e a importância de que todas as suas dimensões sejam levadas em consideração na montagem de um indicador de envolvimento satisfatório, em contraposição às pesquisas realizadas até então, em que os indicadores quantitativos de envolvimento eram frequentemente reduzidos a uma única dimensão.

Dessa forma, os autores propõem a utilização de um "perfil de envolvimento", cujo objetivo é desenvolver uma escala válida e confiável para a identificação do nível de envolvimento do consumidor. Além disso, outro aspecto relevante sobre a escala proposta refere-se à sua conveniência, que os autores descrevem como a aptidão de fazer sentido para qualquer classe de produto além de possuir um número total de itens que permita sua utilização com baixo custo extra na aplicação da pesquisa.

As dimensões selecionadas para criação da escala foram: a importância atribuída ao produto; o risco associado à compra do produto (o impacto de uma escolha ruim ou a probabilidade de errar na escolha); o valor simbólico atribuído ao produto; e, o valor hedônico do produto (seu apelo emocional ou capacidade de gerar prazer).

Através de análise fatorial e de regressão sobre os resultados, os autores identificaram que as dimensões são correlacionadas e devem ser utilizadas simultaneamente por revelarem 
informações específicas do envolvimento do consumidor, contribuindo para corroborar a tese de que o envolvimento do consumidor deve ser observado através de um perfil e não um único indicador. A escala não será reproduzida nesse trabalho pois a mesma não foi integralmente disponibilizada na língua inglesa pelos autores.

\subsubsection{New Involvement Profile}

A partir das escalas PII, IP e de outras escalas nos estudos em envolvimento, Jain e Srinivasan (1990) propuseram uma escala chamada New Involvement Profile (NIP). Como crítica em relação aos estudos prévios sobre envolvimento, os autores levantaram a necessidade do desenvolvimento de melhores instrumentos de medição e testes empíricos, uma vez que estes não teriam avançado tanto quanto o desenvolvimento da conceituação do constructo envolvimento.

A proposta da NIP é apresentar um refinamento em relação a escalas anteriores. Os autores defendem que uma escala unidimensional como a PII de Zaichkowsky (1994) não é capaz de capturar todas as complexidades do constructo envolvimento. Por outro lado, embora a PI de Laurent e Kapferer (1985) atenda ao caráter da multidimensionalidade, o fato de ter sido aplicada com produtos locais franceses e, também, a ausência da tradução completa da escala para o inglês dificulta a sua aplicabilidade em outros contextos (Jain \& Srinivasan, 1990).

Com o intuito de formar uma escala de envolvimento multidimensional e que contemplasse os estudos anteriores, foram testados 49 pares de itens semânticos oriundos dos trabalhos anteriores. Tais pares foram testados para 10 produtos, com um tamanho amostral de 375 respondentes. Para evitar exaustão, cada respondente avaliou os 49 pares para somente dois produtos, o que retornou 735 respostas úteis.

Os dados coletados foram submetidos à análise fatorial para testar a proximidade dos conceitos relacionados ao constructo envolvimento, gerando um agrupamento de cinco fatores: relevância, prazer, valor simbólico, importância de risco e probabilidade de risco. Para formar a NIP, para cada dimensão foram selecionados os três itens com maior carga fatorial dentro de cada fator. Assim, dentre os 49 pares testados, foram selecionados 15 pares semânticos, distribuídos em cinco dimensões.

Como avanço em relação aos trabalhos anteriores, a NIP foi resultado da comparação de escalas existentes, sintetizando uma medida multidimensional ao constructo envolvimento. A escala completa pode ser conferida na Figura 8: 
Figura 8: New Involvement Profile (Jain \& Srinivasan, 1990)

1. essencial - não-essencial*

2. benéfico - não-benéfico*

3. desnecessário - necessário

4. eu não acho prazeroso - eu acho prazeroso

5. não-emocionante - emocionante

6. divertido - não-divertido*

7. fala aos outros sobre mim (é a minha cara) - não fala aos outros sobre mim (não é a minha cara)*

8. serve para os outros me julgarem - os outros não o usariam para me julgar*

9. não passa uma imagem de mim para os outros - passa uma imagem de mim para os outros

10. é realmente irritante fazer uma compra inadequada - não é irritante fazer uma compra inadequada*

11. uma escolha ruim não seria um transtorno - uma escolha ruim seria um transtorno

12. pouco a perder por escolher mal - muito a perder por escolher mal

13. ao comprá-lo, estou certo(a) da minha escolha - ao comprá-lo, não estou certo(a) da minha escolha

14. nunca sei se estou fazendo a compra certa - eu tenho certeza de estar fazendo a compra certa*

15. eu me sinto um pouco perdido(a) ao escolher isto - eu não me sinto perdido(a) ao escolher isto*

* representa itens dispostos inversamente. Fator relevância: itens 1, 2 e 3; fator prazer: itens 4, 5 e 6; fator valor simbólico: itens 7, 8 e 9; fator importância de risco: itens 10, 11 e 12; e fator probabilidade de risco: itens 13, 14 e 15.

Fonte: tradução reversa de Fonseca (1999, p.44)

\subsection{Conjoint Analysis}

A conjoint analysis é uma técnica que permite estimar relações de dependência para compreender preferências individuais baseadas em fundamentação teórica. Ela é apropriada para compreender avaliações de consumidores sobre um conjunto pré-determinado de atributos. Por avaliar o processo de escolha individual e conjunta dos indivíduos, a conjoint analysis é uma técnica adequada para estudar contextos como segmentação de mercado, precificação e desenvolvimento de produtos. A versatilidade da técnica de conjoint analysis permite sua utilização em variadas situações em que se pretenda estudar processos de decisão. Distinguir o conjunto de preferências individuais ou agregadas possibilita estudar uma gama de reações ligadas a produtos ou serviços (Hair et al., 2009).

Segundo Hair et al. (2009, p.365), a conjoint analysis distingue-se de outras técnicas multivariadas devido à: “(1) sua natureza decomposicional, (2) especificação de variável estatística, (3) fato de que as estimativas podem ser feitas no nível individual, e (4) sua flexibilidade em termos de relações entre variáveis dependentes e independentes”. 
A definição de modelos de composição e modelos de decomposição é apresentada por Hair et al. (2009):

Muitas das técnicas multivariadas de dependência que examinamos em capítulos anteriores são chamadas de modelos de composição (p.ex., análise discriminante e muitas aplicações de regressão). Com tais técnicas o pesquisador coleta avaliações do respondente sobre muitas características de produto (p.ex., preferência sobre cor, estilo, características específicas) e então relaciona essas avaliações com alguma avaliação de preferência geral para desenvolver um modelo preditivo. O pesquisador não conhece de antemão as avaliações sobre características de produtos, mas coleta-as a partir do respondente. Com as análises de regressão e discriminante, as avaliações e preferências gerais do respondente são analisadas para "compor" a preferência geral a partir das avaliações do respondente sobre o produto em cada atributo. A análise conjunta, conhecida como um modelo de decomposição, difere no sentido de que o pesquisador precisa saber apenas uma preferência geral do respondente para um estímulo. Os valores de cada atributo (variável independente) já estavam especificados pelo pesquisador quando o estímulo foi criado. Deste modo a análise conjunta pode determinar (decompor) o valor de cada atributo usando somente a medida de preferência geral. (p. 336)

Para a aplicação da técnica é necessário o entendimento dos seguintes conceitos: fator (atributo específico do produto ou serviço), níveis (os valores possíveis para cada fator) e estímulo (combinação de fatores e níveis para descrever um objeto). Ao se formarem combinações específicas é possível compreender uma estrutura de preferências do indivíduo (Hair et al., 2009).

Para garantir o rigor de uma conjoint analysis é necessário definir quais fatores impactam de forma positiva e negativa sobre a preferência e, também, aplicar um modelo bem especificado para obter os valores individuais em avaliações gerais dos indivíduos sobre os objetos de estudo. Como resultados, espera-se identificar a utilidade de cada nível em cada atributo e estabelecer a utilidade geral de cada estímulo para que possam ser comparáveis entre si (Hair et al., 2009).

No que se refere à etapa de coleta de dados, o pesquisador deve definir a forma de apresentação dos estímulos, o tipo de variável e resposta e a metodologia de coleta de dados. Independente da escolha de pesquisa efetuada, deve-se levar em consideração o modelo previamente definido e tornar a escolha do respondente uma tarefa envolvente. Recomenda-se o pré-teste de distintas disposições de métodos de apresentação, a fim de testar a melhor 
adequação ao planejamento da pesquisa, aumentando assim a validade dos dados coletados (Dinnie, 2004; Verlegh \& Steenkamp, 1999).

Embora a conjoint analysis permita visualizar as utilidades parciais das preferências dos indivíduos, é necessário validar o conjunto das preferências. Dessa forma, é possível identificar eventuais padrões não coerentes de estruturas parciais. Assim como qualquer técnica estatística, é necessário um olhar crítico para os resultados obtidos, a fim de garantir que o instrumento esteja de fato medindo o que se propõe medir (Kitchenham, 2004).

Como toda técnica estatística, a conjoint analysis requer um olhar crítico do pesquisador a fim de presumir validade no modelo. Embora a técnica consiga entender as preferências dos consumidores na avaliação de atributos, por outro lado o design do modelo é complexo e sem especificações de fatores e níveis adequados pode retornar respostas pouco coerentes.

A conjoint analysis é uma técnica que foi sendo aprimorada ao longo do tempo, de foram sendo criadas variações da técnica. A técnica originalmente proposta ficou conhecida como conjoint analysis tradicional e, a partir dessa, foram criadas variações que pudessem atender a situações de pesquisa mais específicas.

A conjoint analysis tradicional, também conhecida como full-profile conjoint analysis, caracteriza-se pela avaliação de produtos de perfis completos, em que os respondentes são convidados a avaliar diversos cenários baseados em escalas ordinais ou intervalar. Segundo Rao (2014), esta técnica não é adequada para estudos que envolvam grande quantidade de atributos, pois o respondente será indevidamente sobrecarregado ao realizar julgamentos de preferência para todos os perfis. Orme (2010) também menciona o problema do viés de excesso de informações para o respondente em estudos que apresentam perfís com número de atributos superior a seis. Outra característica da conjoint analysis tradicional é que os perfis são estáticos, o que permite que a pesquisa seja feita a partir de perguntas diretas aos respondentes, utilizando-se questionários em papel.

A evolução da técnica para tratar do viés de excesso de informações culminou com o desenvolvimento da adaptive conjoint analysis em 1985 (Orme, 2010). Essa técnica permite a utilização de elevado número de atributos, pois os respondentes não avaliam todos os atributos de uma única vez. Para manter essa característica, a entrevista vai se adaptando aos entrevistados, à medida que a pesquisa avança. Por esta razão, ao contrário da conjoint analysis tradicional, a pesquisa do tipo adaptive conjoint analysis só pode ser realizada através com auxílio computacional, descartando a possibilidade de questionários em papel. 
No início dos anos 90 a choice-based conjoint analysis começou a ganhar popularidade com a facilidade do uso da informática. Segundo Orme (2010) e Rao (2014), a partir do seu desenvolvimento esta passou a ser a técnica utilizada com mais frequência nas pesquisas. Enquanto conjoint analysis tradicional envolve perfis completos de conceitos de produtos descritos em múltiplos atributos, na choice-based conjoint analysis o respondente é submetido à escolha de um conceito dentre um conjunto de conceitos apresentados simultaneamente. Dessa forma, na choice-based conjoint analysis espera-se que o respondente seja capaz de expressar suas preferências ao realizar a escolha de um dos conceitos ao invés de simplesmente ordená-los ou pontuá-los. Assim, a principal vantagem deste método é simular o comportamento do agente de decisão de maneira mais próxima à realidade de mercado. 


\section{MÉTODO DA PESQUISA}

Tendo em vista os objetivos propostos por este trabalho, a presente pesquisa pode ser classificada como descritiva, pois apresenta como "objetivo primordial a descrição das características de determinada população ou fenômeno ou, então, o estabelecimento de relações entre variáveis" (Gil, 2002, p. 42). Dessa forma, não se pretende encontrar relações de causa e efeito de um fenômeno, mas compreender a maneira a qual determinado fenômeno se manifesta.

A pesquisa desenvolvida nesse trabalho pode ser considerada quantitativa, pois possui propósito de encontrar explicações e previsões utilizando dados numéricos com amostra selecionada a partir de instrumentos padronizados (De Sordi, 2013). Além disso, a pesquisa quantitativa possui medidas controladas, coleta de dados replicável e assume uma realidade estável (Blaxter, Hughes, \& Tight, 2010).

A abordagem de pesquisa adotada por esse estudo é a experimental, pois a partir desta é possível criar uma situação em que uma variável independente é manipulada pelo pesquisador através de condições controladas (Blaxter et al., 2010). No entanto, alguns experimentos podem ser classificados como pré-experimentos, que se referem a delineamentos que não cumprem o requisito da apresentação de um grupo de controle (Martins \& Theóphilo, 2007). Este é o caso da choice-based conjoint analysis, técnica adotada nessa pesquisa.

Com o intuito de responder o problema de pesquisa proposto e atendendo aos objetivos apresentados, foi desenvolvida uma pesquisa experimental utilizando a técnica choice-based conjoint analysis. O sujeito, delineamento, instrumento de coleta de dados e respectiva análise de dados serão descritos nas seções subsequentes. Uma visão geral dos aspectos metodológicos da pesquisa é apresentada na Figura 9. 
Figura 9: Visão geral dos aspectos metodológicos da pesquisa

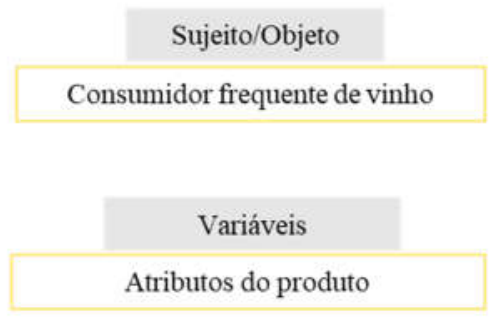

Coleta de dados

Experimento de escolha

Análise dos dados

Choice-Based Conjoint Analysis

Fonte: elaborado pela autora.

Os aspectos metodológicos deste trabalho serão abordados nas seções seguintes. O sujeito e objeto estudados serão discutidos na seção 4.1. As variáveis adotadas para qualificar o objeto serão descritas na seção 4.2.1.1. A implementação da coleta de dados referente ao experimento de escolha será descrita nas seções 4.2.1.2, 4.2.1.3 e 4.2.1.4. Por fim, o método de análise de dados será apresentado na seção 4.2.1.5.

\subsection{Sujeito da pesquisa e delineamento do estudo}

O objeto em que se aplica essa pesquisa é o vinho. O sujeito ao qual é submetida a análise do objeto é o consumidor frequente de vinho, definido como aquele que consome vinho ao menos uma vez a cada quinzena. No que tange ao objeto vinho, consumidor frequente é quem melhor personifica o uso e escolha do produto.

Com o propósito de responder o problema de pesquisa proposto nesse trabalho e em consonância com o referencial teórico que norteia a pesquisa, optou-se pela adoção delineamento experimental, discutido na seção anterior. A técnica utilizada foi a choice-based conjoint analysis, que pela sua natureza de implementação exige dados de fontes primárias.

Uma das grandes críticas a estudos quantitativos que utilizam dados primários é a representatividade da amostra coletada. Muitos questionários de pesquisa são respondidos por estudantes universitários, os quais muitas vezes não são exatamente os consumidores do produto ou serviço que se deseja avaliar (Kitchenham, 2004).

A fim de reduzir o viés que a amostra possa apresentar em relação à população, foram coletadas respostas somente de consumidores frequentes de vinho. Assim, foram realizadas 
perguntas com caráter de filtro na parte inicial do questionário, em que os respondentes foram questionados sobre sua localização geográfica e sobre a frequência de consumo de vinho.

A frequência de consumo de vinho contemplada em trabalhos anteriores é variável. No estudo de Lockshin e Cohen (2011), por exemplo, foram considerados como consumidores de vinho aqueles que consumiam a bebida ao menos uma vez ao mês, sendo que somente os que consumiam semanalmente foram classificados como consumidores de alta frequência. Considerando que o Brasil possui um consumo per capita consideravelmente menor do que outros produtores de vinho mundiais (vide Gráfico 1), nesse trabalho optou-se por considerar consumidor frequente de vinho aquele que consome a bebida ao menos uma vez a cada quinzena.

No que se refere à seleção da amostra para implementação da coleta de dados, a literatura apresenta diversas técnicas de amostragem. A escolha da seleção da amostra depende de fatores como a metodologia de pesquisa adotada, a disponibilidade dos sujeitos e condições disponíveis para implementação da coleta de dados.

O universo de consumidores de vinho é de difícil determinação e sofre mudanças constantes. $\mathrm{O}$ indivíduo que em um primeiro momento se identifica como consumidor de vinho, posteriormente pode passar por uma mudança de hábitos ou preferências e deixar de consumir o produto. Ainda que o universo de consumidores de vinho fosse estático, operacionalizar uma amostragem probabilística seria dificultada pela impossibilidade de acessar os respondentes necessários. Dessa forma, optou-se por utilizar nesse trabalho uma amostra não-probabilística de consumidores de vinho. Considerando a escassez de recursos como tempo e amplo acesso a informação sobre os consumidores, a amostra selecionada para esta pesquisa foi formada por conveniência. Os respondentes foram submetidos a um instrumento de coleta de dados online, que disponibilizou a pesquisa para qualquer dispositivo eletrônico com acesso à internet.

A etapa anterior à coleta de dados contemplou a identificação de variáveis para avaliar atributos do vinho. Os atributos foram selecionados através da revisão da literatura e foram submetidos a um pré-teste, onde foram excluídos atributos que não puderam avaliar de forma satisfatória as escolhas dos respondentes.

Após a definição dos atributos de vinho utilizados nesse trabalho, os mesmos foram avaliados pelos consumidores através de uma choice-based conjoint analysis. Segundo (Bilkey \& Nes, 1982) a conjoint analysis é "uma técnica multivariada usada especificamente para entender como os respondentes desenvolvem preferências por quaisquer tipos de 
objetos" (p. 360). Os autores continuam: "clientes podem fornecer melhor suas estimativas de preferência julgando objetos formados por combinações de atributos” (p. 360).

O objetivo geral desse trabalho foi segmentado em objetivos específicos, amparados pelo referencial teórico. A partir dos objetivos específicos foram identificadas variáveis que podem ser analisadas para cumprir com os objetivos da pesquisa. Após a identificação das variáveis foi proposto um plano de análise para analisar os dados coletados. A visão geral dos aspectos metodológicos adotados nesse trabalho é apresentada no Quadro 2.

Quadro 2: Visão geral dos aspectos metodológicos da pesquisa

\begin{tabular}{|c|c|c|c|c|}
\hline Objetivo Geral & Objetivos Específicos & $\begin{array}{c}\text { Referências para } \\
\text { os objetivos }\end{array}$ & Variáveis & $\begin{array}{l}\text { Plano de } \\
\text { Análise }\end{array}$ \\
\hline \multirow{3}{*}{$\begin{array}{l}\text { Identificar como o } \\
\text { país de origem do } \\
\text { produto interfere } \\
\text { na escolha do } \\
\text { consumidor de } \\
\text { vinho }\end{array}$} & $\begin{array}{c}\text { Identificar qual o efeito país de origem na } \\
\text { escolha do consumidor para produtos } \\
\text { estereotipados }\end{array}$ & $\begin{array}{l}\text { Tseng e Balabanis } \\
\text { (2011) }\end{array}$ & $\begin{array}{l}\text { Experimento de } \\
\text { vinhos e } \\
\text { experimento de } \\
\text { saca-rolhas }\end{array}$ & $\begin{array}{c}\text { choice-based } \\
\text { conjoint } \\
\text { analysis }\end{array}$ \\
\hline & $\begin{array}{l}\text { Identificar a diferença do efeito país de } \\
\text { origem entre regiões produtoras e não } \\
\text { produtoras de vinho dentro de um país } \\
\text { não reconhecido internacionalmente } \\
\text { como produtor }\end{array}$ & $\begin{array}{l}\text { Heslop, } \\
\text { Papadopoulos e } \\
\text { Bourk (1998) }\end{array}$ & $\begin{array}{l}\text { Experimento de } \\
\text { vinhos e estado } \\
\text { de domicílio }\end{array}$ & $\begin{array}{c}\text { choice-based } \\
\text { conjoint } \\
\text { analysis }\end{array}$ \\
\hline & $\begin{array}{l}\text { Identificar a diferença do efeito país de } \\
\text { origem entre consumidores conforme seu } \\
\text { envolvimento com vinho }\end{array}$ & $\begin{array}{c}\text { Zaichkowsky } \\
\text { (1994); Aurifeille, } \\
\text { Quester, Lockshin e } \\
\text { Spawton (2002) }\end{array}$ & $\begin{array}{c}\text { Experimento de } \\
\text { vinhos e PII }\end{array}$ & $\begin{array}{l}\text { choice-based } \\
\text { conjoint } \\
\text { analysis e PII }\end{array}$ \\
\hline
\end{tabular}

Fonte: elaborado pela autora

A apresentação e discussão das variáveis selecionadas para este trabalho, bem como o respectivo plano de análise de dados serão discutidos em detalhes na seção 4.2.

\subsection{Instrumento de coleta de dados}

O instrumento de coleta de dados foi constituído por perguntas filtro, duas conjoint analysis (uma sobre vinho e outra sobre saca-rolhas), uma escala de mensuração de envolvimento com produto e questões para a definição do perfil socioeconômico dos 
respondentes. A amostragem foi não probabilística por conveniência, com consumidores de vinho dos estados de São Paulo e Rio Grande do Sul.

Como a pesquisa envolve a avaliação de bebida alcoólica, o primeiro filtro adotado se refere à maioridade civil dos respondentes. Os participantes que assinalaram idade inferior a 18 anos foram conduzidos ao encerramento do questionário.

A segunda pergunta adotada com caráter de filtro foi sobre a frequência de consumo de vinho. Como nessa pesquisa foi definido como consumidor de vinho aquele que consome a bebida ao menos uma vez a cada quinzena, respondentes que assinalaram frequência de consumo mensal ou esporádica também foram conduzidos ao final do questionário.

O terceiro e último filtro se refere ao estado de domicílio do respondente. Como um dos objetivos do trabalho é comparar escolhas de consumidores que residam nas proximidades da região produtora de vinhos com escolhas de consumidores mais afastados desse centro produtor, foram escolhidas duas regiões para contemplar esse estudo. O estado do Rio Grande do Sul foi selecionado por comportar a maior produção de vinho do Brasil. Segundo dados estatísticos da IBRAVIN, somente a região do Vale dos Vinhedos é responsável por cerca de $85 \%$ da produção nacional. Como contraponto, o estado de São Paulo foi escolhido por estar mais afastado do principal centro produtor, mas ainda assim possuir um grande mercado consumidor de vinho - é o estado com o maior consumo absoluto de vinho no Brasil.

Com o propósito de identificar qual o efeito país de origem na escolha do consumidor para produtos tipificados, isto é, produtos aos quais facilmente se associa uma marca ou região/país de origem, foram realizados dois experimentos de conjoint analysis. Um experimento contemplou escolhas de consumidores a respeito de vinhos e o outro contemplou escolhas sobre saca-rolhas. A mesma amostra de respondentes foi submetida aos dois experimentos de escolha, sendo que saca-rolhas foi escolhido por se tratar de um produto complementar ao vinho, sem ser fortemente associado a nenhuma marca ou país de origem. A descrição completa do design do experimento de escolha encontra-se no APÊNDICE A: Experimento de Escolha.

Embora esse trabalho contemple escolhas de consumidores frequentes de vinho, não é possível afirmar que a frequência de consumo implique em envolvimento com o produto. Dessa forma, foi incluída no questionário uma escala de envolvimento para atender ao objetivo de identificar se diferentes graus de envolvimento do consumidor com vinho estão 
associados a diferentes efeitos país de origem. A discussão da escala de envolvimento adotada encontra-se na seção 4.2.2.

A parte final do questionário, por sua vez, foi composta por questões para fins de classificação socioeconômica. Como por vezes respondentes podem se sentir constrangidos em responder perguntas diretas a respeito da renda pessoal, optou-se por utilizar o Critério Brasil, apresentado pela Associação Brasileira de Empresas de Pesquisa (ABEP, 2016).

O instrumento de coleta de dados está disponível no Apêndice APÊNDICE A: Experimento de Escolha.

\subsubsection{Choice-based conjoint analysis (CBC)}

$\mathrm{Na}$ literatura diversos autores indicam a conjoint analysis como uma técnica multivariada adequada para estudar as escolhas feitas pelos agentes (Hair et al., 2009; Rao \& Pilli, 2014; Rao, 2014). O diferencial da conjoint analysis em relação a outras técnicas estatísticas é a possibilidade de simular situações de escolha para consumidores e a partir desse conjunto de respostas inferir escolhas futuras para um dado conjunto de atributos.

Enquanto a conjoint analysis tradicional reúne avaliações sobre perfis de atributos hipotéticos e estima modelos de utilidade para prever escolhas para novos produtos, a CBC fornece a probabilidade de escolha de uma alternativa a partir da coleta dados de escolhas diretamente declaradas. Dessa forma, a maior vantagem da CBC é trabalhar com escolhas no lugar de avaliações para mensurar preferências. A desvantagem da $\mathrm{CBC}$, no entanto, é que o design desse método é muito mais complexo devido às especificidades para gerar uma série eficiente de conjuntos de escolha (Rao, 2014).

Muitos trabalhos sobre a temática país de origem utilizam esta característica como principal atributo a ser avaliado em suas surveys ou experimentos (Heslop et al., 1998). Esta situação possibilita o respondente a deduzir o que está sendo avaliado - país de origem e não o produto em si - o que pode gerar um viés de resposta.

Com o intuito de reproduzir a ideia de que em um ambiente de compra os indivíduos fazem escolhas a partir de um conjunto de produtos, a abordagem da CBC consiste em apresentar um conjunto de escolhas em perfis hipotéticos, em que cada conjunto é formado por perfis de produtos descritos por um número finito de atributos (Rao, 2014).

A síntese das etapas da choice-based conjoint analysis está apresentada na Figura 10. As etapas apresentadas serão discutidas nas seções subsequentes. 
Figura 10: Etapas para a condução de uma Choice-Based Conjoint Analysis

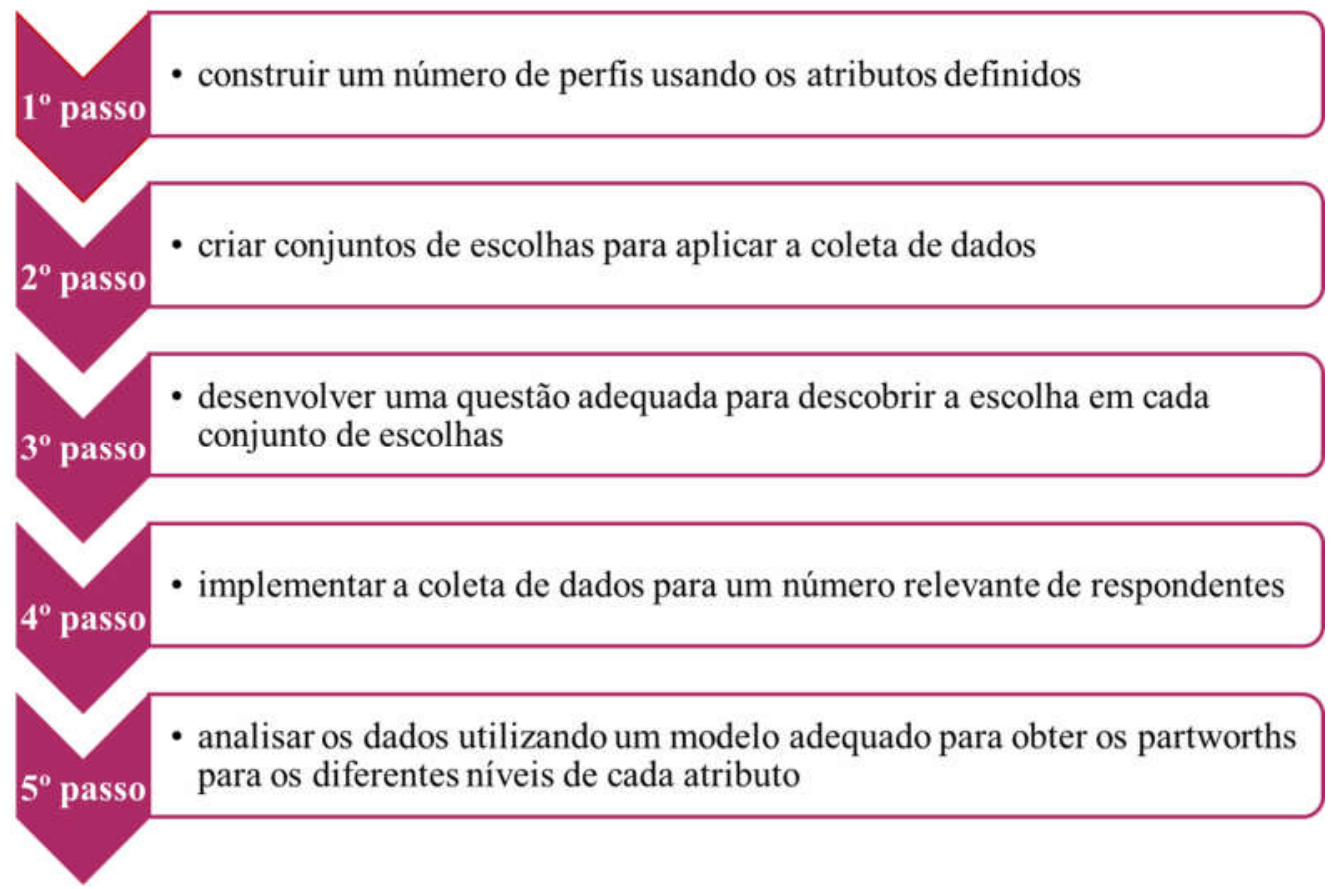

Fonte: adaptado de Rao (2014)

\subsubsection{Construção dos perfis}

Quando se pretende avaliar um produto utilizando $\mathrm{CBC}$ é necessário considerar algumas definições fundamentais. Um produto é formado por atributos (ou fatores), que são características específicas do objeto de estudo representados por variáveis não-métricas, e níveis, que são valores não-métricos que qualificam cada atributo. Cada atributo deve ter ao menos dois níveis.

A seleção dos atributos para uma conjoint analysis deve ser bastante criteriosa. Em trabalhos em que se planeja testar a viabilidade de um novo produto ou serviço é comum o pesquisador acrescentar atributos usualmente menos estudados. Já em trabalhos em que se pretende analisar produtos ou serviços já estabelecidos é recomendável proceder com um levantamento na literatura para identificar atributos comumente usados para buscar validade externa no trabalho.

A mesma recomendação é válida para a escolha dos níveis. Adicionalmente, esperase que o número de níveis não exceda quatro ou cinco. Para trabalhar com um elevado 
número de atributos ou níveis outras técnicas mais sofisticadas em conjoint analysis são recomendadas (Hair et al., 2009).

Os atributos de vinho selecionados para essa pesquisa foram levantados em estudos prévios encontrados na literatura, conforme discutido na seção 3.3. Já os níveis relacionados aos atributos foram escolhidos por serem capazes de representar adequadamente a realidade do mercado. O Quadro 3 apresenta os atributos e níveis para o produto vinho selecionados para este trabalho.

Quadro 3: Atributos e níveis para o produto vinho

\begin{tabular}{|l|ccccc|}
\hline \multicolumn{1}{|c|}{ ATRIBUTOS (ou FATORES) } & \multicolumn{5}{c|}{ NÍVEIS } \\
\hline Tipo de vinho & branco & tinto & espumante \\
\hline País de origem & Brasil & Chile & Argentina & França & Itália \\
\hline Preço & R\$ 60 & R\$ 80 & R\$ 100 & R\$ 120 \\
\hline Ter recebido alguma recomendação & sim & não & & \\
\hline
\end{tabular}

Fonte: elaborado pela autora

Com o intuito de contemplar o problema de pesquisa proposto nesse trabalho, o atributo país de origem necessariamente deveria ser incluído na análise. Os níveis escolhidos refletem os países com maior percentual de importações para o Brasil (Chile e Argentina), países com a maior produção mundial de vinhos (França e Itália) e o Brasil, escopo dessa pesquisa.

Como níveis para tipos de vinho foram considerados vinho branco, vinho tinto e espumante por serem as variedades encontradas em maior abundância nos canais de vendas nacionais. Vinhos rosês e vinhos fortificados foram desconsiderados pois podem eventualmente remeter diretamente a algum país de origem específico. Vinho rosê, por exemplo, pode ser facilmente associado à região de Provence, na França.

Os níveis preços abordados refletem os preços médios praticados no mercado interno brasileiro ( $\mathrm{R}$ \$ 60, R\$ 80, R\$ 100 e R\$ 120) e a realidade econômica do consumidor nacional. O atributo "ter recebido alguma recomendação", por sua vez, foi caracterizado por dois níveis - sim ou não.

Com o propósito de entender se produtos tipificados possuem diferentes efeitos de país de origem em relação a produtos que não são associados à nenhuma marca ou país de origem 
foi realizado um segundo experimento de $\mathrm{CBC}$, utilizando o produto saca-rolhas. Os atributos e níveis adotados para o produto estão descritos no Quadro 4.

Quadro 4: Atributos e níveis para o produto saca-rolhas

\begin{tabular}{|l|cccc|}
\hline \multicolumn{1}{|c|}{ ATRIBUTOS (ou FATORES) } & \multicolumn{3}{c|}{ NÍVEIS } \\
\hline Tipo de saca-rolhas & dois estágios & abas & elétrico & pressão \\
\hline País de origem & Brasil & Chile & França & Itália \\
\hline Preço & $\mathrm{R} \$ 15$ & $\mathrm{R} \$ 25$ & $\mathrm{R} \$ 85$ & $\mathrm{R} \$ 65$ \\
\hline Ter recebido alguma recomendação & $\operatorname{sim}$ & não & & \\
\hline
\end{tabular}

Fonte: elaborado pela autora

No experimento de escolha sobre o produto saca-rolhas foram utilizados atributos semelhantes ao experimento de vinho, a fim de facilitar comparações de resultados. A principal diferença em relação ao experimento anterior se refere à introdução de pares proibidos, que consistem em uma combinação de dois níveis em diferentes atributos que não podem aparecer em um mesmo estímulo, pois do contrário não resultariam em um estímulo crível.

Nesse delineamento foram definidos oito pares de níveis como pares proibidos. Sacarolhas do tipo abas e dois estágios possuem preços médios próximos de $\mathrm{R} \$ 15$ e $\mathrm{R} \$ 20$, já saca-rolhas elétricos e de pressão custam, em média, entre R\$ 65 e R \$ 85. Se todos os níveis de preços pudessem ser combinados com todos os tipos de saca-rolhas seriam gerados estímulos não realistas, que muito provavelmente não seriam escolhidos por nenhum consumidor. A relação do conjunto de pares proibidos utilizada nesse trabalho encontra-se no Quadro 5.

Quadro 5: Combinações de pares proibidos para saca-rolhas

\begin{tabular}{|cc|}
\hline \multicolumn{2}{|c|}{ COMBINAÇÕES DE PARES PROIBIDOS } \\
\hline Atributo tipo de saca-rolhas & Atributo preço \\
\hline dois-estágios & $\mathrm{R} \$ 65,00$ \\
dois-estágios & $\mathrm{R} \$ 85,00$ \\
abas & $\mathrm{R} \$ 65,00$ \\
abas & $\mathrm{R} \$ 85,00$ \\
elétrico & $\mathrm{R} \$ 15,00$ \\
elétrico & $\mathrm{R} \$ 25,00$ \\
pressão & $\mathrm{R} \$ 15,00$ \\
pressão & $\mathrm{R} \$ 25,00$ \\
\hline
\end{tabular}

Fonte: elaborado pela autora 
A definição de atributos e seus respectivos níveis permite a formação de estímulos, também conhecidos por perfis, conceitos ou tratamentos. Estímulos são combinações de níveis que serão avaliadas pelos respondentes. Os estímulos utilizados no desenho desse experimento foram de perfil completo, ou seja, cada estímulo foi formado por todos os quatro atributos discutidos anteriormente, e a cada atributo foi designado um respectivo nível.

\subsubsection{Construção dos conjuntos de escolha}

A construção dos perfis a partir dos atributos e níveis possibilita a construção dos conjuntos de escolha, também conhecidos como tarefas. Um conjunto de escolha é formado por um certo número de perfis, que geralmente variam entre dois e quatro. $\mathrm{Na}$ literatura não há uma recomendação clara a respeito do número ideal de perfis por conjunto de escolha, diversos autores indicam que essa seja uma escolha do pesquisador. No entanto, quanto mais perfis formarem um conjunto de escolha, menor será o tamanho amostral mínimo necessário para efetuar a análise de dados (Johnson \& Orme, 2002; Rao, 2014).

Além do número de perfis escolhidos para compor cada conjunto de escolhas é possível inserir a opção "nenhuma das alternativas". Os respondentes podem escolher "nenhuma das alternativas" por julgarem que nenhuma das alternativas apresentada é atraente ou para evitar escolhas difíceis, quando os conceitos mais atraentes possuem uma utilidade muito parecida (Johnson \& Orme, 2002).

Embora a opção "nenhuma das alternativas" opção seja útil para nas tarefas em que o respondente não consegue apontar nenhum perfil como preferido, é possível identificar algumas limitações em sua utilização. A opção "nenhuma das alternativas" é geralmente escolhida com maior frequência nas tarefas finais, o que pode ser por fadiga ou por relutância em escolher um conceito com utilidade inferior após ter sido apresentado a conceitos com utilidades superiores nas tarefas anteriores (Johnson \& Orme, 2002).

Dessa forma, para evitar esse viés de escolha nas respostas finais, optou-se por não incluir a opção "nenhuma das alternativas". Em relação ao número de perfis em cada conjunto de escolha optou-se por quatro perfis. Esse número de perfis é também mais adequado considerando a não inclusão da opção "nenhuma das alternativas".

Outra decisão importante na elaboração do design de uma CBC é a escolha do número de conjunto de escolhas ao qual cada respondente será submetido. Essa escolha é delicada, pois o número de conjuntos de escolha não pode ser pequeno o bastante de modo que não 
consiga captar a estrutura de preferências do respondente, e nem tão grande a ponto de se tornar a tarefa cansativa demais para o respondente.

O número de conjuntos de escolha foi definido como três vezes o número de atributos no design de cada experimento. Assim, foram escolhidos 15 conjuntos de escolha no experimento de vinhos e 12 conjuntos de escolha no experimento de saca-rolhas. No pré-teste realizado o experimento de vinhos foi composto por cinco atributos, mas após resultados do pré-teste optou-se por fazer o design do experimento com apenas quatro atributos. Apesar da diminuição do número de atributos foi decidido manter o número de conjuntos de escolha, pois o design do experimento de vinhos possui um número maior de níveis do que o experimento de saca-rolhas.

Essa opção de pesquisa referente ao número de conjuntos de escolha é coerente com os achados de Johnson e Orme (2002), que postulam que é possível um respondente ser submetido a pelo menos 20 conjuntos de escolha sem que se tenha perda de qualidade nas respostas.

Considerando o número de atributos selecionado para cada experimento foi possível realizar formar conjuntos de escolha full profile, isto é, quando todos os atributos aparecem em todos os perfis avaliados em cada conjunto de escolha.

Após definir os atributos, níveis, perfis e conjuntos de escolha é necessário escolher o método para gerar os delineamentos dos conjuntos de escolha. Por restrição de software e devido ao número de pares proibidos incluídos no experimento de saca-rolhas o delineamento escolhido foi o randomizado, em que cada nível se apresenta um número equivalente de vezes no conjunto de todos os conjuntos de escolha.

\subsubsection{Desenvolvimento da questão para a descoberta da escolha}

O desenvolvimento de uma questão para a descoberta inferir a escolha do respondente é uma etapa do design da $\mathrm{CBC}$ que exige bastante cuidado. A questão que antecede os conjuntos de escolha deve ter clareza, objetividade, não ambiguidade e deve contemplar o problema de pesquisa proposto no estudo.

As perguntas formadas para os experimentos de vinho e saca-rolhas seguem abaixo:

a) Experimento de vinho: "Se você está em um estabelecimento que vende vinhos (seja loja especializada, supermercado, bar, restaurante e afins), e se depara com as opções abaixo, qual vinho você escolheria?”. 
b) Experimento de saca-rolhas: "Uma loja de vinhos pretende vender saca-rolhas, e para isso gostaria de saber qual o produto que melhor atende as expectativas de seus clientes. Se você fosse comprar um saca-rolhas para uso pessoal, dentre as opções seguintes qual você escolheria?"

Vinho é um produto cujo consumo está associado a diversas ocasiões específicas conforme cada consumidor. Em uma pesquisa quantitativa - e especialmente em uma conjoint analysis - é pouco razoável contemplar todas essas especificidades de ambiente de consumo. Dessa forma, foi elaborada uma questão que contemplasse o maior número possível de situações de consumo de vinho. Considerando que nesse estudo participaram respondentes identificados como consumidores frequentes de vinho, espera-se que para este público uma situação genérica de escolha minimize eventuais vieses ligados a situações específicas de escolha como, por exemplo, festividades.

Já a questão relacionada à escolha de saca-rolhas é menos problemática por ser menos passível de viés. Geralmente quem adquire um saca-rolhas o faz para um mesmo fim, que independe da ocasião relacionada.

\subsubsection{Implementação da coleta de dados}

Diante da complexidade da elaboração e operacionalização de um experimento de CBC é recomendado que o mesmo seja realizado através de uma plataforma ou software específico. Alguns softwares e plataformas disponíveis possuem recursos para criação do design, operacionalização da coleta e análise de dados, como o Sawtooth Software e a QuestionPro, e outros softwares apenas criam o design e fazem a análise de dados, como o XLSTAT.

Considerando que a disponibilização online de um instrumento de coleta de dados proporciona um maior alcance amostral da pesquisa e, ainda, que os softwares específicos para $\mathrm{CBC}$ possuem um elevado custo, foi utilizada nessa pesquisa a plataforma QuestionPro na versão Enterprise. Conforme já abordado anteriormente, a amostragem foi realizada por conveniência.

Ainda em relação à implementação de dados, é importante ressaltar um fenômeno relacionado à CBC relatado como efeito aprendizado. Johnson e Orme (2002) apontam que as repostas oriundas dos conjuntos de escolha finais de cada respondente são levemente mais 
confiáveis do que as respostas anteriores. Esse efeito acontece porque o respondente vai se familiarizando (ou auferindo aprendizado) com os atributos e níveis conforme os mesmos são apresentados ao longo do experimento. Entretanto, como a formação e a ordem dos conjuntos de escolha variam entre os respondentes, o efeito aprendizado (ou a falta dele) não afeta de significativamente a análise final dos dados.

Ao implementar a coleta de dados é necessário considerar o tamanho mínimo amostral recomendado. Segundo Orme (2010), em um design de CBC o tamanho amostral recomendado é:

$$
n \geq \frac{500 * c}{t * a}
$$

em que:

$n=$ tamanho da amostra

$t=$ número de tarefas ou de conjuntos de escolha

$a=$ número de perfis por conjunto de escolha

$\mathrm{c}=$ número máximo de níveis dentre os atributos

A recomendação de tamanho mínimo de amostra para essa pesquisa possui os seguintes parâmetros:

a) Experimento de vinho: 15 tarefas, 4 perfis por conjunto de escolha, máximo de 5 níveis, o que implica em $n \geq 41,67$, resultando em um tamanho amostral mínimo de 42 respondentes.

b) Experimento de saca-rolhas: 12 tarefas, 4 perfis por conjunto de escolha, máximo de 4 níveis, o que implica em $\mathrm{n} \geq 55,56$, resultando assim em um tamanho amostral mínimo de 56 respondentes.

\subsubsection{Análise de dados}

A CBC é uma técnica amparada na proposição de que consumidores julgam o valor de um bem agrupando diferentes valores associados a cada atributo. Para se aproximar da ideia de que indivíduos fazem escolhas diante de um conjunto de produtos, essa técnica apresenta diversos conjuntos de escolha hipotéticos baseados em uma quantidade finita de atributos, em que o consumidor escolhe o produto cuja utilidade é a mais alta dentre todas os produtos. (Hair et al., 2009; Rao, 2014). 
Os resultados explorados através da conjoint analysis contemplam diversas variáveis quantitativas. As mais frequentemente utilizadas são as medidas de utilidade, importância relativa, contagem e probabilidade de escolha. Conforme Orme (2010), é fundamental reconhecer os tipos de dados quantitativos associados a cada escala de medida, para que a interpretação dos resultados esteja correta. Neste sentido, o autor segmenta os tipos de dados em quatro tipos gerais: dados nominais, dados ordinais, dados de intervalo, e dados de relação.

Dados nominais são aqueles em que os números representam categorias, por exemplo: 1 = vinho tinto e 2 = vinho branco. Neste caso, não se realizam operações matemáticas com os números e nem tampouco compara-se os seus tamanhos relativos. Por dados ordinais compreendem-se aqueles obtidos geralmente sob a forma de rankings, em que há uma escala de preferência entre os valores. Numa escala de 1 a 10, por exemplo, 2 é preferível a 1 assim como 3 é preferível a dois, e assim sucessivamente, até que se atinja o nível mais alto. Tal como no caso de dados nominais, não se aplica a utilização de operações matemáticas em dados ordinais. Os dados de intervalo são aqueles utilizados nas escalas de rating e permitem a realização das operações matemáticas de adição e subtração. Orme (2010) exemplifica tais dados através da escala Celsius. É possível inferir que cada adição de 1 grau de temperatura representa um incremento igual de calor, contudo, a divisão de 20 graus por 10 graus, por exemplo, não tem significado. Por fim, os dados de relação são aqueles que permitem todas as operações aritméticas básicas, incluindo divisão e multiplicação, como por exemplo, peso, altura, incrementos de tempo, receita e lucro. A diferença entre 20 e 30 quilos é a mesma que a diferença entre 30 e 40 quilos e 40 quilos é duas vezes mais pesado que 20 quilos.

Utilidade é um dos conceitos mais importantes em CBC. Num contexto de CBC, "a utilidade do item escolhido é a mais alta dentre as utilidades de todas as todas as alternativas em consideração" (Rao, 2014, p.129). A abordagem apropriada segmenta a utilidade de um item em dois componentes: um determinístico, o qual é possível ser modelado em termos de vários fatores; e, um aleatório, que representa todos os fatores não observáveis do processo de escolha (Rao, 2014).

Segundo Orme (2010), após calculadas, as utilidades são geralmente re-escaladas para somar zero considerando os respectivos níveis de cada atributo. Dessa forma, o fato de alguns níveis apresentarem utilidade negativa não significa que estes não se mostraram atrativos aos respondentes, mas sim, que os níveis cuja utilidade foi superior se mostraram preferíveis. Ainda segundo o autor, os valores calculados para as utilidades são do tipo dados de intervalo 
e, portanto, conforme discutido anteriormente, não admitem operações matemáticas. Portanto, os resultados apurados para as utilidades não podem ser utilizados para comparações entre atributos, bem como inferir conclusões que não apenas de ordenação de níveis dentro de um mesmo atributo.

Para ilustrar esta observação, suponha dois atributos para o produto vinho: tipo de vinho e preço. A Figura 11 apresenta as utilidades fictícias associadas aos atributos.

Figura 11: Exemplo de apresentação de utilidade

\begin{tabular}{|c|c|}
\hline Tipo de Vinho & Utilidade \\
\hline Tinto & 30 \\
\hline Branco & 20 \\
\hline Espumante & 10 \\
\hline
\end{tabular}

\begin{tabular}{|c|c|}
\hline Preço & Utilidade \\
\hline $\mathrm{R} \$ 15$ & 20 \\
\hline $\mathrm{R} \$ 20$ & 40 \\
\hline $\mathrm{R} \$ 25$ & 10 \\
\hline
\end{tabular}

Fonte: elaborado pela autora

Ao escolher vinho tinto ao invés de vinho espumante, a utilidade aumenta em vinte pontos, valor idêntico ao optar pelo produto de preço R\$ 15 em detrimento daquele de R\$25. Contudo, devido à origem arbitrária do valor da utilidade, não é possível comparar diretamente os valores entre os atributos. Portanto, não seria correto afirmar que vinho tinto (utilidade $=30$ ) é preferível a vinho de R $\$ 25$ (utilidade $=10$ ) ou que vinho branco (utilidade $=20$ ) é igualmente preferível a vinho de $\mathrm{R} \$ 15$ (utilidade $=20$ ). Além disso, por se tratar de dados de intervalo - os quais não admitem operações de divisão - a escala de utilidade não permite comparação de magnitude dentro do próprio atributo do tipo: vinho tinto é três vezes preferível a vinho espumante.

A importância relativa, também conhecida como importância do atributo, reflete o efeito que cada atributo tem na escolha do produto, dado o intervalo de níveis que foram incluídos no questionário, indicando quais dentre os atributos de um produto são mais ou menos importantes na decisão de escolha do consumidor (Orme, 2010).

Os valores calculados para as importâncias relativas são mensurados em escala ordinal e, também, são dados de relação, permitindo inferir conclusões como: um atributo com uma importância de vinte por cento é duas vezes mais importante que um atributo com uma importância de dez por cento, dado o conjunto de atributos e níveis utilizados no estudo. 
Entretanto, é importante mencionar que, quando calculamos a importância de um atributo, os valores obtidos são comparáveis somente relativamente aos demais atributos considerados no próprio estudo, ou seja, não há validade para comparações entre estudos com diferentes grupos de atributos.

A importância relativa dos atributos é calculada com base nas respectivas utilidades parciais, indicando o quanto cada atributo representa na utilidade total do produto. $\mathrm{O}$ detalhamento do cálculo da importância está ilustrado no Quadro 6.

Quadro 6: Exemplo de cálculo de importância de atributo

\begin{tabular}{|c|c|c|c|c|}
\hline Atributo & Nível & $\begin{array}{l}\text { Part-Worth } \\
\text { Utilidade }\end{array}$ & $\begin{array}{l}\text { Intervalo de } \\
\text { Utilidade }\end{array}$ & $\begin{array}{l}\text { Importância } \\
\text { do Atributo }\end{array}$ \\
\hline $\begin{array}{l}\text { País de } \\
\text { Origem }\end{array}$ & $\begin{array}{l}\text { A } \\
\text { B } \\
\text { C }\end{array}$ & $\begin{array}{l}30 \\
60 \\
20\end{array}$ & $\rightarrow 60-20=40$ & $(40 / 150) \times 100 \%=26,7 \%$ \\
\hline Preço & $\begin{array}{c}\mathrm{R} \$ 50 \\
\mathrm{R} \$ 75 \\
\mathrm{R} \$ 100\end{array}$ & $\begin{array}{c}90 \\
55 \\
0\end{array}$ & $\longrightarrow 90-0=90$ & $(90 / 150) \times 100 \%=60,0 \%$ \\
\hline $\begin{array}{l}\text { Tipo de } \\
\text { Vinho }\end{array}$ & $\begin{array}{c}\text { Tinto } \\
\text { Branco }\end{array}$ & $\left.\begin{array}{c}20 \\
0\end{array}\right]$ & $\begin{array}{c}\longrightarrow 20-0=20 \\
\text { Intervalo de Utilidade } \\
40+90+20=150\end{array}$ & $\underset{(20 / 150) \times 100 \%=13,3 \%}{(1}$ \\
\hline
\end{tabular}

Fonte: adaptado de (Orme, 2010)

Em primeiro lugar, calcula-se a diferença entre os valores máximos e mínimos das utilidades associadas aos níveis de cada atributo (40 para o atributo país de origem, 90 para o atributo preço e 20 para atributo tipo de vinho). No passo subsequente, os valores resultantes são somados para apurar o valor total do intervalo de utilidade, o que no caso do exemplo totaliza 150. Em seguida, as importâncias relativas são então obtidas calculando o quanto o valor de cada atributo contribui percentualmente para o valor total do intervalo de utilidade, resultando nos percentuais de 26,7\%, 60\% e 13,3\% para o primeiro, segundo e terceiro atributos, respectivamente. 


\subsubsection{Escala de mensuração de envolvimento}

Toda escala de mensuração de um constructo, mesmo que amplamente utilizada por diversos pesquisadores em diferentes áreas e objetos de estudo, deve ser aplicada e interpretada com cautela, pois a validade e confiabilidade alcançada em trabalhos prévios não garante o mesmo resultado em pesquisas posteriores.

Nesse trabalho optou-se por mensurar envolvimento utilizando-se a escala PII de Zaichkowsky (1994). A mesma já foi aplicada para consumidores brasileiros apresentando resultados satisfatórios em relação à confiabilidade e validade convergente (de Almeida \& Düsenberg, 2014).

A escala foi apresentada na Figura 7 e discutida na seção 3.4.1. O grau de envolvimento foi calculado a partir da mensuração dos 10 pares de qualificadores, avaliados em uma escala de sete pontos, com resultado variando de 10 a 70. Como na literatura levantada para este trabalho não foram encontrados trabalhos dedicados a categorizar envolvimento de acordo com o valor encontrado na respectiva escala, optou-se por classificar a escala de envolvimento conforme quantis, que serão discutidos na seção 5.4. 


\section{ANÁLISE DOS RESULTADOS}

Esta seção está estruturada em quatro partes, formadas pelos seguintes tópicos: caracterização da amostra coletada, análise do efeito de país de origem para produtos tipificados, análise do efeito país de origem entre região produtora e não produtora de vinhos, e análise do efeito país de origem de acordo com o envolvimento do consumidor com vinho.

As análises de efeito país de origem foram realizadas utilizando a técnica da choicebased conjoint analysis (CBC). Em relação à técnica de análise dados adotada, algumas considerações são necessárias para uma garantir maior precisão e coerência na interpretação de dados.

A primeira observação se refere à interpretação da importância relativa dos atributos. É necessário relembrar que a importância dos atributos é relativa, pois depende do delineamento do estudo. Dessa forma, se dentre um conjunto de atributos A, B, C e D o atributo A é referido como o de maior importância, esse mesmo resultado poderia ser diferente se houvesse a adição de um atributo $\mathrm{E}$ ao estudo.

Outra ressalva essencial concerne à comparação entre utilidades e importâncias relativas. $\mathrm{Na} \mathrm{CBC}$ o respondente escolhe o perfil preferido em cada um dos conjuntos de escolha apresentados, de modo que não é possível ter o conjunto completo de preferências do consumidor dentre os perfis apresentados. Assim, as utilidades são calculadas considerando a contagem das escolhas e a interpretação das utilidades e das importâncias relativas só é válida dentro de um mesmo conjunto de escolhas.

\subsection{Caracterização da amostra}

A coleta de dados foi realizada através da plataforma online QuestionPro entre os dias 30 de junho de 2018 e 18 de julho de 2018. A amostra foi coletada de forma não probabilística por conveniência. O questionário teve adesão de 193 respondentes, desconsiderando abandonos antes da conclusão do questionário. No entanto, após as perguntas filtro sobre maioridade civil, frequência de consumo de vinho e estado de residência, o questionário foi respondido integralmente por 120 consumidores. Deste número, 60 consumidores possuem domicílio no estado do Rio Grande do Sul e 60 possuem domicílio no estado de São Paulo. A disposição do sexo dos respondentes que compõem a amostra pode ser conferida na Figura 12. 
Figura 12: Distribuição da amostra conforme sexo dos respondentes
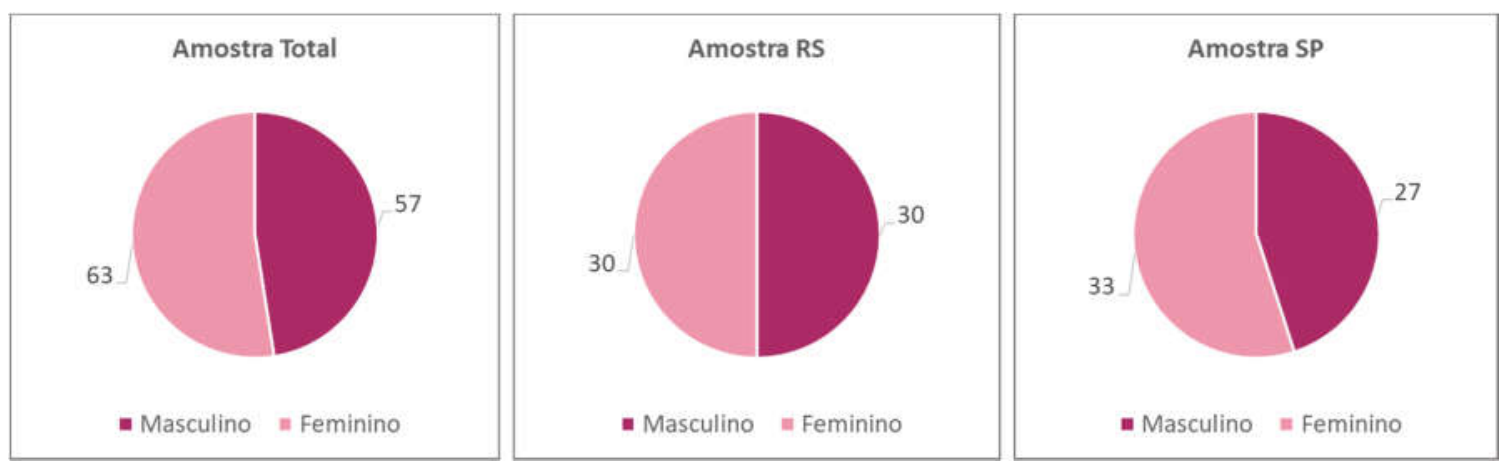

Fonte: elaborado pela autora

A composição da amostra coletada mostrou-se equilibrada em relação ao sexo dos consumidores (52,5\% mulheres e 47,5\% homens). Esse equilíbrio permite que eventuais vieses de escolha relacionados ao sexo não afetem os resultados do experimento de escolha. A proporção de homens e mulheres na amostra é semelhante tanto para o grupo dos consumidores domiciliados no RS (50\% mulheres e 50\% homens), quanto para o grupo de consumidores com residência em São Paulo (55\% mulheres e $45 \%$ homens).

A distribuição dos respondentes conforme a idade está representada no Gráfico 5. Para facilitar a visualização os respondentes foram agrupados em faixas de idade, com intervalos de cinco anos entre os grupos. A idade mínima registrada entre os respondentes foi de 27 anos, enquanto que a idade máxima foi de 68 anos. A média de idade foi 42,33 anos, a mediana 40,5 anos e o desvio-padrão 10,96 anos. A amostra coletada sugere que o vinho é uma bebida alcoólica mais consumida pela população acima de 30 anos. 
Gráfico 5: Distribuição dos respondentes conforme idade

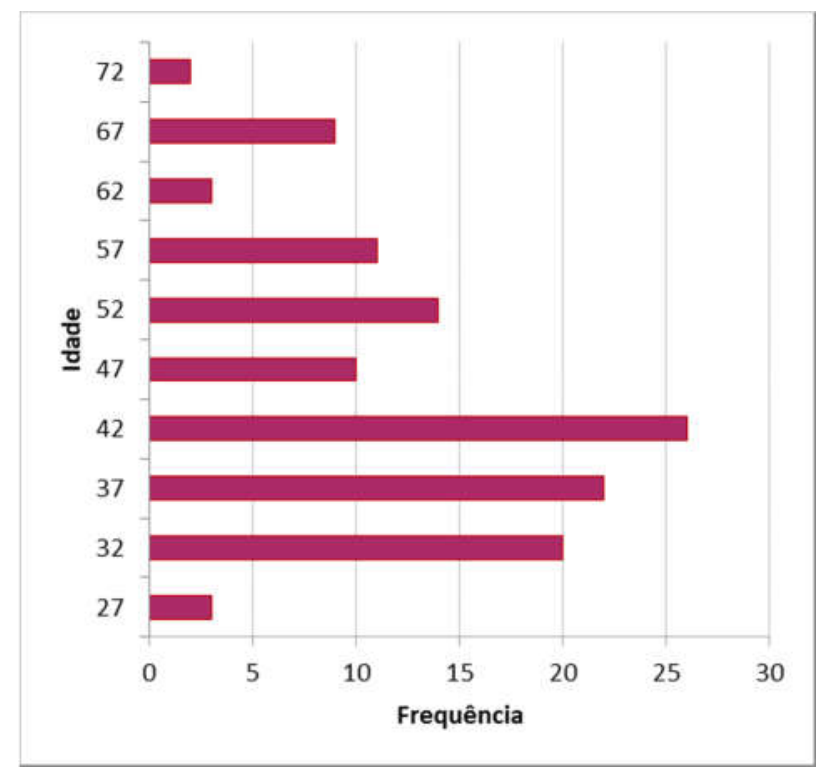

Fonte: elaborado pela autora

O Gráfico 6 apresenta a distribuição dos respondentes que compõem a amostra conforme a classificação socioeconômica, baseada na metodologia do Critério Brasil (ABEP, 2016). Entre os consumidores que participaram dos experimentos de escolha, 35,83\% pertencem à classe A cuja renda média, segundo o Critério Brasil, é $\mathrm{R} \$ 20.888$. A classe B1 contém 26,67\% dos respondentes da amostra coletada, com renda média de R\$ 9.254 conforme Critério Brasil. A classe B2, por sua vez, compreendeu 32,50\% dos consumidores da amostra, com renda média de $\mathrm{R} \$ 4.852$. Juntas, as classes A, B1 e B2 comportam 95\% dos respondentes que participaram dos experimentos. A classe $\mathrm{C} 1$, por fim, representou $5 \%$ da amostra coletada, cuja renda média R \$ 2.705, conforme Critério Brasil.

Gráfico 6: Distribuição da amostra conforme classe social

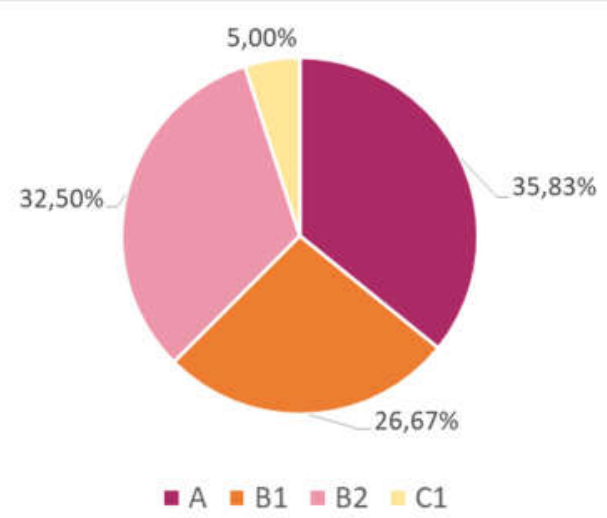

Fonte: elaborado pela autora 
A frequência de consumo de vinho foi uma das perguntas usadas como filtro para selecionar a amostra de consumidores. O objetivo na coleta de dados era formar uma amostra com consumidores frequentes de vinho, definidos como aqueles que em média consomem vinho ao menos uma vez a cada quinzena.

A distribuição dos respondentes conforme a frequência declarada de consumo de vinho é apresentada no Gráfico 7. Os respondentes que consomem vinho mais de uma vez por semana representam $47,5 \%$ da amostra. A frequência de consumo de uma vez por semana foi a identificação de 33,33\% dos respondentes que compõem a amostra. Entre os pesquisados, $19,16 \%$ declarou consumir vinho uma vez a cada quinzena.

A amostra foi formada somente com consumidores com frequência mínima quinzenal de consumo de vinho. Entre o total de respondentes que iniciaram o questionário, 33 respondentes declararam consumir vinho uma vez por mês e 26 declararam consumir o produto com frequência superior a mensal. Por não integrarem o público-alvo pretendido nessa pesquisa, esses 59 respondentes foram conduzidos ao encerramento do questionário, não participando assim dos experimentos de escolha.

Gráfico 7: Frequência de Consumo de Vinho

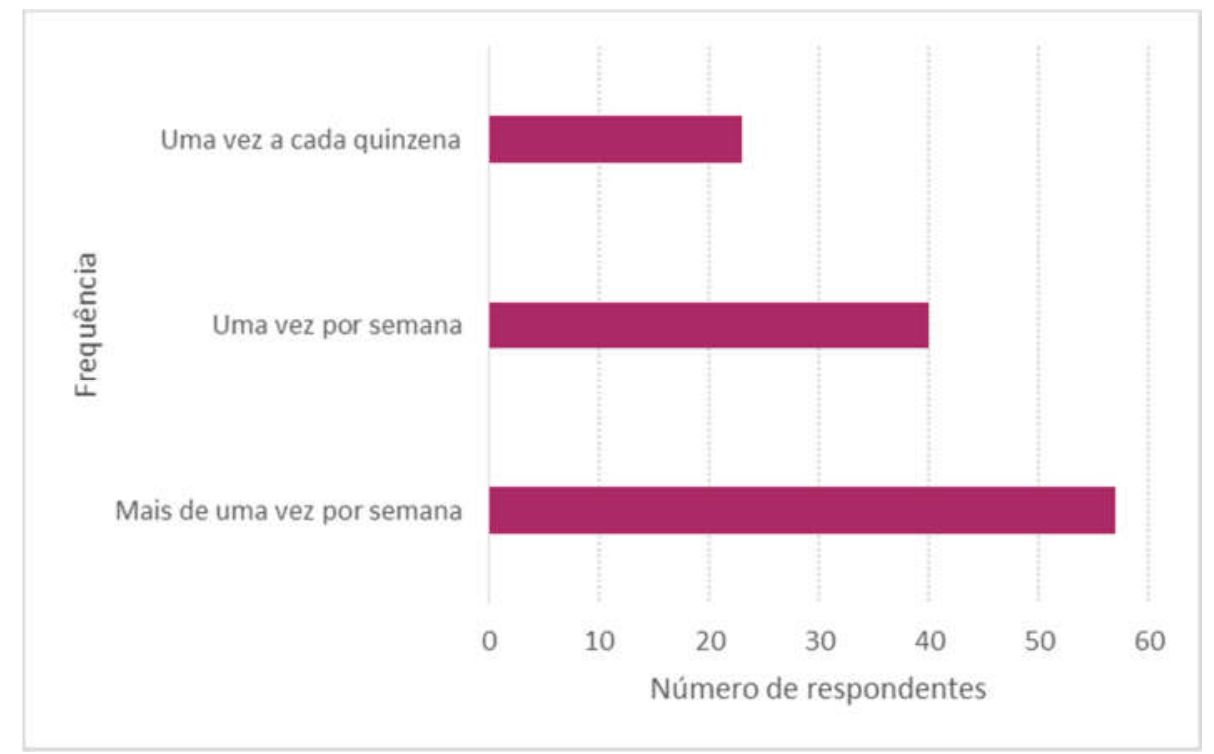

Fonte: elaborado pela autora

A amostra coletada segue o tamanho mínimo necessário discutido na seção 4.2.1.4, que recomenda no mínimo 42 respondentes para o experimento de escolha de vinho e 56 
respondentes para o experimento de escolha de saca-rolhas. A amostra coletada atingiu 120 respondentes, sendo 60 com domicílio no estado do RS e 60 residindo no estado de SP.

\subsection{Efeito país de origem para produtos tipificados}

Com o propósito de atender ao objetivo de verificar o efeito país de origem na escolha do consumidor para produtos tipificados foram realizados dois experimentos de escolha para a mesma amostra de consumidores frequentes de vinho. No primeiro experimento de escolha o produto analisado foi o vinho, e no segundo experimento o produto estudado foi saca-rolhas. Ambos os experimentos foram realizados para os 120 consumidores integrantes da amostra, sendo 60 domiciliados no estado do Rio Grande do Sul e 60 domiciliados no estado de São Paulo.

Conforme discutido nas seções anteriores, o vinho foi escolhido para representar um produto tipificado pois é facilmente associado a alguns países (Spielmann, 2015; Tseng \& Balabanis, 2011). Os países escolhidos para avaliação foram aqueles com maior volume de importação para o Brasil. Os resultados do experimento da $\mathrm{CBC}$ para vinho podem ser verificados na Figura 13. 
Figura 13: Importância relativa e utilidade para vinho

\begin{tabular}{|c|c|c|c|c|}
\hline Attribute 8 & Importance & Level & Utility & Value \\
\hline \multirow[t]{3}{*}{ Preço } & $34 \%$ & $R \$ 60$ & & 0.62 \\
\hline & & $R \$ 80$ & & 0.31 \\
\hline & & $R \$ 100$ & $-0.22 \square$ & \\
\hline \multirow[t]{2}{*}{ Tipo de vinho } & $33 \%$ & branco & $-0.42=$ & \\
\hline & & tinto & & 0.87 \\
\hline \multirow{4}{*}{ Pais de origem } & & Chile & & 0.17 \\
\hline & & Argentina & $-0.42=$ & \\
\hline & & França & & 0.33 \\
\hline & & Itália & $-0.08=$ & \\
\hline $\begin{array}{l}\text { Ter recebido alguma } \\
\text { recomendaçāo }\end{array}$ & $14 \%$ & não & $-0.28 \square$ & \\
\hline
\end{tabular}

Fonte: elaborado pela autora

Analisando a importância relativa dos atributos para o experimento de vinho, verificase que o preço possui a maior importância relativa dentre o conjunto de atributos, com um impacto de $34 \%$ na utilidade total do produto vinho. No atributo preço, os níveis com maior utilidade são os valores $\mathrm{R} \$ 60$ e $\mathrm{R} \$ 80$. Esse resultado é coerente com a racionalidade econômica dos indivíduos, que sempre que possível preferem pagar menos por um mesmo produto. Por consequência, preços mais elevados (R\$ 100 e R\$120) apresentaram utilidade menor.

O tipo de vinho é o atributo com segunda maior importância relativa, com 33\%. Ao examinar as utilidades dos níveis, é evidente a maior preferência por vinhos tintos em detrimento a vinhos brancos ou espumantes.

O país de origem, principal objetivo de estudo desse trabalho, apresentou uma importância relativa de 19\%, sendo que França e Chile foram os países com maior utilidade. Por outro lado, Argentina e Itália apresentaram as menores utilidades. O Brasil teve utilidade positiva, mas próxima a zero. 
$\mathrm{O}$ atributo com menor importância relativa foi o correspondente a ter recebido alguma recomendação. Como era de se esperar, receber uma recomendação é preferível a não receber recomendação, de acordo com a observação das respectivas utilidades.

A Figura 14 sintetiza as importâncias relativas e utilidades para o produto saca-rolhas, que foi escolhido como representante de produto não tipificado por não ter associação direta com país de origem nem marca, mas ainda assim ser um produto utilizado por consumidores de vinho.

Figura 14: Importância relativa e utilidade para saca-rolhas

\begin{tabular}{|c|c|c|c|c|}
\hline Attribute $\mathbf{3}$ & Importance & Level & Utility & y Value \\
\hline \multirow[t]{4}{*}{ Preço } & \multirow{4}{*}{$50 \%$} & $R \$ 15$ & & - \\
\hline & & $R \$ 25$ & & 0.42 \\
\hline & & $R \$ 65$ & $-0.26 \square$ & \\
\hline & & $R \$ 85$ & $-1.16 \square$ & \\
\hline \multirow[t]{4}{*}{ Tipo de saca-rolhas } & \multirow[t]{4}{*}{$32 \%$} & dois estágios & & 0.63 \\
\hline & & abas & & 0.43 \\
\hline & & elétrico & $-0.30=$ & \\
\hline & & pressão & $-0.76 \square$ & \\
\hline \multirow[t]{2}{*}{$\begin{array}{l}\text { Ter recebido alguma } \\
\text { recomendação }\end{array}$} & \multirow[t]{2}{*}{$10 \%$} & não & $-0.22=$ & \\
\hline & & $\operatorname{sim}$ & & 0.22 \\
\hline \multirow[t]{4}{*}{ País de origem } & \multirow[t]{4}{*}{$8 \%$} & Brasil & & 0.17 \\
\hline & & Chile & $-0.16 \square$ & \\
\hline & & França & -0.03 I & \\
\hline & & Itália & & 0.03 \\
\hline
\end{tabular}

Fonte: elaborado pela autora

O atributo preço apresentou 50\% de importância relativa na utilidade total do produto saca-rolhas. Da mesma forma que o vinho, os preços menores apresentaram as maiores utilidades e os preços maiores tiveram menores utilidades. Como saca-rolhas é um produto mais simplificado em uso e valor simbólico quando comparado a vinho é compreensível que o preço exerça maior impacto na utilidade do produto. 
Em seguida, o atributo com a segunda maior importância relativa é o tipo de sacarolhas. A maior utilidade está associada ao saca-rolhas tipo dois estágios e, na sequência, ao saca-rolhas de abas. É importante ressaltar, no entanto, que a formação dos perfis nos conjuntos de escolhas de saca-rolhas considerou pares proibidos, conforme discutido na seção 4.2.1.1 e apresentado no Quadro 5. Os tipos de saca-rolhas dois-estágios e abas foram restritos aos preços de $\mathrm{R} \$ 15$ e $\mathrm{R} \$ 25$, e os tipos elétrico e pressão foram restritos aos preços $\mathrm{R} \$ 65$ e R\$ 85. Assim, é esperado que a direção das utilidades dos tipos de saca-rolhas estejam no mesmo sentido conforme a respectiva restrição de preço.

O terceiro atributo com maior importância relativa é ter recebido recomendação, com impacto de $10 \%$ sobre a utilidade total do produto. Da mesma forma do que o auferido com o produto vinho, ter recebido alguma recomendação é preferível a não ter recebido nenhum tipo de recomendação em relação ao produto.

O atributo país de origem, por sua vez, possui a menor importância relativa para o produto saca-rolhas, com $8 \%$ de peso sobre a utilidade total do produto. As utilidades associadas aos países de origem ficaram em torno de zero, de forma que não foi possível identificar uma preferência clara por algum país de origem específico.

Os resultados evidenciam que de fato vinho pode ser estudado como produto tipificado e que saca-rolhas pode ser entendido como um produto não tipificado. É possível ratificar, portanto, que para produtos tipificados as preferências por país de origem do produto apresentam maior impacto na escolha do consumidor, quando comparados com produtos não tipificados. No entanto, é importante ressaltar que essa evidência foi identificada comparando o produto vinho e saca-rolhas, e aplicando especificamente para a amostra selecionada neste estudo.

\subsection{Efeito país de origem entre região produtora e não produtora de vinho no Brasil}

Com o propósito de identificar a diferença do efeito país de origem entre regiões produtoras e não produtoras de vinho dentro de um país não reconhecido internacionalmente como produtor, foram realizados experimentos de escolha com respondentes de duas regiões distintas do Brasil. O estado do Rio Grande do Sul (RS) foi escolhido por conter cerca de 90\% da produção de vinho nacional e o estado de São Paulo foi selecionado por estar geograficamente afastado do maior centro produtor, mas ainda assim ser o estado com maior consumo de vinho no Brasil. 
A Figura 15 apresenta as importâncias relativas de atributos e as respectivas utilidades para vinho, formada por uma amostra de 60 consumidores frequentes de vinho com domicílio no RS.

Figura 15: Importância relativa e utilidade para vinho para respondentes com domicílio no RS

\begin{tabular}{|c|c|c|c|c|}
\hline Attribute ? & Importance & Level & Utility & Value \\
\hline \multirow[t]{3}{*}{ Tipo de vinho } & \multirow{3}{*}{$34 \%$} & branco & \multirow[t]{2}{*}{$-0.61 \square$} & \\
\hline & & tinto & & 1.02 \\
\hline & & espumante & $-0.42 \square$ & \\
\hline \multirow[t]{4}{*}{ Preço } & \multirow[t]{4}{*}{$32 \%$} & $R \$ 60$ & & 0.73 \\
\hline & & $R \$ 80$ & & 0.35 \\
\hline & & $R \$ 100$ & $-0.27 \square$ & \\
\hline & & $R \$ 120$ & -0.80 & \\
\hline \multirow[t]{5}{*}{ País de origem } & \multirow{5}{*}{$21 \%$} & Brasil & & 0.49 \\
\hline & & Chile & & 0.04 \\
\hline & & Argentina & $-0.52 \square$ & \\
\hline & & França & & 0.25 \\
\hline & & Itália & -0.26 & \\
\hline \multirow[t]{2}{*}{$\begin{array}{l}\text { Ter recebido alguma } \\
\text { recomendação }\end{array}$} & \multirow[t]{2}{*}{$13 \%$} & não & $-0.32 \square$ & \\
\hline & & $\operatorname{sim}$ & & 0.32 \\
\hline
\end{tabular}

Fonte: elaborado pela autora

Ao analisar a importância relativa dos atributos de vinho para consumidores do RS percebe-se que o atributo tipo de vinho possui a maior importância relativa, com 34\% de peso na utilidade total do produto. O vinho do tipo tinto é o que possui a maior utilidade, em detrimento do vinho branco e do espumante, que possuem utilidade negativa por serem os menos preferidos.

O preço é o atributo com segunda maior importância relativa dentre os atributos, com $32 \%$ de impacto sobre a utilidade total do produto. Conforme o esperado, a utilidade é maior para preços menores, isto é, os preços $\mathrm{R} \$ 60$ e $\mathrm{R} \$ 80$ proporcionam maior utilidade do que os preços R\$100 e R\$ 120. 
O atributo país de origem apresenta importância relativa de $21 \%$ na utilidade total do vinho. O Brasil é o país que proporciona maior utilidade para o consumidor, seguido de França e Chile. Os países menos preferidos são Itália e Argentina, por apresentarem menores utlidades.

Ter recebido alguma recomendação possui $13 \%$ de impacto sobre a utilidade total do produto, sendo que receber alguma recomendação de vinho é preferível a não receber alguma recomendação.

A Figura 16 apresenta a importância relativa e utilidade para o produto vinho para consumidores frequentes de vinho residentes no estado de SP.

Figura 16: Importância relativa e utilidade para vinho para respondentes com domicílio em SP

\begin{tabular}{|c|c|c|c|c|}
\hline Attribute ? & Importance & Level & Utility & Value \\
\hline \multirow[t]{4}{*}{ Preço } & \multirow[t]{4}{*}{$34 \%$} & $R \$ 60$ & & 0.65 \\
\hline & & $R \$ 80$ & & 0.31 \\
\hline & & $R \$ 100$ & $-0.24 \square$ & \\
\hline & & $R \$ 120$ & -0.72 & \\
\hline \multirow[t]{3}{*}{ Tipo de vinho } & \multirow{3}{*}{$33 \%$} & branco & -0.30 & \\
\hline & & tinto & & 0.82 \\
\hline & & espumante & -0.52 & \\
\hline \multirow[t]{5}{*}{ País de origem } & \multirow{5}{*}{$20 \%$} & Brasil & $-0.44 \square$ & \\
\hline & & Chile & & 0.30 \\
\hline & & Argentina & $-0.35 \square$ & \\
\hline & & França & & 0.37 \\
\hline & & Itália & & 0.11 \\
\hline \multirow[t]{2}{*}{$\begin{array}{l}\text { Ter recebido alguma } \\
\text { recomendação }\end{array}$} & \multirow[t]{2}{*}{$14 \%$} & não & -0.28 & \\
\hline & & $\operatorname{sim}$ & & 0.28 \\
\hline
\end{tabular}

Fonte: elaborado pela autora

Entre os atributos avaliados pelos respondentes domiciliados em SP o que apresentou maior importância relativa foi o preço, com $34 \%$ de impacto sobre a utilidade total do 
produto. Assim como nas análises para o estado do RS e para a amostra contendo os dois estados, as maiores utilidades foram alcançadas com os menores preços do produto.

O tipo de vinho possui uma importância relativa alta, representando $33 \%$ da utilidade total do produto. O vinho com maior preferência é o tinto mas, diferentemente dos respondentes do RS, a utilidade associada aos espumantes é menor do que a associada aos vinhos brancos.

A importância relativa do país de origem é de $20 \%$. No entanto, o maior contraste encontrado comparando com as escolhas dos consumidores do RS se refere às preferências por países. $\mathrm{Na}$ amostra de consumidores de SP, vinhos do Brasil possuem a menor utilidade dentre todas as opções de países apresentadas. Em outras palavras, o consumidor de SP possui maior preferência por vinhos importados do que por vinhos nacionais, evidentemente considerando as opções de países de origem apresentadas. O país de origem com a segunda menor utilidade associada é a Argentina. Vinhos oriundos do Chile e França possuem maiores utilidades associadas.

O ato de receber uma recomendação de um vinho contribui $14 \%$ da utilidade total do produto. Condizente com os resultados dessa pesquisa, a utilidade é maior quando o consumidor recebe uma recomendação de um vinho do que quando ele não tem nenhuma informação a respeito do vinho.

Embora a intensidade das utilidades e das importâncias relativas na CBC não possam ser comparados entre amostras diferentes pois a utilidade está relacionada a conceito ordinal, é possível comparar a ordenação das preferências. Os resultados do experimento de escolha para o vinho, quando analisados para as amostras dos dois estados evidenciam que as preferências por país de origem nos dois estados são distintas. Enquanto os consumidores do RS apresentam maior utilidade com o vinho brasileiro, cuja produção é geograficamente próxima, consumidores de SP (que estão distantes do centro produtor do BR) possuem menor utilidade associada ao vinho brasileiro.

É importante relembrar que esse é um resultado que compara regiões dentro de um país que não é reconhecido internacionalmente como grande produtor em volume e em qualidade de vinhos. Seria interessante estender esse estudo a diferentes regiões de uma país reconhecido como produtor para verificar se essa relação preferência pelo produto nacional ocorre apenas nas regiões próximas dos centros produtores ou se ela independe da localização geográfica. Outra possibilidade seria estudar se essa diferença de preferências entre regiões 
ocorre apenas no Brasil ou se pode ser encontrada em outros países que não são produtores tradicionais de vinho.

O experimento de escolha com consumidores frequentes de vinho domiciliados no RS e em SP foi realizado, também, para avaliar escolhas do produtos saca-rolhas, conforme Figura 17. Por este ser um produto não tipificado, poderia-se esperar que o país de origem tivesse pouco efeito sobre a utilidade do produto. No entanto, foi possível identificar algumas particularidades a respeito das preferências conforme origem do produto.

Figura 17: Importância relativa e utilidade para saca-rolhas conforme domicílio dos respondentes

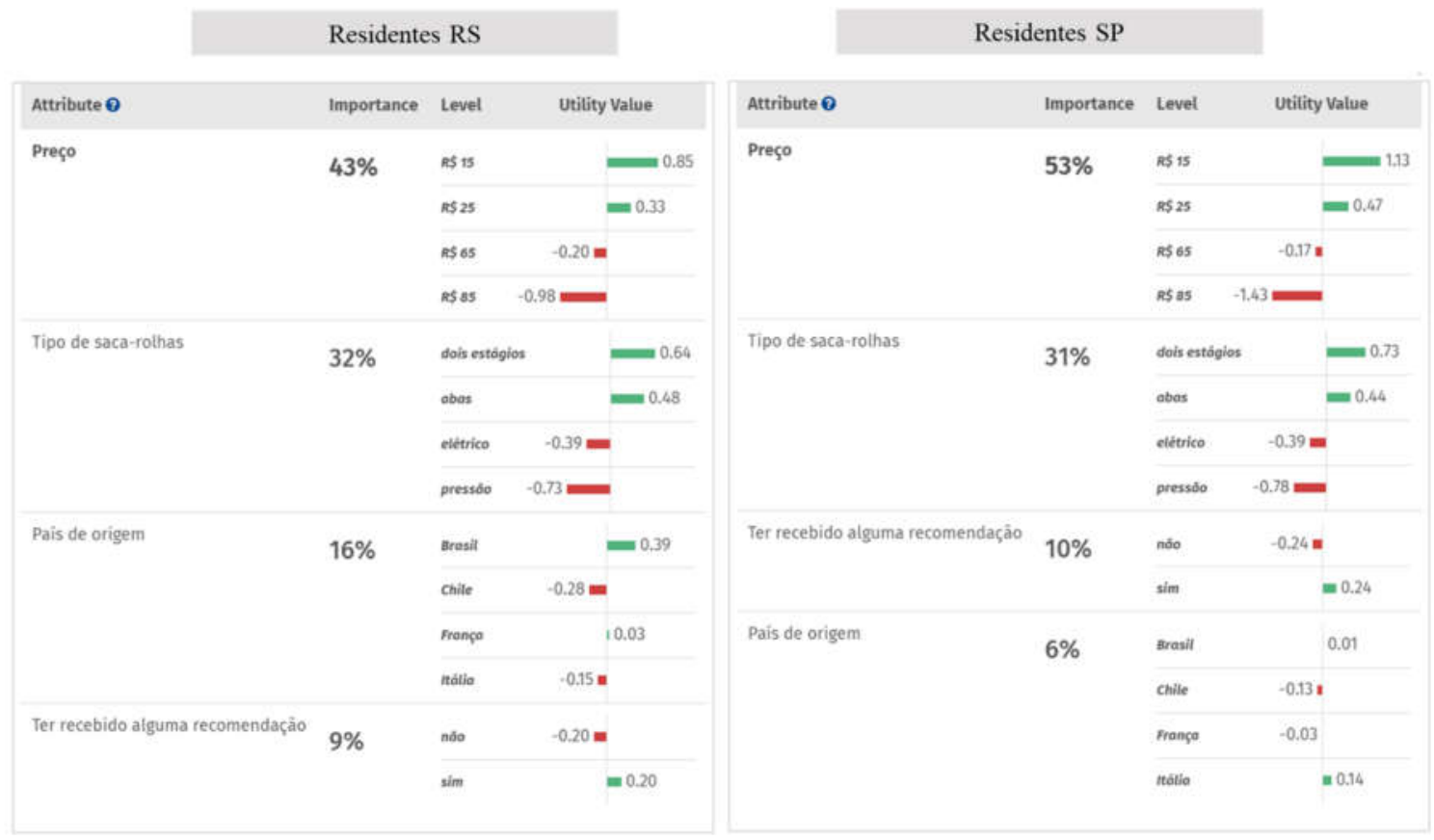

Fonte: elaborado pela autora

Ao analisar as escolhas do experimento dos consumidores residentes no RS e as escolhas dos residentes em SP é possível identificar que as maiores importâncias relativas estão associadas ao atributo preço e tipo de saca-rolhas. No entanto, ao examinar a importância do país de origem percebe-se que o atributo possui a menor importância relativa na utilidade total dos consumidores de SP, mas que essa ordenação não é válida para a amostra de consumidores residentes no RS.

Enquanto que para os consumidores de SP as utilidades associadas a cada país de origem ficam próximas a zero, apresentando pouca amplitude e por isso gerando baixa 
importância relativa do atributo, as preferências por país de origem dos consumidores do RS são mais pronunciadas. A utilidade associada ao país de origem Brasil é maior do que para os demais países. Embora saca-rolhas não seja um produto diretamente associado a alguma marca ou país de origem, para a amostra de consumidores do RS, que estão mais próximas do centro nacional de produção de vinho, o atributo país de origem atribuído a saca-rolhas possui um impacto maior na composição da utilidade do produto.

Embora a natureza metodológica desse trabalho não permita verificar a causa desse efeito, o resultado encontrado pode ser objeto de estudos posteriores. Nesse contexto, uma explicação alternativa a ser testada se refere à possibilidade de o efeito país de origem associado ao vinho ser tão forte para consumidores geograficamente próximos ao centro produtor a ponto deste efeito se transferir em parte para produtos que são complementares ao vinho, como é o caso do saca-rolhas.

\subsection{Efeito país de origem conforme envolvimento com vinho}

O constructo envolvimento, em âmbito pessoal, está relacionado aos interesses inerentes, valores ou necessidades que motivam uma pessoa em relação a um objeto. No domínio físico, envolve características específicas de um objeto que provocam diferenciação e aumento de interesse (Zaichkowsky, 1985). É razoável esperar, nesse sentido, que o grau de envolvimento de um consumidor com determinado produto resulte em diferentes expectativas e preferências relacionadas ao produto.

Com o intuito de entender os efeitos de país de origem sobre a escolha do consumidor de vinho, o constructo envolvimento foi utilizado como variável de estudo para fomentar essa caracterização. O objetivo dessa seção é verificar se diferentes graus de envolvimento estão associados a diferentes efeitos de país de origem sobre a escolha do consumidor de vinho.

A escala de envolvimento utilizada nesse trabalho foi a PII de Zaichkowsky (1994), cuja metodologia foi apresentada e discutida nas seções 3.4.1 e 4.2.2. A distribuição dos níveis da escala de envolvimento pode ser conferida no Gráfico 8. 
Gráfico 8: Distribuição da frequência dos níveis de envolvimento

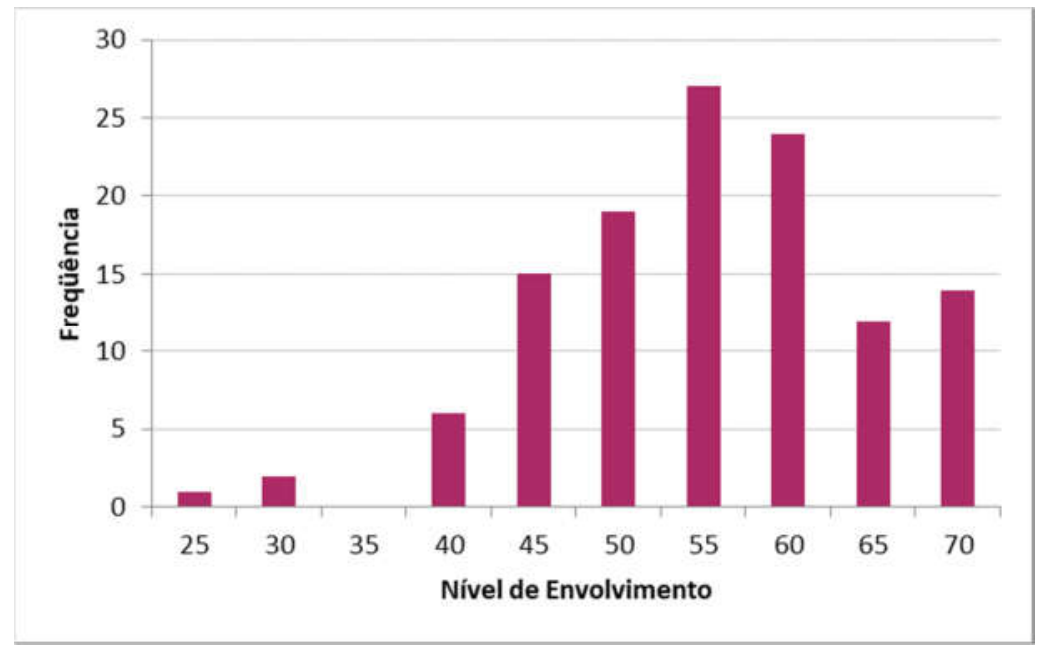

Fonte: elaborado pela autora

Apesar da escala de envolvimento indicar que em seus níveis mais altos os consumidores possuem maior envolvimento com o produto e, em seus níveis mais baixos os consumidores possuem menor envolvimento com o produto, não foram encontrados trabalhos dedicados a categorizar quais níveis podem ser considerados de alto ou baixo envolvimento especificamente para o produto vinho. Dessa forma, optou-se por segmentar a amostra entre consumidores que possuem níveis de envolvimento mais alto e mais baixo a partir dos quantis da distribuição de valores observados.

Assim, os respondentes foram divididos em grupos conforme a respectiva magnitude da escala de envolvimento. Na Figura 18 os consumidores foram organizados em dois grupos de 60 observações cada. O grupo sinalizado como " $50 \%$ inferiores" contém os consumidores cuja escala de envolvimento está abaixo da mediana $(\leq 52,5)$. Já o grupo " $50 \%$ superiores" reúne os consumidores cuja escala de envolvimento está acima da mediana $(\geq 52,5)$. Essa medida foi adotada para garantir a coerência com o tamanho mínimo de amostra para analisar os resultados da $\mathrm{CBC}$ proposta, ou seja, ao menos 42 respondentes para cada análise, conforme discutido na seção 4.2.1.4.

Na comparação entre os grupos segmentados, a principal diferença observada refere-se à ordenação das preferências dos atributos preço e tipo de vinho. Quando observados os consumidores associados a níveis mais altos de envolvimento com vinho, o atributo tipo de vinho possui maior importância relativa em relação ao preço. Por outro lado, para o grupo 
cujo nível de envolvimento é inferior observa-se uma maior importância relativa do preço em detrimento do tipo de vinho.

No que se refere ao atributo país de origem, não foram observadas diferenças na ordenação da importância relativa do atributo, quando considerados os grupos divididos conforme a mediana. É importante lembrar que a comparação das importâncias relativas entre diferentes grupos não é estatisticamente viável, conforme discutido na seção 4.2.1.5.

Figura 18: Importância relativa e utilidade para vinho conforme envolvimento com produto respondentes distribuídos em dois grupos

\begin{tabular}{|c|c|c|c|c|c|c|c|}
\hline \multirow{4}{*}{$\begin{array}{l}\text { Attribute } 0 \\
\text { Preço }\end{array}$} & \multirow{2}{*}{\multicolumn{4}{|c|}{$50 \%$ Inferiores }} & \multirow{2}{*}{\multicolumn{3}{|c|}{$50 \%$ Superiores }} \\
\hline & & & & & & & \\
\hline & Level & \multirow{2}{*}{$\begin{array}{l}\text { Importance } \\
39 \%\end{array}$} & \multicolumn{2}{|c|}{ Utility Value } & \multirow{3}{*}{$\begin{array}{l}\text { Importance } \\
29 \%\end{array}$} & \multicolumn{2}{|c|}{ Utility Value } \\
\hline & $R \$ 60$ & & & 0.74 & & & 0.65 \\
\hline & $R \$ B 0$ & & & 0.41 & & & $=0.24$ \\
\hline & $R \$ 100$ & & $-0.26=$ & & & $-0.27=$ & \\
\hline & $R \$ 120$ & & $88=$ & & & $-0.62 \simeq$ & \\
\hline \multirow[t]{3}{*}{ Tipo de vinho } & branco & \multirow[t]{3}{*}{$34 \%$} & \multicolumn{2}{|c|}{$-0.25=$} & \multirow[t]{3}{*}{$37 \%$} & $-0.65 \simeq$ & \\
\hline & tinto & & & 0.83 & & & 0.99 \\
\hline & espumante & & .58 & & & $-0.34=$ & \\
\hline \multirow[t]{5}{*}{ Pais de origem } & Brasil & \multirow{5}{*}{$15 \%$} & -0.10 & & \multirow{5}{*}{$20 \%$} & & \pm 0.16 \\
\hline & Chile & & & $=0.25$ & & & 0.10 \\
\hline & Argentina & & $-0.35=$ & & & $-0.54 \square$ & \\
\hline & França & & & $=0.26$ & & & $=0.35$ \\
\hline & Itâlia & & -0.06 & & & $-0.08=$ & \\
\hline \multirow[t]{2}{*}{ Ter recebido alguma recomendaçāo } & nẫo & \multirow[t]{2}{*}{$13 \%$} & $-0.27=$ & & \multirow[t]{2}{*}{$14 \%$} & $-0.32=$ & \\
\hline & sim & & & $=0.27$ & & & $=0.32$ \\
\hline
\end{tabular}

Fonte: elaborado pela autora

Como não foram identificados na literatura estudos que categorizassem o grau de envolvimento de consumidores com vinho e, além disso, a divisão realizada entre dois grupos em escala crescente de envolvimento não mostrou diferenças no que se refere ao atributo país 
de origem, foi realizada uma nova divisão da amostra de acordo com o envolvimento. Os grupos foram divididos conforme Figura 19.

Figura 19: Classificação da escala de envolvimento em três grupos

\begin{tabular}{|l|c|c|}
\cline { 2 - 3 } \multicolumn{1}{c|}{} & Intervalo da escala de envolvimento PII & Número de respondentes \\
\hline 1을 terço & $26-49$ & 41 \\
\hline 20 terço & $50-57$ & 42 \\
\hline 3o terço & $58-70$ & 37 \\
\hline
\end{tabular}

Fonte: elaborado pela autora

Embora a classificação entre três grupos de envolvimento não atenda totalmente ao requisito de tamanho mínimo de amostra discutido na seção 4.2.1.4, cujo valor mínimo é de 42 respondentes para o experimento de vinhos, é possível identificar algumas relações entre envolvimento e país de origem. Assim, a Figura 20 apresenta a importância relativa e a utilidade para consumidores divididos em três grupos, organizados em ordem crescente de envolvimento.

Figura 20: Importância relativa e utilidade para vinho conforme envolvimento com produto respondentes distribuídos em três grupos

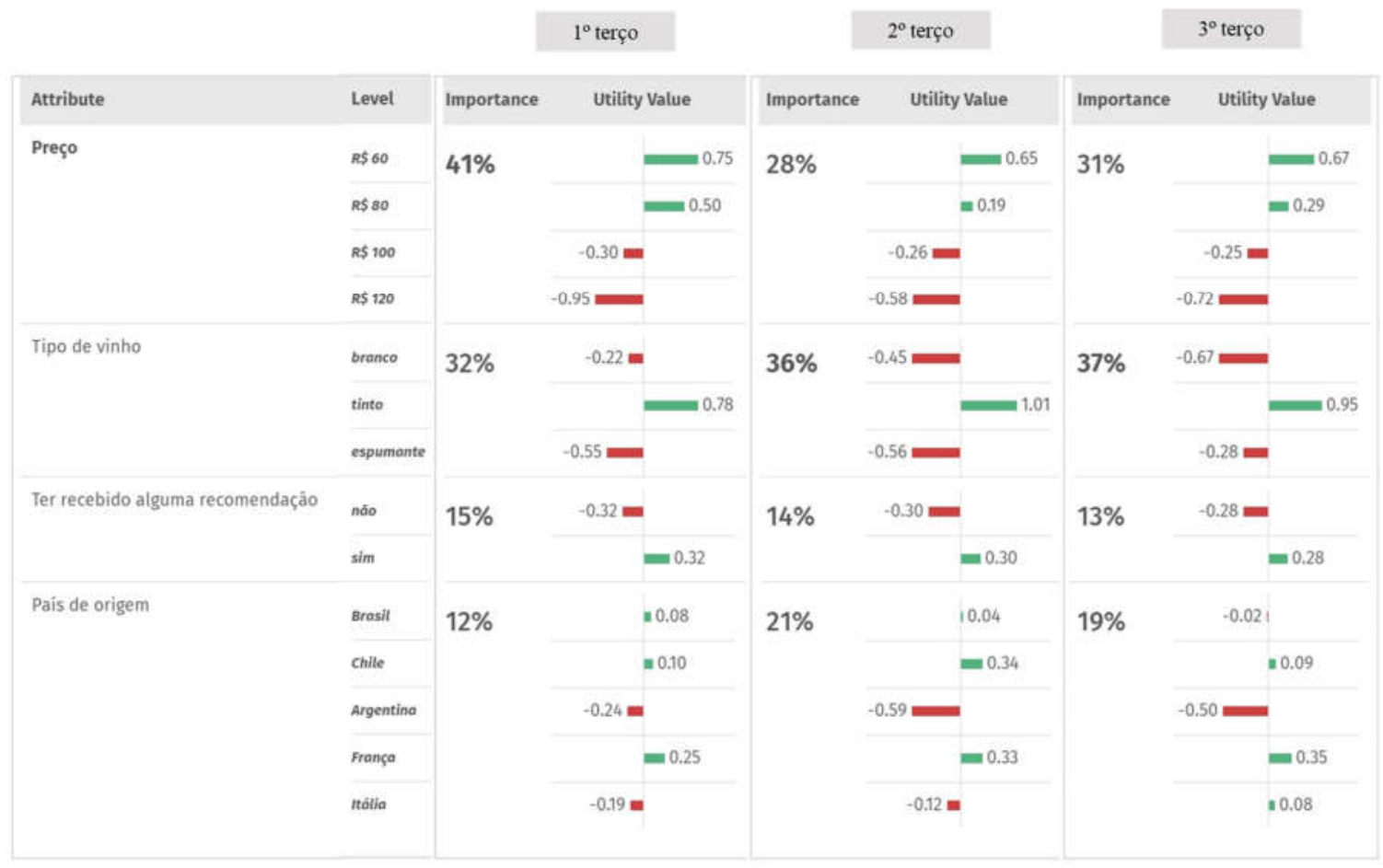

Fonte: elaborado pela autora 
Quando os respondentes são divididos em três grupos conforme o envolvimento é possível identificar grandes diferenças entre o grupo do $1^{\circ}$ terço e o do $2^{\circ}$ terço. Entre os respondentes do $1^{\circ}$ terço, o atributo preço é o que apresenta maior importância relativa, com peso de $41 \%$ sobre a utilidade total do produto. Em segundo aparece o atributo tipo de vinho, com 32\% de importância relativa. Em último lugar em termos de importância relativa aparece o país de origem com $12 \%$ de participação sobre a utilidade do produto. Isso nos permite interpretar que o atributo país de origem é o que apresenta o menor impacto sobre a escolha do consumidor para o produto vinho, considerando a amostra formada pelos consumidores com menor nível de envolvimento com este produto.

$\mathrm{O}$ conjunto de consumidores agrupados no $2^{\circ}$ terço possui diferenças importantes na ordenação das utilidades. Em relação ao grupo de consumidores do $1^{\circ}$ terço, se invertem as ordenações de importância relativa entre preço e tipo de vinho. No grupo do $2^{\circ}$ terço o tipo de vinho é o atributo com maior importância relativa, com $36 \%$ de impacto sobre a utilidade total do produto. O preço, por sua vez, aparece na segunda posição em importância relativa, com $28 \%$. O país de origem é o terceiro atributo com maior importância relativa, com $21 \%$ de peso sobre a utlidade total do produto. Ter recebido alguma recomendação, por sua vez, possui a menor importância entre os atributos, explicando $14 \%$ da utilidade total do produto. Já os consumidores agrupados no $3^{\circ}$ terço, que possui os maiores níveis de envolvimento com vinho, possuem a ordenação de importância relativa idêntica ao grupo do $2^{\circ}$ terço.

A divisão da amostra de consumidores de vinho em três grupos mostrou-se mais adequada para captar as diferenças de utilidade para os atributos, quando comparada à divisão entre dois grupos. O valor da escala de envolvimento no ponto 50 parece estar associado a uma mudança nas preferências dos consumidores de vinho em relação aos atributos apresentados. É importante salientar que por este trabalho considerar apenas consumidores com alta frequência de consumo de vinho, é esperado que os níveis de envolvimento dos respondentes dessa amostra sejam de fato mais elevados.

\subsection{Análise de confiabilidade}

A confiabilidade de um instrumento de medição reporta o quanto a análise de dados produz os mesmos resultados após sucessivas repetições (Sampieri, Collado, \& Lucio, 2006). 
Assim, um instrumento de medição de dados é considerado confiável quando apresenta consistência e precisão na medição de uma variável (Martins \& Theóphilo, 2007).

Dentre as formas possíveis de se aferir confiabilidade é a análise de consistência interna, que calcula a consistência entre variáveis oriundas de uma escala múltipla. A essência da consistência interna consiste na suposição de que as unidades de medida de uma escala devem medir o mesmo constructo, apresentando assim alta correlação (Hair et al., 2009).

O cálculo para a confiabilidade da escala de envolvimento e para os dados do experimento de escolha em vinhos seguem respectivamente nas seções 5.5.1 e 5.5.2.

\subsubsection{Confiabilidade para escala de envolvimento}

Com o intuito de verificar a confiabilidade dos dados coletados na escala de envolvimento foi calculado o Alpha de Cronbach. Este indicador analisa a consistência interna das variáveis a partir das variâncias individuais dos indicadores e da variância da soma dos itens de cada respondente, conforme a seguinte equação:

$$
\alpha=\frac{k}{k-1}\left[\frac{\sigma_{t}^{2}-\sum_{i=1}^{k} \sigma_{i}^{2}}{\sigma_{t}^{2}}\right]
$$

Em que:

$\mathrm{k}=$ número de variáveis

$\sigma_{t}^{2}=$ variância da soma das respostas dos respondentes

$\sigma_{i}^{2}=$ variância de cada variável

O cálculo do coeficiente do Alfa de Cronbach foi efetuado no software IBM SPSS Statistics versão 21, e retornou os resultados da Figura 21. 
Figura 21: Alfa de Cronbach para a escala de envolvimento

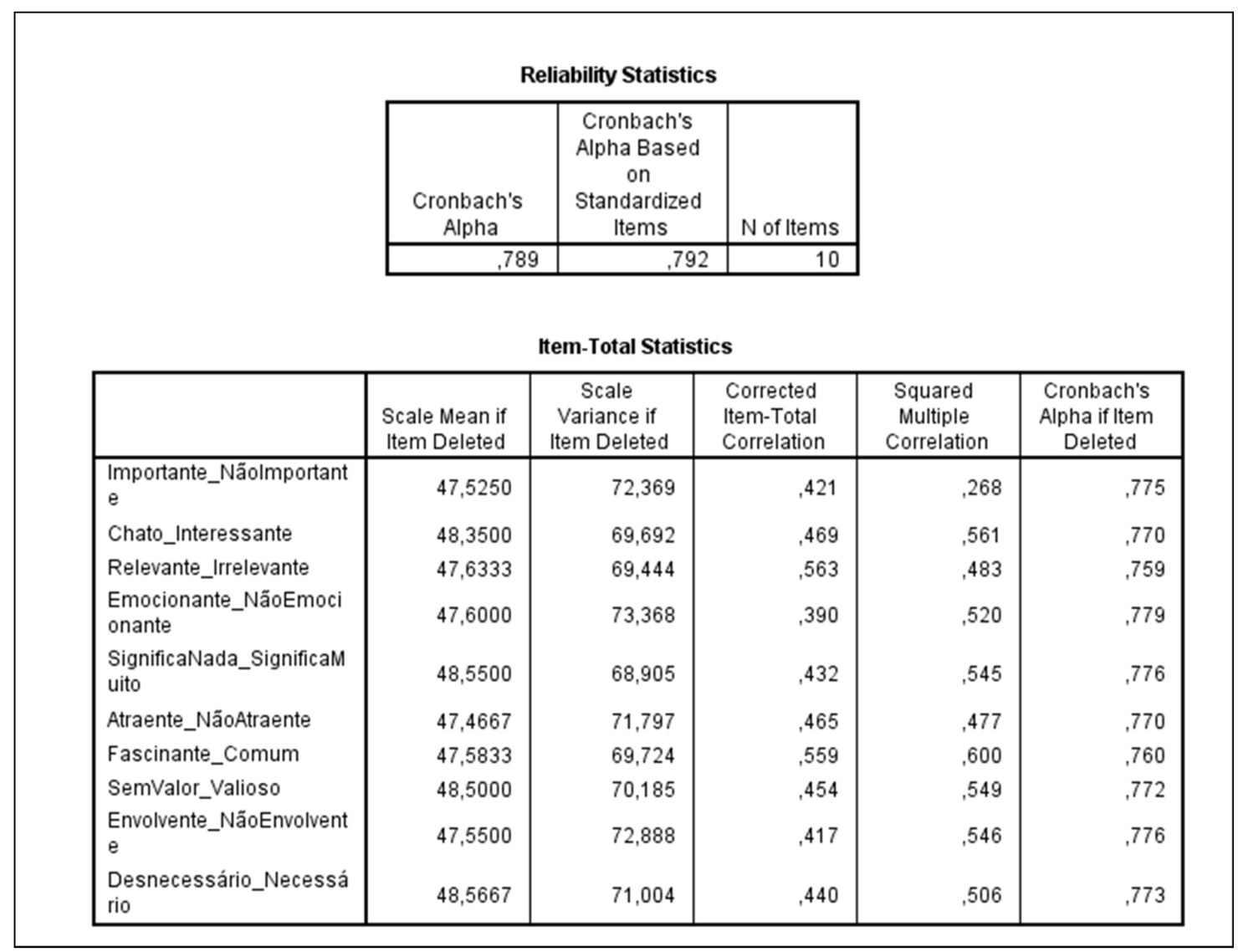

Fonte: elaborado pela autora

O valor correspondente ao coeficiente do Alfa de Cronbach na escala de envolvimento foi igual a 0,789. Conforme Hair et al. (2009), usualmente o limite inferior aceito para o coeficiente é 0,70 , o que permite considerar que o valor encontrado nessa pesquisa é satisfatório.

\subsubsection{Confiabilidade para $\mathrm{CBC}$}

A análise de confiabilidade do experimento de escolha seguiu a orientação de Johnson e Orme (2002), que recomendam a comparação das utilidades a partir da formação de dois grupos randomizados.

A amostra de respondentes foi dividida em dois grupos. Como a amostra é formada por consumidores do Rio Grande do Sul e por consumidores do estado de São Paulo, essa 
proporção foi mantida. Dessa forma, tanto para o experimento de vinhosquanto para o experimento de saca-rolhas foram formados dois grupos com 30 consumidores do RS e 30 consumidores de SP, selecionados de forma aleatória.

O Quadro 7 apresenta as utilidades e importâncias relativas para os grupos formados de forma randomizada entre os respondentes do experimento de vinhos. Ao comparar o grupo randomizado 1 com o grupo randomizado 2, percebe-se que tanto o atributo país de origem quanto o atributo ter recebido alguma recomendação possuem a mesma ordenação nas utilidades. Embora os atributos tipo de vinho e preço tenham posições trocadas, a ordenação dos níveis dentro de cada atributo segue a mesma ordenação para ambos os grupos. O mesmo ocorre para os níveis dos atributos país de origem e ter recebido alguma recomendação.

Quadro 7: Importância relativa e utilidade do experimento de vinho para grupos randomizados

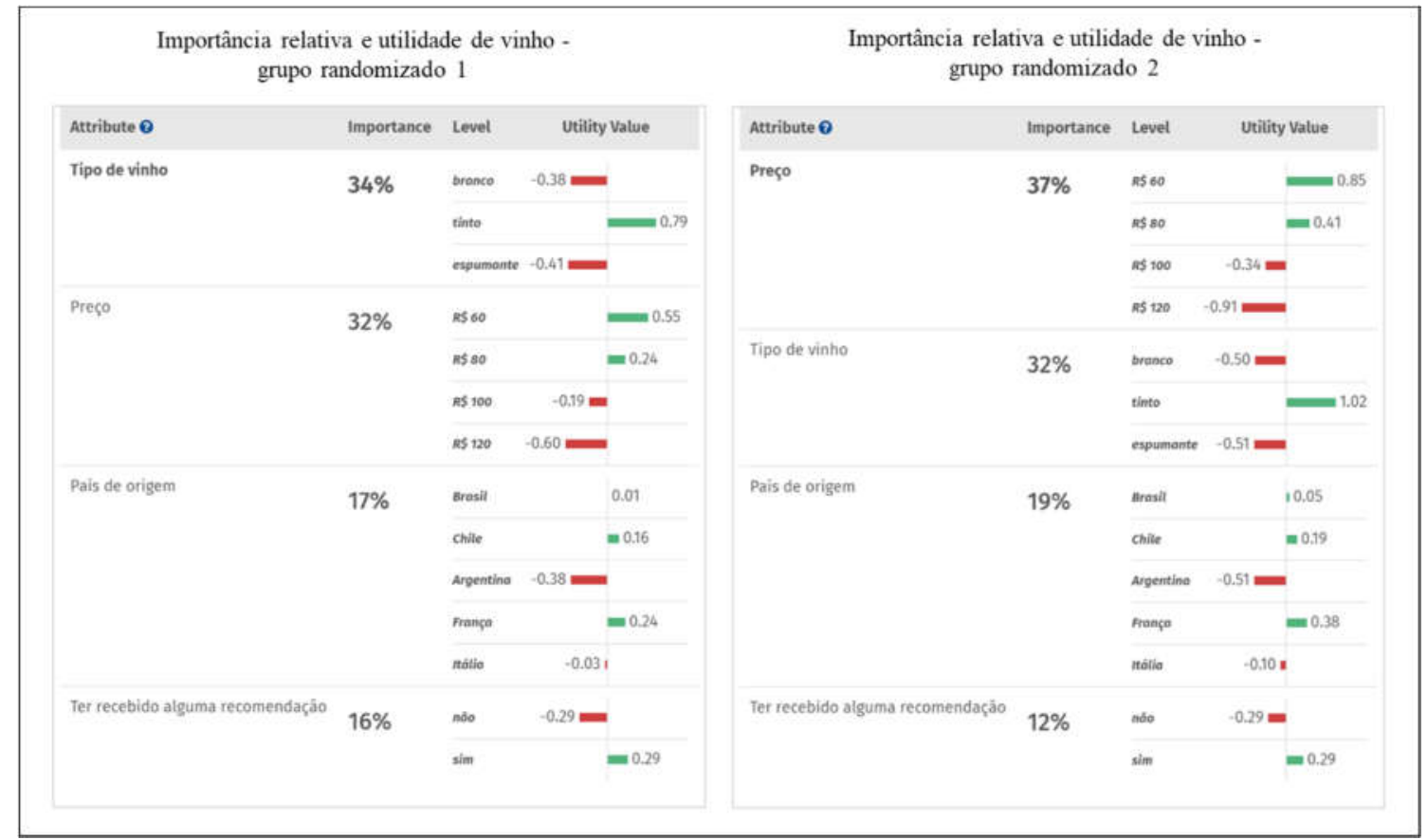

Fonte: elaborado pela autora

O Quadro 8 mostra as utilidades e importâncias relativas para os grupos formados de forma randomizada entre os respondentes do experimento de saca-rolhas. Ao comparar o grupo randomizado 1 com o grupo randomizado 2, nota-se que o preço e o tipo de saca-rolhas são os atributos com maior importância relativa. A ordenação desses atributos é a mesma em termos de importância relativa, e é a mesma também para a ordenação dos níveis de cada 
atributo. A importância relativa para os atributos país de origem e ter recebido alguma recomendação possui ordem invertida. Ainda assim, para o atributo ter recebido alguma recomendação os níveis apresentam a mesma ordenação. No entanto, isso não é verificado para o atributo país de origem.

Quadro 8: Importância relativa e utilidade do experimento de saca-rolhas para grupos randomizados

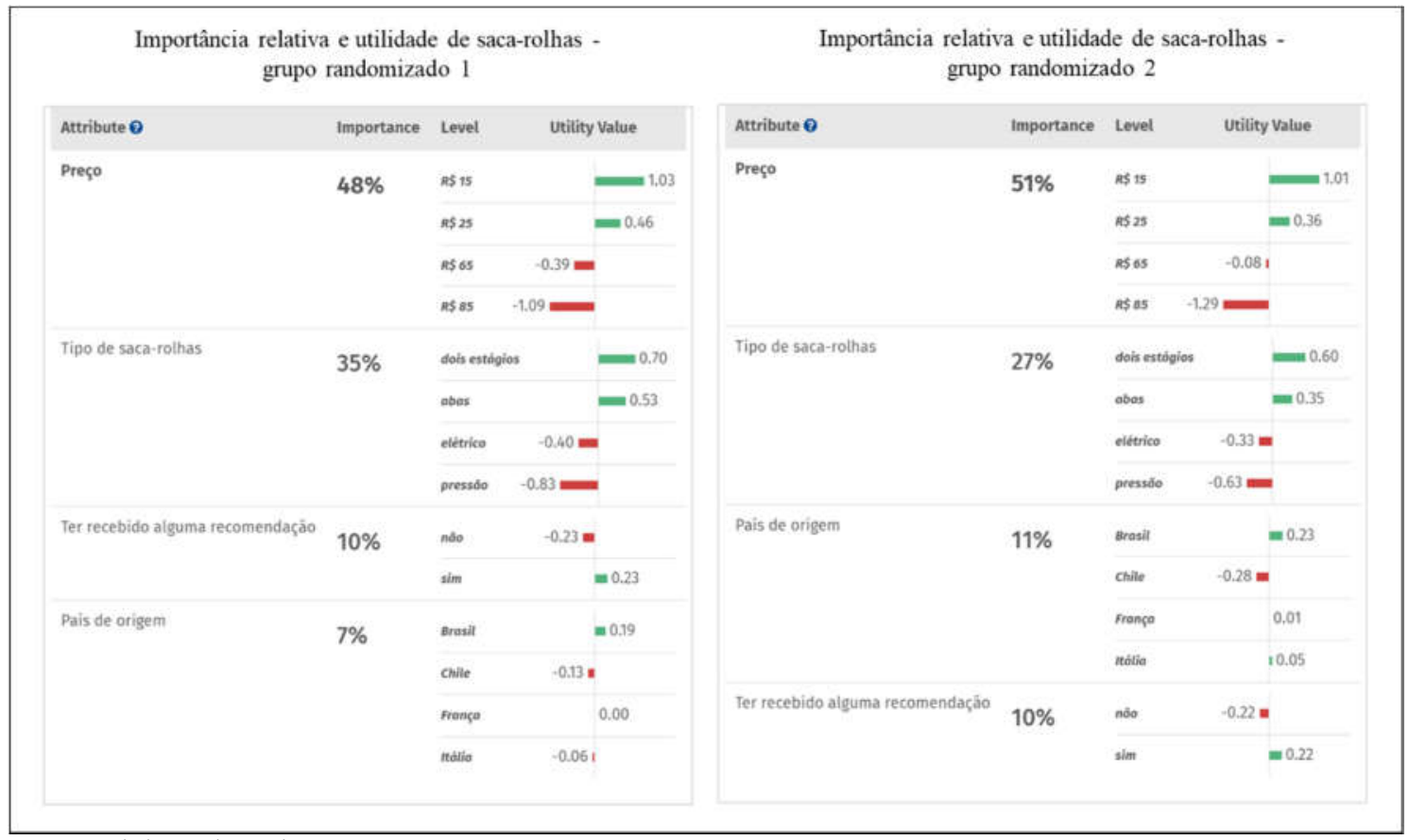

Fonte: elaborado pela autora

Embora tenham sido identificadas algumas diferenças entre as utilidades dos grupos randomizados, de forma geral é possível assumir que as preferências, traduzidas através das utilidades, possuem comportamentos muito próximos. Assim, presume-se que os dados coletados nos experimentos de escolha possuem a confiabilidade adequada para a correta interpretação dos resultados da choice-based conjoint analysis. 


\section{CONCLUSÕES}

O objetivo principal desse trabalho foi identificar como o país de origem do produto interfere na escolha do consumidor de vinho, através da aplicação da metodologia da choicebased conjoint analysis. Para atender este objetivo foram propostos outros três objetivos específicos, a saber: a) identificar o efeito país de origem para produtos tipificados; b) identificar a diferença do efeito país de origem entre regiões produtoras e não produtoras de vinho dentro de um país não reconhecido internacionalmente como produtor; c) identificar a diferença do efeito país de origem entre consumidores de vinho conforme seu respectivo grau de envolvimento com vinho.

Ao analisar os resultados do experimento de escolha de vinhos e do experimento de escolha para saca-rolhas, foi possível identificar que o vinho é um produto em que o atributo país de origem possui maior importância relativa do que para saca-rolhas. Isso permite inferir que o país de origem atua como um influenciador na escolha de vinho, enquanto que para um produto não tipificado o país de origem é um atributo com menor relevância no processo de escolha dos consumidores.

A realização do experimento de escolha de vinho para duas regiões dentro do Brasil possibilitou a identificação de diferenças significativas. Embora a ordenação da importância relativa no atributo país de origem tenha sido a mesma entre os dois grupos, consumidores do estado do Rio Grande do Sul apresentaram a maior utilidade associada a vinhos brasileiros. Em contrapartida, para consumidores do estado de São Paulo a utilidade associada aos vinhos nacionais foi a menor dentre todas as opções de países apresentadas.

Esses resultados demonstraram que consumidores mais próximos da região produtora de vinho revelaram maior preferência pelo produto local, enquanto que esse comportamento não foi observado para os consumidores domiciliados em uma região mais afastada do principal centro produtor. Tal comportamento, em parte, foi observado também para o produto saca-rolhas. Embora saca-rolhas não seja um produto ao qual se associe alguma marca ou país de origem, os efeitos de país de origem foram parcialmente reproduzidos nas escolhas desse produto. Consumidores do Rio Grande do Sul atribuíram maior importância relativa ao país de origem e, novamente, tiveram maior utilidade associada ao produto oriundo do Brasil.

No que se refere às relações entre efeito país de origem e grau de envolvimento do consumidor com vinho, foi observado que consumidores com menor envolvimento com o 
produto foram aqueles que atribuíram menor importância relativa ao país de origem. Ainda nesse grupo de consumidores, o preço foi o atributo mais representativo na utilidade total do produto. Os consumidores com maior envolvimento com vinho, por sua vez, apresentaram maior utilidade associada ao tipo de vinho (tinto, branco ou espumante). Para estes consumidores, ainda, o atributo país de origem apresentou ordenação superior na importância relativa quando comparado aos consumidores com menor envolvimento com vinho. Dessa forma, entende-se que o efeito país de origem possui maior influência nas escolhas dos consumidores mais envolvidos com vinho.

Em termos de contribuições acadêmicas, este trabalho apresenta uma sistematização das etapas de elaboração e de implementação de um experimento de escolha usando a técnica da choice-based conjoint analysis. Através dessa sistematização, foi possível elaborar um instrumento de coleta de dados que contempla dois experimentos de escolha e uma escala de envolvimento, que pode ser total ou parcialmente reaplicada em trabalhos futuros.

A opção pela abordagem através do método da choice-based conjoint analysis para avaliar os efeitos de país de origem sobre o processo de escolha do consumidor, mostrou-se adequada e pode servir de base para nortear trabalhos futuros que venham a tratar de tema correlato.

Outra contribuição oferecida por esse trabalho se refere à identificação de diferentes efeitos de país de origem no contexto de consumidores brasileiros. Embora o vinho seja um produto bastante analisado sob suas características de origem, essa investigação não foi encontrada na literatura levantada para a realização desse trabalho.

$\mathrm{Na}$ esfera gerencial, esse trabalho proporciona a identificação de comportamentos distintos entre diversos segmentos de consumidores frequentes de vinho. Foram encontradas, por exemplo, diferenças nas preferências dos consumidores conforme a região de domicílio. Embora não tenha sido objetivo desse trabalho identificar as causas dessas diferenças, essa característica pode ser ponto de partida para diferentes posicionamentos de mercado e ações de marketing mais especificas por parte dos setores que atuam no mercado de vinho. Assim, o melhor conhecimento do mercado consumidor de vinhos no Brasil possibilita compreender em maior profundidade as demandas dos consumidores para melhor atender as suas necessidades e expectativas.

Como limitações do estudo, é necessário lembrar que as amostras de consumidores foram coletadas por conveniência, de modo que podem ser não representativas do universo de consumidores de vinho de cada região estudada. Adicionalmente, o tamanho da amostra 
coletada não representa o universo de consumidores de vinho de cada região, uma vez que a amostragem realizada neste trabalho foi não-probabilística.

No experimento de escolha desenvolvido nesse trabalho os respondentes foram orientados a escolher um vinho dentre um conjunto de possibilidades, considerando que essa escolha seria em um ambiente genérico que comercializasse vinhos, como loja especializada, supermercado, bar, restaurante e afins. No entanto, sabe-se que o processo de escolha de um vinho pode ser influenciado pela ocasião de consumo da bebida. O consumo de espumantes, por exemplo, frequentemente é associado a festividades. Sendo assim, assume-se neste trabalho a eventual limitação da não contemplação de todas as especificidades do processo de escolha.

Os experimentos de escolha aos quais os consumidores brasileiros foram submetidos podem ser reaplicados em diferentes regiões, com distintos grupos de consumidores. Tal exercício permitiria o aprofundamento do entendimento das diferenças regionais dentro de um mesmo país. Outro desdobramento sugerido é o estudo das causas dos diferentes efeitos de país de origem entre regiões. Esse estudo poderia ser aprofundado considerando características intrínsecas das regiões utilizando, por exemplo, a teoria do etnocentrismo. Por fim, cabe lembrar que os resultados desse trabalho se referem a consumidores frequentes de vinho, e que caberia, assim, a extensão desse estudo contemplando também consumidores ocasionais de vinho. 


\section{REFERÊNCIAS BIBLIOGRÁFICAS}

ABEP. (2016). Critério Brasil 2015 e atualização da distribuição de classes para 2016. Retrieved from http://www.abep.org/criterio-brasil

Ahmed, S. A., \& D'Astous, A. (2001). Canadian consumers' perceptions of products made in newly industrializing East Asian countries. International Journal of Commerce and Management, 11(1), 54-81. https://doi.org/10.1108/eb047415

Aurifeille, J., Quester, P. G., Lockshin, L., \& Spawton, T. (2002). Global vs international involvement-based segmentation: a cross-national exploratory study. International Marketing Review, 19(4), 369-386. https://doi.org/10.1108/02651330210435672

Azevedo, A. F. Z. de, \& Portugal, M. S. (1998). Abertura comercial brasileira e instabilidade da demanda de importações. Nova Economia, 8(1), 1-19.

Bernabéu, R., Díaz, M., Olivas, R., \& Olmeda, M. (2012). Consumer preferences for wine applying best-worst scaling: A Spanish case study. British Food Journal, 114(9), 1228 1250. https://doi.org/10.1108/00070701211258790

Bilkey, W. J., \& Nes, E. (1982). Country-of-Origin Effects on Product Evaluations. Journal of International Business Studies, 13(1), 89-100. https://doi.org/10.1057/palgrave.jibs.8490539

Blaxter, L., Hughes, C., \& Tight, M. (2010). How to Research (4ª). New York: McGraw-Hill.

Bloch, P. H. (1981). An Exploration Into the Scaling of Consumers' Involvement With a Product Class. Advances in Consumer Research, 8, 61-65. Retrieved from http://acrwebsite.org/volumes/9786/volumes/v08/NA-08

Cohen, E., D'Hauteville, F., \& Sirieix, L. (2009). A cross-cultural comparison of choice criteria for wine in restaurants. International Journal of Wine Business Research, 21(1), 50-63. https://doi.org/10.1108/17511060910948035

de Almeida, V. M. C., \& Düsenberg, N. B. (2014). Envolvimento do consumidor com o produto: Comparação das escalas PII e NIP no contexto Brasileiro. Revista Brasileira de Gestao de Negocios, 16(50), 75-95. https://doi.org/10.7819/rbgn.v1650.959

De Sordi, J. O. (2013). Elaboração de pesquisa científica: seleção, leitura e redação (1 $\left.{ }^{\mathrm{a}}\right)$. São Paulo: Saraiva.

Dinnie, K. (2004). Country-of-Origin 1965-2004: A Literature Review. Journal of Customer Behaviour, 3(2), 165-213. https://doi.org/10.1362/1475392041829537

Fatma Smaoui, Abdellah, F., \& Touzani, K. M. (2016). Country-of-origin versus brand: consumers' dilemma when choosing between generic and branded drugs in emerging countries. Journal of Product \& Brand Management, 25(2), 148-159. https://doi.org/http://dx.doi.org/10.1108/JPBM-04-2014-0553

Fonseca, M. J. (1999). Avaliação da Aplicabilidade da Escala New Involvement Profile para Mensuração do Envolvimento do Consumidor na Cidade de Porto Alegre. Universidade Federal do Rio Grande do Sul.

Gil, A. C. (2002). Como Elaborar Projetos de Pesquisa (4a). São Paulo: Atlas.

Gürhan-Canli, Z., \& Maheswaran, D. (2000). Determinants of Country-of-Origin Evaluations. Journal of Consumer Research, 27(June 2000), 96-108. https://doi.org/10.1086/314311

Hair, J. F., Black, W. C., Babin, B. J., Anderson, R. E., \& Tatham, R. L. (2009). Analise multivariada de dados. Bookman $\left(6^{\mathrm{a}}\right)$. Porto Alegre: Bookman. https://doi.org/10.1119/1.3129093

Heslop, L. A., Papadopoulos, N., \& Bourk, M. (1998). An Interregional and Intercultural 
Perspective on Subcultural Differences in Product Evaluations. Canadian Journal of Administrative Sciences, 15(2), 113-127. https://doi.org/10.1111/j.19364490.1998.tb00156.x

Huang, J. B. J. (2012). Wine product involvement and consumers' BYOB behaviour in the South Australian on-premise market. Asia Pacific Journal of Marketing and Logistics, 24(3), 461-481. https://doi.org/10.1108/13555851211237911

IBRAVIN. (2007). Cadastro Vinícola. Retrieved from http://www.ibravin.org.br/DadosEstatisticos

Iyengar, S. S., \& Lepper, M. R. (2000). When choice is demotivating: Can one desire too much of a good thing? Journal of Personality and Social Psychology, 79(6), 995-1006.

Jain, K., \& Srinivasan, N. (1990). An Empirical Assessment of Multiple Operationalizations of Involvement. Advances in Consumer Research, 17, 594-602. Retrieved from http://acrwebsite.org/volumes/7071/volumes/v17/NA-17\%0A

Jehle, G. A., \& Reny, P. J. (2011). Advanced Microeconomic Theory (3 $\left.{ }^{\mathrm{a}}\right)$. Gosport: Prentice Hall.

Johnson, R. M., \& Orme, B. K. (2002). How Many Questions Should You Ask in ChoiceBased Conjoint Studies ?, 98382(360), 1-24.

Kahneman, D., Knetsch, J. L., \& Thaler, R. H. (1991). Anomalies: The endowment effect, loss aversion, and status quo bias. The Journal of Economic Perspectives, 5(1), 193-206.

Kahneman, D., \& Tversky, A. (1979). Prospect theory: An analysis of decision under risk. Econometrica: Journal of the Econometric Society, 47(2), 263-292.

Kelley, K., Hyde, J., \& Bruwer, J. (2015). U.S. wine consumer preferences for bottle characteristics, back label extrinsic cues and wine composition. Asia Pacific Journal of Marketing and Logistics, 27(4), 516-534. https://doi.org/10.1108/APJML-09-2014-0140

Kitchenham, B. (2004). Procedures for performing systematic reviews. Keele, UK, Keele University, 33(TR/SE-0401), 28. https://doi.org/10.1.1.122.3308

Kreps, D. M. (1990). A Course in Microeconomic Theory. Princeton: Princeton University Press.

Krugman, H. E. (1967). The Measurement of Advertising Involvement. American Association for Public Opinion Research, 30(4), 583-596.

Laurent, G., \& Kapferer, J.-N. (1985). Measuring Consumer Involvement Profiles. Journal of Marketing Research, 22(1), 41-53.

Lockshin, L., \& Cohen, E. (2011). Using product and retail choice attributes for crossnational segmentation. European Journal of Marketing, 45(7/8), 1236-1252. https://doi.org/10.1108/03090561111137697

Martins, G. de A., \& Theóphilo, C. R. (2007). Metodologia da investigação científica para ciências sociais aplicadas $\left(10^{\mathrm{a}}\right)$. São Paulo: Atlas.

Mas-Colell, A., Whinston, M. D., \& Green, J. R. (1995). Microeconomic Theory. New York: Oxford University Press.

McQuarrie, E. F., \& Munson, J. M. (1987). The Zaichkowsky personal involvement inventory: modification and extension. Advances in Consumer Research, 14(1), 36-40. Retrieved from http://acrwebsite.org/volumes/6631/volumes/v14/NA-14

McQuarrie, E. F., \& Munson, J. M. (1992). A Revised Product Involvement Inventory: Improved Usability and Validity. Advances in Consumer Research, 19(1), 108-115. Retrieved from http://acrwebsite.org/volumes/7277/volumes/v19/NA-19

Muzafer Sherif, \& Hadley Cantril. (1947). The Psychology of Ego -Involvements: social 
attitudes \& identifications. (I. JOHN WILEY \& SONS, Ed.) (2 $\left.2^{\mathrm{a}}\right)$. New York.

Nicholson, W., \& Snyder, C. M. (2011). Microeconomic Theory: Basic Principles and Extensions (11 $\left.{ }^{\mathrm{a}}\right)$. Mason: South-Western College Pub.

OIV. (2018). State of The Vitiviniculture World Market. Retrieved from http://www.oiv.int/

Orme, B. K. (2010). Getting Started with Conjoint Analysis: Strategies for Product Design and Pricing Research. Research Publishers ( $2^{\mathrm{a}}$ ed). Madison: Research Publishers LLC All.

Rao, V. R. (2014). Applied Conjoint Analysis. Retrieved from http://search.ebscohost.com/login.aspx?direct=true $\& \mathrm{db}=$ cat00327a\&AN=stgal.00065559 0\&authtype=shib\&site=ehost-live\%5Cnhttp://dx.doi.org/10.1007/978-3-540-87753-0

Rao, V. R., \& Pilli, L. E. (2014). Conjoint Analysis for Marketing Research in Brazil. Revista Brasileira de Marketing, 13(04), 25-38. https://doi.org/10.5585/remark.v13i4.2707

Rodríguez-Santos, M. C., González-Fernández, A. M., \& Cervantes-Blanco, M. (2013). An analysis of the construct " involvement" in consumer behaviour, 47(2), 1105-1123. https://doi.org/10.1007/s11135-011-9588-9

Sampieri, R. H., Collado, C. F., \& Lucio, P. B. (2006). Metodologia de Pesquisa. São Paulo: McGraw-Hill.

Sanchez, M., \& Gil, J. M. (1997). A Conjoint Analysis of Quality Wine. Journal of Food Products Marketing, 4(2), 63-78. https://doi.org/10.1300/J038v04n02_05

Schouten, J. W., \& McAlexander, J. H. (1995). Subcultures of Consumption: An Ethnography of the New Bikers. Journal of Consumer Research, 22(1), 43. https://doi.org/10.1086/209434

Sharma, P. (2011). Country of origin effects in developed and emerging markets: Exploring the contrasting roles of materialism and value consciousness. Journal of International Business Studies, 42(2), 285-306. https://doi.org/10.1057/jibs.2010.16

Smaoui, F., Abdellah Kilani, F., \& Touzani, M. (2016). Country-of-origin versus brand: consumers? dilemma when choosing between generic and branded drugs in emerging countries. Journal of Product \& Brand Management, 25(2), 148-159. https://doi.org/10.1108/JPBM-04-2014-0553

Spielmann, N. (2015). Anything but typical: how consumers evaluate origin products based on their cues. International Journal of Wine Business Research, 27(1), 23-39. https://doi.org/10.1108/IJWBR-07-2014-0031

Thaler, R. H. (1999). Mental accounting matters. Journal of Behavioral Decision Making, 12(3), 183-206.

Tseng, T., \& Balabanis, G. (2011). Explaining the product-specificity of country-of-origin effects. International Marketing Review, 28(6), 581-600. https://doi.org/10.1108/02651331111181420

Veale, R., \& Quester, P. (2009). Do consumer expectations match experience? Predicting the influence of price and country of origin on perceptions of product quality. International Business Review, 18(2), 134-144. https://doi.org/10.1016/j.ibusrev.2009.01.004

Verlegh, P. W. J., \& Steenkamp, J.-B. E. M. (1999). A review and meta-analysis of countryof-origin research. Journal of Economic Psychology, 20(5), 521-546. https://doi.org/10.1016/S0167-4870(99)00023-9

Zaichkowsky, J. L. (1985). Measuring the Involvement Construct. Journal of Consumer Research, 12(3), 341. https://doi.org/10.1086/208520

Zaichkowsky, J. L. (1994). The Personal Involvement Inventory: Reduction, Revision, and 
Application to Advertising. Journal of Advertising, 23(4), 59-70. Retrieved from http://www.jstor.org/stable/4188951 


\section{APÊNDICES}

APÊNDICE A: Experimento de Escolha

Prezado(a) respondente

Esse levantamento faz parte de um estudo conduzido por Caroline Graebin, mestranda do Programa de Pós-Graduação em Administração da Universidade de São Paulo, sob a orientação da Prof. Dra. Adriana Backx Noronha Viana. O objetivo dessa pesquisa é entender as preferências e hábitos de consumo de consumidores de vinho.

Gostaríamos de solicitar sua colaboração voluntária preenchendo o questionário abaixo. $\mathrm{O}$ tempo estimado para o preenchimento é de aproximadamente 20 minutos. Suas respostas serão tratadas com sigilo e confidencialidade.

Desde já agradecemos sua colaboração e o tempo despendido, destacando que tão logo tenhamos os resultados da pesquisa, teremos grande satisfação em disponibilizá-los para os interessados.

Em caso de dúvidas, por favor entre em contato por e-mail com o endereço caroline.graebin@usp.br

Obrigada!

1) Você possui mais de 18 anos?

( ) $\operatorname{sim}$

( ) não

2) Em geral, com que frequência você costuma beber/degustar vinho?

( ) Mais de uma vez por semana

( ) Uma vez por semana

( ) Uma vez a cada quinzena

( ) Uma vez por mês

( ) Menos de uma vez por mês

3) Em qual estado você reside? 
4) Se você está em um estabelecimento que vende vinhos (seja loja especializada, supermercado, bar, restaurante e afins), e se depara com as opções abaixo, qual vinho você escolheria? Por favor, marque somente uma opção. Cada vez que você clicar em prosseguir, um novo conjunto de opções será apresentado e você novamente terá de escolher apenas uma opção.

(Abaixo segue o exemplo genérico de uma tarefa)

\begin{tabular}{|c|c|c|c|c|}
\hline Tipo de vinho & branco & branco & tinto & branco \\
\hline País de origem $>$ & Chile & Argentina & Itália & Chile \\
\hline Preço & $\mathrm{R} \$ 120$ & $\mathrm{R} \$ 100$ & $\mathrm{R} \$ 120$ & $\mathrm{R} \$ 120$ \\
\hline \multirow[t]{2}{*}{$\begin{array}{l}\text { Ter recebido alguma } \\
\text { recomendação }\end{array}$} & sim & sim & $\operatorname{sim}$ & não \\
\hline & 0 & 0 & 0 & 0 \\
\hline
\end{tabular}

5) Agora gostaríamos de entender suas preferências por saca-rolhas. Por favor, observe abaixo os tipos de saca-rolhas que serão analisados nas questões subsequentes:

(não é necessário escolher nenhuma alternativa, apenas observe as opções e siga para a questão seguinte)

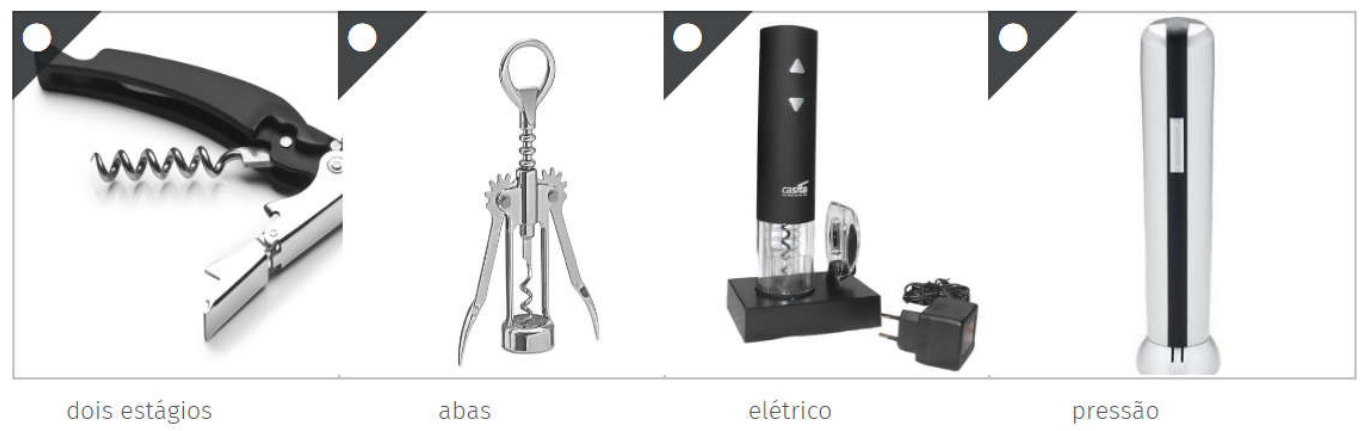

6) Uma loja de vinhos pretende vender saca-rolhas, e para isso gostaria de saber qual o produto que melhor atende as expectativas de seus clientes. Se você fosse comprar um saca-rolhas para uso pessoal, dentre as opções seguintes qual você escolheria? 
Por favor, marque somente uma opção. Cada vez que você clicar em prosseguir, um novo conjunto de opções será apresentado e você novamente terá de escolher apenas uma opção.

(Abaixo segue o exemplo genérico de uma tarefa)

\begin{tabular}{|c|c|c|c|c|}
\hline Tipo de saca-rolhas & pressāo & pressāo & abas & elétrico \\
\hline Pais de origem , & Brasil & Chile & Itália & Brasil \\
\hline Preço & RS 85 & R\$ 85 & $\mathrm{R} \$ 25$ & $\mathrm{R} \$ 65$ \\
\hline $\begin{array}{c}\text { Ter recebido alguma } \\
\text { recomendaçăo }\end{array}$ & $\operatorname{sim}$ & năo & $\operatorname{sim}$ & não \\
\hline & 0 & 0 & 0 & 0 \\
\hline
\end{tabular}

7) Abaixo estão alguns pares de adjetivos. Para cada par, assinale com qual você se identifica mais. Quanto mais próximo de uma extremidade, maior sua identificação com o respectivo adjetivo. A coluna central indica neutralidade.

Para você VINHO é:

totalmente bastante ligeiramente neutro ligeiramente bastante totalmente

\begin{tabular}{|c|c|c|c|c|c|c|c|c|}
\hline - importante & $\odot$ & 0 & $\odot$ & 0 & 0 & $\odot$ & $\odot$ & $\begin{array}{l}\text { não } \\
\text { importante }\end{array}$ \\
\hline chato & (1) & $\odot$ & O & 0 & 0 & 0 & $\odot$ & interessante \\
\hline relevante & (6) & (1) & $\odot$ & 0 & 0 & $\Theta$ & $\Theta$ & irrelevante \\
\hline 'emocionante & 0 & $\odot$ & $\odot$ & $\odot$ & $\odot$ & 0 & 0 & $\begin{array}{l}\text { não } \\
\text { emocionante }\end{array}$ \\
\hline • significa nada & (1) & (1) & 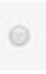 & 0 & 0 & 0 & 0 & $\begin{array}{l}\text { significa } \\
\text { muito }\end{array}$ \\
\hline atraente & 0 & (1) & C & $\odot$ & $\ominus$ & ○ & $\odot$ & não atraente \\
\hline fascinante & 0 & 0 & 0 & 0 & 0 & 0 & 0 & comum \\
\hline sem valor & 0 & (1) & $\odot$ & 0 & $\odot$ & $\odot$ & $\odot$ & valioso \\
\hline *envolvente & $\odot$ & $\odot$ & 0 & 0 & 0 & 0 & 0 & $\begin{array}{l}\text { nâo } \\
\text { envolvente }\end{array}$ \\
\hline desnecessário & 0 & (1) & () & $\odot$ & $\ominus$ & $\odot$ & $\odot$ & $\begin{array}{l}\text { Abaixo } \\
\text { necessário }\end{array}$ \\
\hline
\end{tabular}

8) Qual o seu sexo?

( ) feminino

( ) masculino 
9) Qual a sua idade?

10) Onde você geralmente consome vinho?

(se necessário, marque mais de uma alternativa)
( ) Na própria casa
( ) Na casa de amigos ou familiares
( ) Em bares ou restaurantes
( ) Outros. Qual?

11) Agora vamos fazer algumas perguntas sobre itens do seu domicilio para efeito de classificação econômica. Todos os itens de eletroeletrônicos que vamos citar devem estar funcionando, incluindo os que estão guardados. Caso não estejam funcionando, considere apenas se tiver intenção de consertar ou repor nos próximos seis meses. Indique a quantidade de cada um dos itens que você possui.

\begin{tabular}{|c|c|c|c|c|c|}
\hline & nảo possuo & 1 & 2 & 3 & 4 ou mais \\
\hline $\begin{array}{l}\text { Automóvel de passeio exclusivamente para uso } \\
\text { particular }\end{array}$ & O & e & e & e & • \\
\hline Máquinas de lavar noupa, excluindo tanquinho & e & e & e & • & e \\
\hline $\begin{array}{l}\text { ovo, incluindo qualquer dispositivo que leia DVD e } \\
\text { desconsiderando oVD de automóvel }\end{array}$ & e & e & e & e & e \\
\hline Geladeira & e & e & e & $\bullet$ & $\bullet$ \\
\hline Freezers independentes ou parte da geladeira duplex & e & 0 & 0 & e & e \\
\hline Lavadora de louşas & ○ & e & $\ominus$ & $\bullet$ & $\ominus$ \\
\hline Forno micro-ondas & • & e & $\ominus$ & $\bullet$ & $\bullet$ \\
\hline $\begin{array}{l}\text { Motocicletas, descorisiderando as usadas } \\
\text { exclusivamente para uso profissional }\end{array}$ & 0 & ○ & 0 & 0 & 0 \\
\hline $\begin{array}{l}\text { Máquina secadoras de roupas, considerando lava e } \\
\text { seca }\end{array}$ & • & 0 & $\bullet$ & $\odot$ & • \\
\hline
\end{tabular}

12) A água utilizada neste domicílio é proveniente de?

( ) Rede geral de distribuição

( ) Poço ou nascente 
( ) Outro meio

13) Considerando o trecho da rua do seu domicílio, você diria que a rua é:

( ) Asfaltada/Pavimentada

( ) Terra/Cascalho

14) Qual é o grau de instrução do(a) chefe da família? Considere como chefe da família a pessoa que contribui com a maior parte da renda do domicílio

( ) Analfabeto / Fundamental I incompleto

( ) Fundamental I completo / Fundamental II incompleto

( ) Fundamental II completo / Médio incompleto

( ) Médio completo / Superior incompleto

( ) Superior completo

15) Caso queira receber os resultados dessa pesquisa, insira seu e-mail abaixo. 
APÊNDICE B: Importância relativa e utilidade conforme envolvimento para o produto saca-rolhas

Importância relativa e utilidade para saca-rolhas conforme envolvimento com produto respondentes do $1^{\circ}$ terço

\begin{tabular}{|c|c|c|c|c|}
\hline Attribute $?$ & Importance & Level & Utility & Value \\
\hline \multirow[t]{4}{*}{ Preço } & $49 \%$ & $R \$ 15$ & & 1.10 \\
\hline & & $R \$ 25$ & & 0.40 \\
\hline & & $R \$ 65$ & -0.09 & \\
\hline & & $R \$ 85$ & $-1.40 \square$ & \\
\hline \multirow[t]{4}{*}{ Tipo de saca-rolhas } & $34 \%$ & dois estágios & & 0.58 \\
\hline & & abas & & 0.71 \\
\hline & & elétrico & $-0.26=$ & \\
\hline & & pressão & $-1.03 \square$ & \\
\hline \multirow[t]{2}{*}{$\begin{array}{l}\text { Ter recebido alguma } \\
\text { recomendação }\end{array}$} & $9 \%$ & não & $-0.22=$ & \\
\hline & & $\operatorname{sim}$ & & 0.22 \\
\hline \multirow[t]{4}{*}{ País de origem } & $9 \%$ & Brasil & & 0.28 \\
\hline & & Chile & -0.031 & \\
\hline & & França & $-0.16 \square$ & \\
\hline & & Itália & -0.09 = & \\
\hline
\end{tabular}


Importância relativa e utilidade para saca-rolhas conforme envolvimento com produto respondentes do $2^{\circ}$ terço

\begin{tabular}{|c|c|c|c|c|}
\hline Attribute ? & Importance & Level & Utility & y Value \\
\hline \multirow[t]{4}{*}{ Preço } & $46 \%$ & $R \$ 15$ & & 0.97 \\
\hline & & $R \$ 25$ & & 0.47 \\
\hline & & $R \$ 65$ & -0.52 & \\
\hline & & $R \$ 85$ & -0.92 & \\
\hline \multirow[t]{4}{*}{ Tipo de saca-rolhas } & $29 \%$ & dois estágios & & 0.70 \\
\hline & & abas & & 0.14 \\
\hline & & elétrico & -0.48 & \\
\hline & & pressāo & $-0.36 \square$ & \\
\hline \multirow[t]{4}{*}{ País de origem } & $15 \%$ & Brasil & & 0.38 \\
\hline & & Chile & $-0.22 \square$ & \\
\hline & & França & -0.02 । & \\
\hline & & Itália & $-0.14=$ & \\
\hline \multirow[t]{2}{*}{$\begin{array}{l}\text { Ter recebido alguma } \\
\text { recomendação }\end{array}$} & $10 \%$ & não & $-0.20=$ & \\
\hline & & $\operatorname{sim}$ & & 0.20 \\
\hline
\end{tabular}


Importância relativa e utilidade para saca-rolhas conforme envolvimento com produto respondentes do $3^{\circ}$ terço

\begin{tabular}{|c|c|c|c|c|}
\hline Attribute ? & Importance & Level & Utility & Value \\
\hline \multirow[t]{4}{*}{ Preço } & \multirow[t]{4}{*}{$52 \%$} & $R \$ 15$ & & 1.18 \\
\hline & & $R \$ 25$ & & 0.52 \\
\hline & & $R \$ 65$ & $-0.16 \square$ & \\
\hline & & $R \$ 85$ & $-1.54 \square$ & \\
\hline \multirow[t]{4}{*}{ Tipo de saca-rolhas } & \multirow[t]{4}{*}{$25 \%$} & dois estágios & & 0.57 \\
\hline & & abas & & 0.38 \\
\hline & & elétrico & $-0.21=$ & \\
\hline & & pressão & $-0.74 \square$ & \\
\hline \multirow[t]{4}{*}{ País de origem } & \multirow{4}{*}{$12 \%$} & Brasil & -0.05 I & \\
\hline & & Chile & $-0.41=$ & \\
\hline & & França & & 0.22 \\
\hline & & Itália & & 0.24 \\
\hline \multirow[t]{2}{*}{$\begin{array}{l}\text { Ter recebido alguma } \\
\text { recomendação }\end{array}$} & \multirow[t]{2}{*}{$11 \%$} & não & $-0.27=$ & \\
\hline & & $\operatorname{sim}$ & & 0.27 \\
\hline
\end{tabular}

